\title{
A Deep Dive into the Land Development Dynamics of a Complex Landscape
}

\author{
Pariya pourmohammadi \\ West Virginia University, papourmohammadi@mix.wvu.edu
}

Follow this and additional works at: https://researchrepository.wvu.edu/etd

Part of the Geographic Information Sciences Commons, Spatial Science Commons, Sustainability Commons, Urban, Community and Regional Planning Commons, and the Urban Studies and Planning Commons

\section{Recommended Citation}

pourmohammadi, Pariya, "A Deep Dive into the Land Development Dynamics of a Complex Landscape" (2019). Graduate Theses, Dissertations, and Problem Reports. 7419.

https://researchrepository.wvu.edu/etd/7419

This Dissertation is protected by copyright and/or related rights. It has been brought to you by the The Research Repository @ WVU with permission from the rights-holder(s). You are free to use this Dissertation in any way that is permitted by the copyright and related rights legislation that applies to your use. For other uses you must obtain permission from the rights-holder(s) directly, unless additional rights are indicated by a Creative Commons license in the record and/ or on the work itself. This Dissertation has been accepted for inclusion in WVU Graduate Theses, Dissertations, and Problem Reports collection by an authorized administrator of The Research Repository @ WVU.

For more information, please contact researchrepository@mail.wvu.edu. 
A Deep Dive into the Land Development Dynamics of a Complex Landscape

Pariya Pourmohammadi

\author{
Dissertation submitted to the \\ Davis College of Agriculture, Natural Resources and Design \\ at West Virginia university \\ in partial fulfillment of the requirements \\ for the degree of \\ Doctor of Philosophy \\ in \\ Human and Community Development
}

Michael P Strager, Ph.D., Chair

Donald Adjeroh, Ph.D.

Hodjat Ghadimi, Ph.D.

Michael Dougherty, Ph.D.

Charles B. Yuill, M.L.A.

School of Design and Community Development

Morgantown, West Virginia

2019

Keywords: Developed Land Expansion, Deep Learning, Ecosystem Services, Spatial Data Analysis

Copyright 2019 Pariya Pourmohammadi 


\begin{abstract}
A Deep Dive into the Land Development Dynamics in a Complex Landscape
\end{abstract}

\title{
Pariya Pourmohammadi
}

Land development is a complex and dynamic process simultaneously interacting with numerous environmental, cultural and economic procedures. In this research we studied past, present and future of land transformation in Appalachia. This dissertation is organized in three-essay format and each essay is focused on one aspect of land development processes in a sub-region in the Appalachian region. In the first essay, deep learning techniques are used to build predictive models for the land development. This study presets deconvolutional neural networks models in predicting land development. On the second essay, spatial data analysis and remote sensing are used to investigate the history of land development in WV from 1985 to 2015. Global and local coefficient analysis is conducted to analyze the variables impacting the land development. Through this analysis we discussed the role of energy development in the land development of WV. The results of this paper show that land transformation in the study area is highly dynamic and fragmented. Changing patterns of energy extraction impacts the patterns of land development in this region. These dynamic patterns not only influence the social life of communities but also the ecosystem services supply-demand patterns. In the third essay, we mapped and monitored the non-monetary budget of land transformation through the essence of Ecosystem Services (ES). Our analysis provides information for urban and regional planners, environmental scientist and developers towards making efficient and sustainable decisions. Findings of this research facilitate communities with a resourceful roadmap toward higher quality of life and indicators. 


\section{ACKNOWLEDGMENTS}

I would like to express my sincere gratitude to my advisor Prof. Strager for the continuous support of my Ph.D study.

I would like to thank the rest of my thesis committee: Prof. Adjeroh, Prof. Dougherty, Prof. Ghadimi, and Prof. Yuill, for their insightful comments and encouragement.

My sincere thanks also go to Dr. Kinder, who gave access to the Natural Resource Analysis Center facilities. Without his precious support it would not be possible to conduct this research. 


\section{TABLE OF CONTENTS}

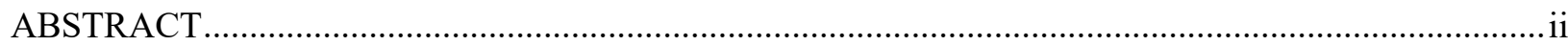

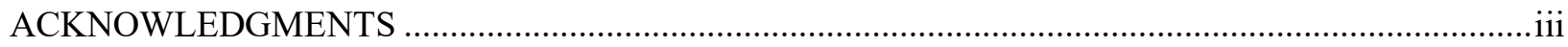

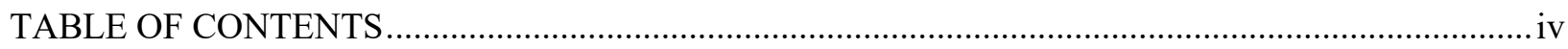

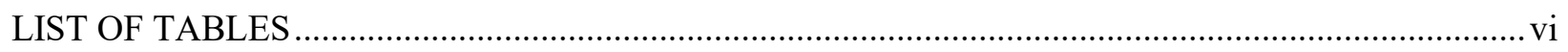

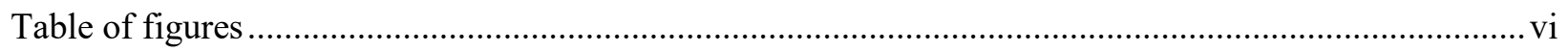

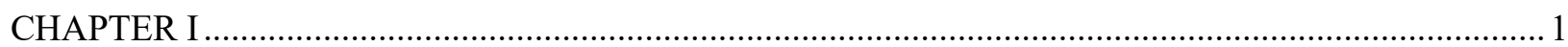

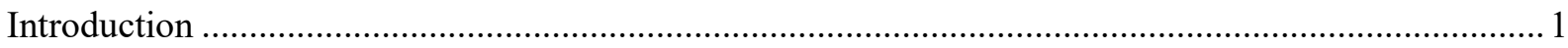

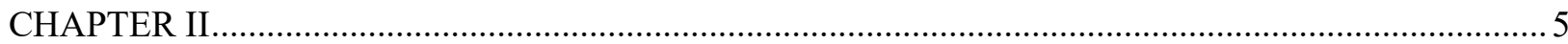

Paper I: Predicting developed land expansion using deep deconvolutional neural networks .................5

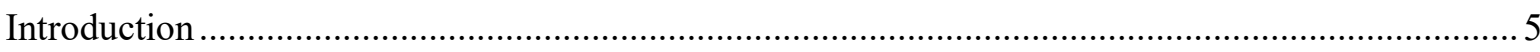

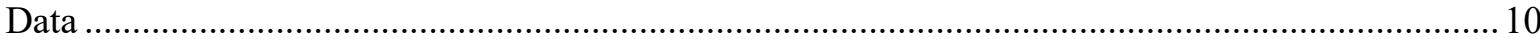

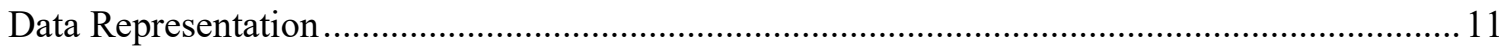

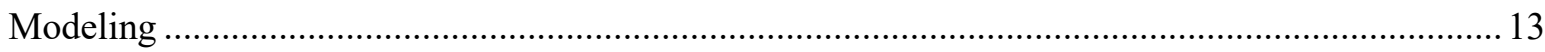

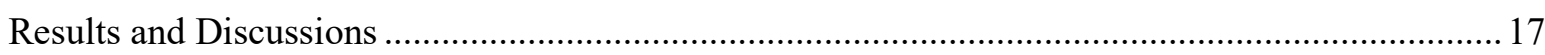

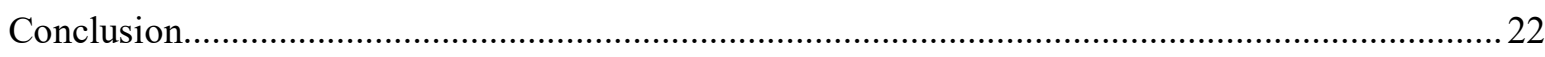

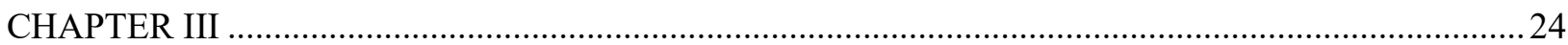

Paper II: Integrating Multi-Source Spatial Data, Remote Sensing and Data Transformation to Analyze the Variables of Land Development in West Virginia .........................................................................24

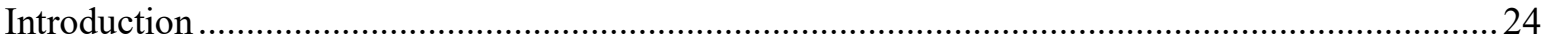

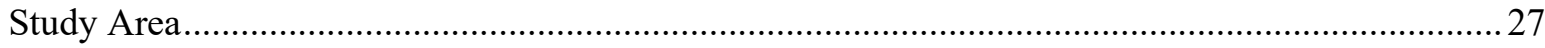

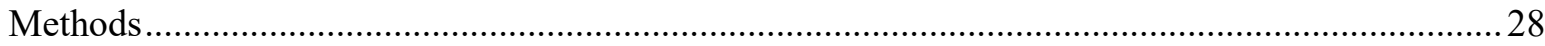

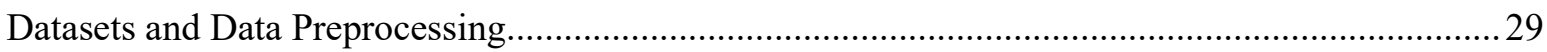

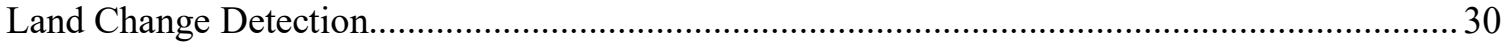

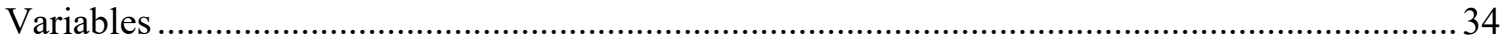

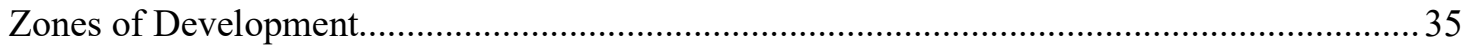

Hot Spot Analysis of the Developed Land Expansion ........................................................... 36

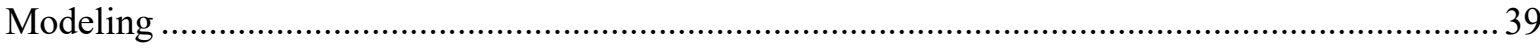

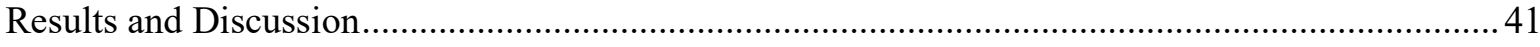


Paper III: Mapping Ecosystem Services through Land Use/Cover Change; a Non-Monetary Investigation

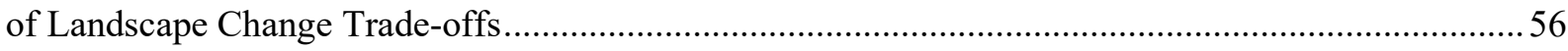

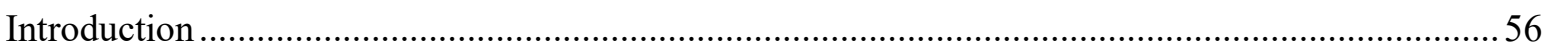

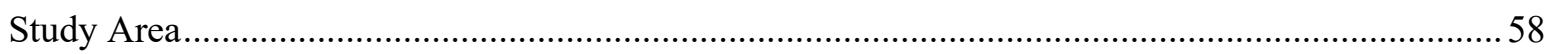

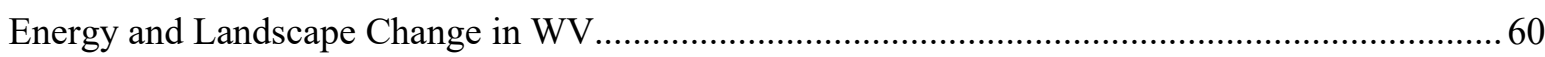

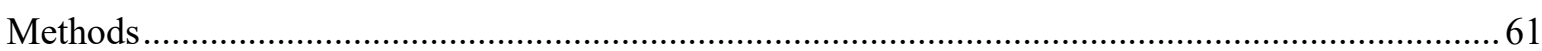

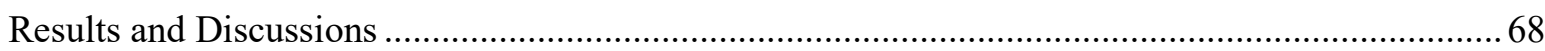

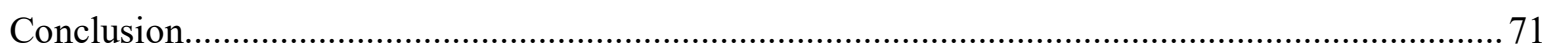

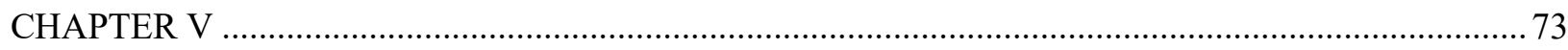

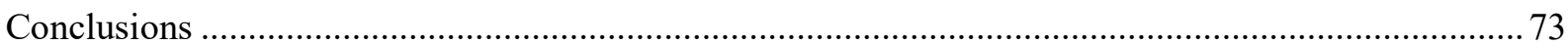

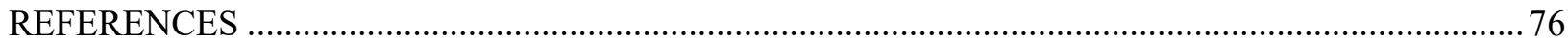




\section{LIST OF FIGURES}

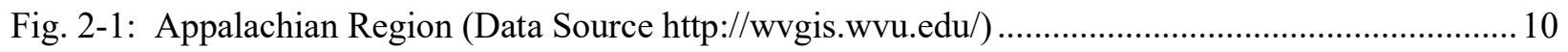

Fig. 2- 2: Illustration of the multidimensional multispectral data cube .................................................. 13

Fig. 2-3: An illustration of the deepLand-U architecture........................................................................ 15

Fig. 2- 4: An illustration of the deepLand-S architecture .................................................................... 15

Fig. 2-5: Comparison of training loss vs. validation loss.................................................................. 18

Fig. 2-6: Comparison the AUC for different models ........................................................................... 18

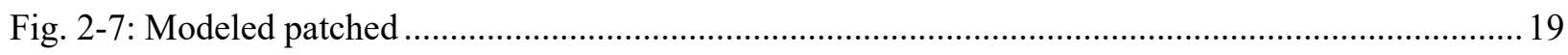

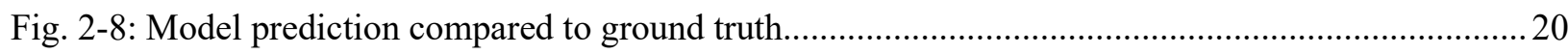

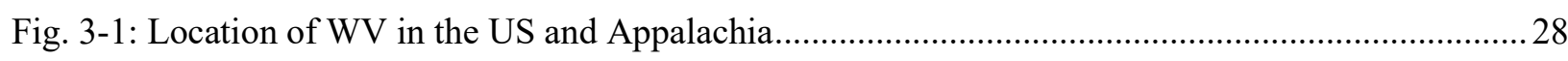

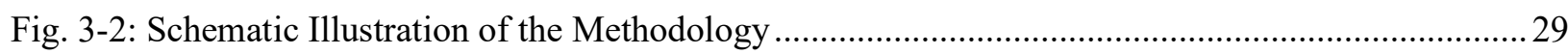

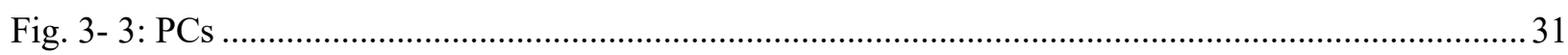

Fig. 3-4: Illustrates the land development trends in the state of WV in three decades ............................. 32

Fig. 3-5: Density of the land change per square Miles in WV ...............................................................33

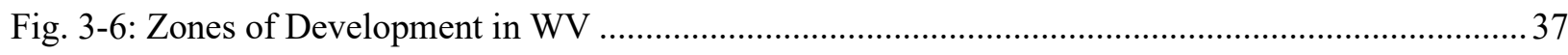

Fig. 3-7: Hot Spot Analysis of Land Development Per Decade ............................................................ 38

Fig. 3-8: Multicollinearity Diagnostics Analysis of the Variables in Regression model of 1985-1995 ..... 39

Fig. 3-9: Multicollinearity Diagnostics Analysis of the Variables in Regression model of 1995-2005 ..... 40

Fig. 3-10: Multicollinearity Diagnostics Analysis of the Variables in Regression model of 2005-2015 ... 40

Fig. 3- 11: Coefficients of the Regression Analysis in Different Zones of Development (1985-1995) ..... 44

Fig. 3-12: Coefficients of the Regression Analysis in Different Zones of Development (1995-2005) ...... 45

Fig. 3-13: Coefficients of the Regression Analysis in Different Zones of Development (2005-2015) ...... 46

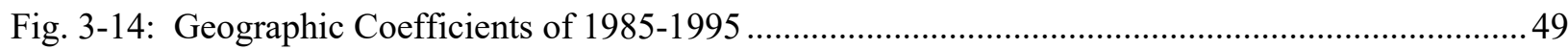

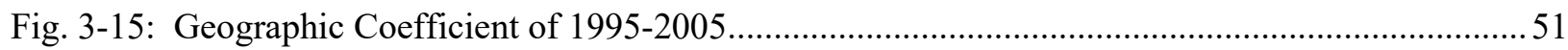

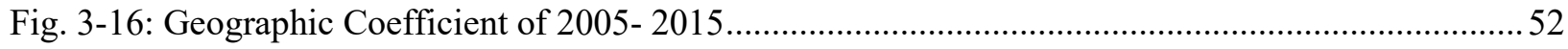

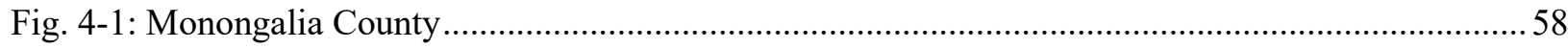

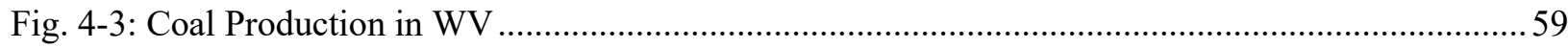

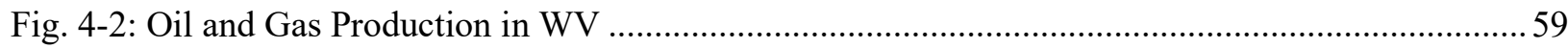

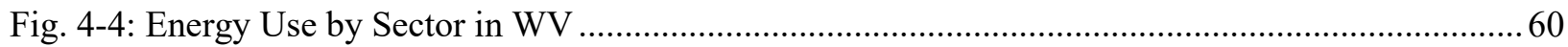

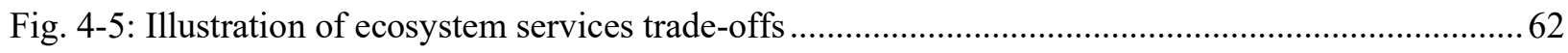

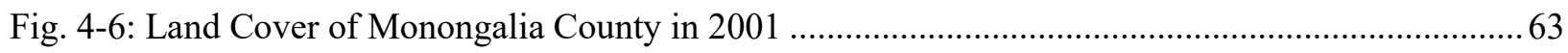

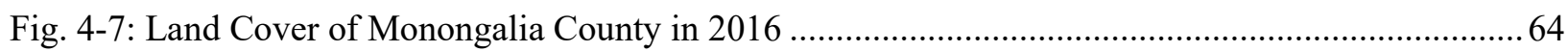

Fig. 4-8: Cross Class Land Conversion in Monongalia County, 2001-2016 .......................................... 65

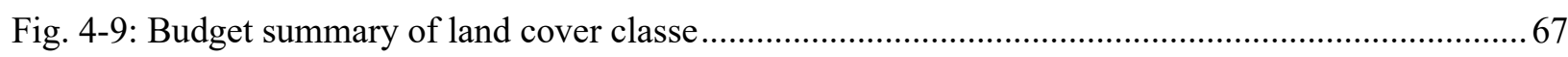




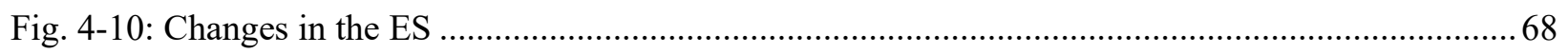

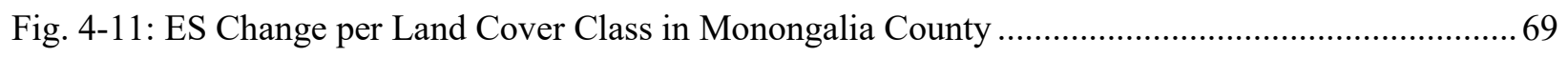

Fig. 4-12: Hotspot analysis of major ES declines and land development spatial representations ..............70 


\section{LIST OF TABLES}

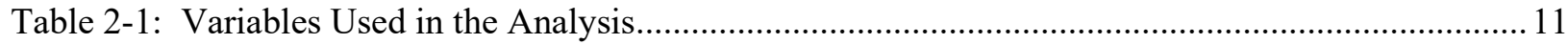

Table 2-2- Comparison of the Time Required for the Model Run on CPU and GPUs ...........................22

Table 3-1: User-producer accuracy assessment of the change detection .................................................. 32

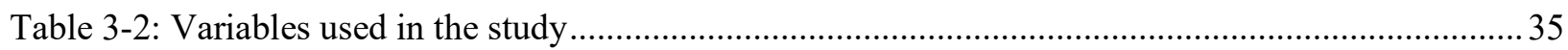

Table 3-3: Multivariate Analysis of Variance of Zones of Development................................................36

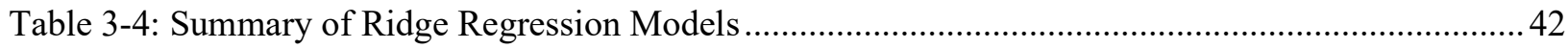

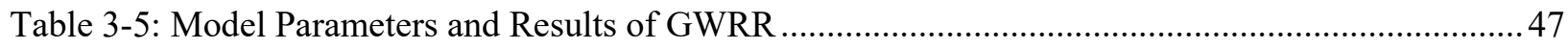

Table 4-1: The Capacity of Different Land Cover Classes........................................................................66

Table 4-2: The Demand for ES within different Land Cover Classes ...................................................66

Table 4-3: Budgets of ES's Supply Demand within different classes of land cover ...............................67 


\section{CHAPTER I}

\section{Introduction}

Appalachia is a cultural region which lies on the spine of Appalachian Mountains; this region stretches from the southern tier of New York to northern Alabama and Georgia. Appalachia is rich in natural resources which has meant it has a variety of threats, weaknesses, but also strengths and potential. Numerous studies have addressed the development progress of this region in relation to its abundant energy resources. We consider the landscape of this region a complex landscape because this region is highly sensitive to any changes in its ecosystem. The anthropogenic changes in Appalachia have considerable effects on both the ecosystem of the region and its residents' quality of life. Land development is an important landscape change that influences the communities of Appalachia and has an extreme impact on the region's natural assets, i.e. hydrology, biodiversity, and forested lands. Understanding the directions of land and its future direction is critical to help the communities of Appalachia. An affluence in resources of Appalachian region and scattered growth of rural communities create a complex and unique landscape. In this research we analyze the human-environment interactions in Appalachian region; we specifically address land development processes in different scales of this region.

To accomplish this goal, the process of land development in various sub-regions of Appalachia have been studied. Each chapter of this research is in response to a question on the land transformation processes and mechanisms. This dissertation is in a three-essay format, each essay is presented as a chapter (CHAPTER II, III and IV). The following are research questions each chapter addresses:

1. Which modeling technique can best predict development in the Appalachian study area?

2. What are the driving variables that affect the various types of land development? 
3. What is the ecosystem service impacts of land transformations?

Many aspects of land-use management and policy making require information regarding how and where land cover and land-uses will change in the future. In CHAPTER II, we propose a method for modeling and predicting developed land expansion using the idea of pixel-wise semantic segmentation through deep deconvolutional neural networks. This analysis is done on the Monongalia Watershed in Appalachia with a focus on where developed lands are predicted to expand. In this chapter, we introduce a method to construct data cubes of land patches which represent important information related to diverse characteristics of the area under consideration. We model the developed land expansion using an encoder-decoder network, and then perform prediction using a simple softmax layer. Our results indicate a performance accuracy of $98 \%$ in the test data. The proposed technique could thus play an important role in improving our understanding of mapping and modeling spatially explicit landscape changes, and in facilitating land-use decision making. We also investigated the driving factors of land development in WV. Dynamic processes of land development are driven by complex interactions between various socio-economic, spatial and ecological components. Each of these collaborating factors are undeniably unique to the geography of the change. Awareness of the motivating processes of developed land expansion benefits urban and regional planners, environmental scientist and policy makers to acquire insights on the directions and urging factors of landscape change.

In CHAPTER III, we investigate the processes and trends of land development in West Virginia (WV), USA within 1985-2015 in ten-year time-steps. Through this study we identify and examine the critical processes of land transformation to developed lands. Land development in WV, essentially includes a combination of rural development and urbanization. In CHAPTER III we show that the development patterns have been exceedingly dynamic in WV; this dynamicity is 
reflected in both the concentration and distribution of land development at each time-step. Accordingly, the changing pattern of land development has been studied with regards to the variables influencing the land development. In CHAPTER III, we also studied the impact of major place-based, energy related, socio-economic and landscape-based features on the process of urban and rural land development. The applied methods for variable analysis are ridge regression, parsing based regression and Geographically Weighted Ridge Regression (GWRR) analysis. This analysis implies that in WV there are strong connections and synergies between urban and rural land developments; moreover, shifts in the energy extraction trends and the sources of these energies have considerable effects on the configuration of the land development. According to the results of CHAPTER III, unstable processes of land development in WV hinders development of small communities and provokes creation of fragmented localities. This fragmentation consequently impacts the well-being indicators of these communities. Historical process of land development is also notable from the sustainability point of view.

In CHAPTER IV, the objective was to examine the burden that land transformation imposed to the environment in the time span of 2001-2016. In this time period, a new form of landscape change appeared in Appalachia. The extraction of shale gas appeared as small patches of transformation with considerable environmental consequences. In this chapter we considered this form of land development, along with other forms of development and landscape change to assess the ecosystem services in a supply-demand budget. From the ecosystem services perspective, different types of land cover have monetary and non-monetary values. Mapping and monitoring the supply-demand budget of the classes has been a challenge for environmental scientists. In this chapter matrices were built of non-monetary analysis of land cover change based on Anderson system of land classification (the system which is used in National Land Cover Dataset 
classification). The constructed matrices have specific subclasses for developed lands and barren lands so that energy related or the impact of various sectors on the environment is considered. We utilized the information of these matrices to analyze the ecosystem services budget of land transformation.

CHAPTER V is elaborated to link the results and discussions of the three former chapters. In this part, entire perspective of this study is drawn. This chapter is a conclusion to the study, in which we establish the relationship between the three-essays, and we make our final inferences on the whole study. 


\section{CHAPTER II}

\section{Paper I: Predicting developed land expansion using deep deconvolutional neural networks}

\section{Introduction}

Land use and land cover represents one of the major spatial data characteristics used to measure global and local environmental changes. In the past, many statistical, empirical and stochastic models have been developed to predict land changes (E .F Lambin, Rounsevell, \& Geist, 2000). These models date back to the 1960s, when new environmental concerns were raised about the changing landscape (A. Foley, 1999). In the past few years, machine learning and deep learning techniques were used by land change modelers as powerful modeling methods to predict land transformations (Kamusoko \& Gamba, 2015; Bryan C Pijanowski, Brown, Shellito, \& Manik, 2002; Tayyebi \& Pijanowski, 2014). Neural networks, one of the most powerful techniques in modeling, has been widely applied in image processing and pattern recognition; this technique has also been applied for land change purposes. While the scientific community has seen applications of neural networks in modeling, what has been missing are examples in developing predictive models of land change and specifically integrating state-of-the-art neural network-based models. In the past, many statistical, empirical and stochastic models have been developed to predict land This need has been identified as a way to improve the accuracy of model predictors (Kamusoko \& Gamba, 2015; Tayyebi \& Pijanowski, 2014).

This paper was submitted on 05/14/2019 "This work was supported by the National Science Foundation/EPSCoR Award No. 1458952 as a part of Appalachian Freshwater Initiative project.", "This work used the Extreme Science and Engineering Discovery Environment (XSEDE), which is supported by the National Science Foundation under Cooperative Agreement Number OIA-1458952. Any opinions, findings, and conclusions or recommendations expressed in this material are those of the author(s) and do not necessarily reflect the views of the National Science Foundation.". 
Building predictive models for land change which deploy deep learning-based semantic segmentation is a cutting-edge approach. One of the most popular neural network models in this area was introduced by Pijanowski et al (2002), where they developed a multi-layer perceptron (MLP) network of Land Transformation Model (LTM), to predict land change and urban expansion. LTM is based on backpropagation for feedforward networks (Stuttgart Neural Network Simulator) with one or two layers in each of which there are at least as many nodes as the number of the variables (Pijanowski B.C., Brown D.G., Shellito B.A.A., 2002; Pijanowski B.C., Hyndman, \& Shellito, 2001). In LTM “change likelihood values" are calculated as the predicted results. In LTM a factor called "principle index driver" (PID) represents the number of cells that will transform from state 0 (non-urban) to state 1 (urban). PID is computed as one of the input values for model prediction (Bryan C Pijanowski et al., 2002). LTM can find the location of the specified number for the PID amount of change. However, to process data for larger areas in an efficient manner (Pijanowski B.C., Tayyebi, Delavar, \& Yazdanpanah, 2009; Pijanowski B.C., Brown D.G., Shellito B.A.A., 2002) it needed to deploy the advances in computational methods through parallel computing techniques for their analysis ( Pijanowski B.C.,et al., 2014). LTM and other models used by land change prediction modelers provide a basis for our study; improvement in these methods requires more technical and computationally complex methods. We were interested in developing a model which can determine the amount of change as well as its configuration. In remote sensing, various architectures of neural networks models have been deployed, the majority of which were developed to perform object detection, classification, and semantic segmentation of the land (Kampffmeyer, Salberg, \& Jenssen, 2016; Sherrah, 2016). Hu et al. (2015) and Castelluccio (2015) applied several architectures such as AlexNet, VGG (from Visual Geometry Group), Caffe, and PlaceNet to label patches of land images and compare the accuracy 
of models. These efforts are good examples of the use of advanced, well-known deep learning designs in analyzing geographic data of the land. Kampffmeyer et al. ( 2016; Sherrah, 2016) used the Convolutional Neural Network (CNN) architecture of Fully Connected Networks (FCNs) layers. This design was used for pixel-wise segmentation of True Ortho Photos (TOP) with a patch size $256 \times 256$ into 6 classes, namely, Impervious surfaces, Building, Low vegetation, Tree, Car, and Clutter/background (Kampffmeyer et al., 2016). This application of an FCN network in pixelwise segmentation for unbalanced data, has been noted as a novel method in land analysis. However, the architecture of this study is limited by computational power in the GPU and therefore, the authors used strides of 2 in the first convolutional layer to overcome this limitation (Kampffmeyer et al., 2016). These innovative approaches in deploying deep learning models are used in land cover classification, results of which have been shown to improve the precision of the classification.

In image processing and bio-medical image segmentation, deep learning is utilized in pixelwise semantic segmentation. The two models in these disciplines, addressing a problem similar to the problem of this paper are segNet (Badrinarayanan, Kendall, \& Cipolla, 2017) and U-Net (Ronneberger, Fischer, \& Brox, 2015). These models apply deconvolutional neural networks, by creating an encoder and decoder. The encoder of U-Net convolution layers of $3 \times 3$, two layers each of $64,128,256$ and 512 filters, each pair is followed by rectified linear unit (ReLU) activation function and $2 \times 2$ max pooling and stride 2 for down-sampling. The decoder layers are followed by upsampling and the last layer consists of a $1 \times 1$ convolutional layer; this network has 23 convolutional layers. In design and application of U-net for classification of biomedical image processing data augmentation through elastic deformation is applied. Data augmentation is a technique which facilitates training the invariance of the deformations while these transformations 
are not labeled in the training data. This procedure is used in coordination with the nature of the data of the study; in our study we used the contextual information and inherent traits of geographic data to come up with the data manipulation technique. In segNet (Badrinarayanan et al., 2017) a deeper network is designed, the encoder is identical to a VGG16 network and the decoder is topologically symmetric to the encoder with up-sampling. The activation function that is used after each layer in segNet is also ReLU, just like U-Net.

In this work, we propose deepLand, a deep deconvolutional neural network for predicting impervious land expansion. We construct two networks which are morphologically similar to segNet and U-Net, respectively. Our networks are however shallower than the corresponding networks in segNet (Badrinarayanan et al., 2017) and U-net (Ronneberger et al., 2015) We call these deepLand-U and deepLand-S corresponding to the two base models segNet and U-Net, respectively. Our proposed networks are two different versions of U-net and segNet with slight changes in their architecture. We make modifications in the parameters of these models so the fine-tuned parameters of our suggested models can be applied. We apply our proposed networks to investigate land change processes and the influence of a range of variables by using high dimensional data and advanced modeling strategies. A data fusion and data manipulation technique is proposed to stack the environmental characteristics of land and generate high dimensional data cubes. The models utilize different parameters to explain the nature of the change to developed land, a cell with more than $20 \%$ of imperviousness and with built constructions (https://www.mrlc.gov/nlcd06_leg.php), hence, in this paper we use both terms of developed land and impervious land interchangeably.

We adjusted the networks, so they could specify the configuration and integration of land changes. The applied models in this study are deep deconvolutional neural network for pixel wise semantic 
segmentation, which fine-tune the weights such that the transition rules of patches of data can be explained. Our models use contextual information about the land in each patch which provides encouraging or discouraging configurations for the future transition. These filters are extracted by training the network on the data from National Land Cover Dataset (NLCD) 2001 (Homer, Huang, Yang, Wylie, \& Coan, 2013) while the test data of land cover is from the 2011 NLCD (Homer et al., 2015). Developed land expansion is a phenomenon that is driven by latitudinal factors that are not merely spatial; there are socio-economic and policy related variables that stimulate development expansion (Verburg, 2006). The variables of this study constitute a high dimensional set of data for a large geographic area. Since analyzing such a large dataset requires more advanced technologies, this study takes advantage of parallelizing the structure of the proposed network. In addition, we use the High-Performance Computing (HPC) facilities at the Pittsburgh Supercomputing Center (PSC) to reduce running time, leading to improved time efficiency.

The major contributions of this research are: i) data manipulation through application of a novel method based on the concept of multispectral imagery, and ii) application of deep deconvolutional semantic pixel-wise segmentation for land change modeling and prediction. The computational power provided through Graphics Processing Units (GPUs) from the Pittsburgh Supercomputing Center (PCS) was used to expedite the required processing. We compare the results of our proposed network with these segNet and U-Net and LTM. We also considered an implementation of the LTM, and based on this we compared the LTM results with those from the deep learning models - U-Net and segNet models, and the proposed deepLand models. The paper is organized as follows. In Section II, we describe the datasets used in this work and the data transformations applied. Section III presents our proposed deepLand models for predicting developed land cover expansion, built on top of two popular neural network architectures used in image segmentation 
and bio-medicine. Section IV presents the results and discussions. In Section V, we draw conclusions from the work.

\section{Data}

The focus area for this study is a watershed that includes parts of West Virginia, Pennsylvania and Maryland from the Appalachian Region of the United States (Fig 2-1).

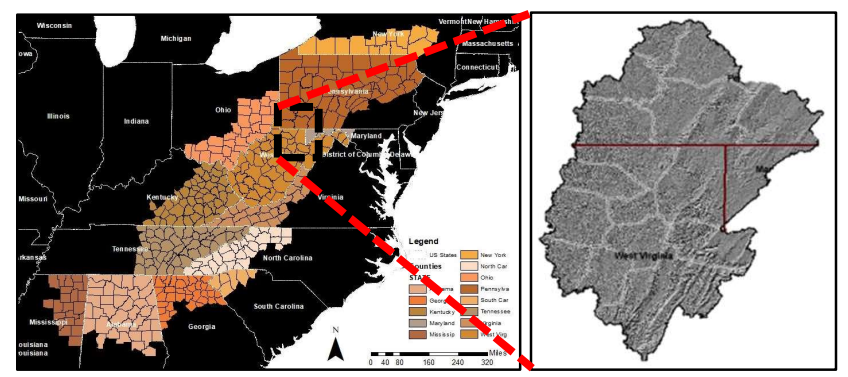

Fig. 2-1: Appalachian Region (Data Source http://wvgis.wvu.edu/)

The study area region is the Monongahela River watershed. It has an abundance of natural, energy and anthropogenic resources, which creates additional complexity and helps to highlight the importance of analyzing development expansion. Given the scope of our research and the focus area, it is difficult to take all the explanatory factors of land development into account. Even if it was possible, it does not always mean an improvement in predictive modeling. Our approach to identify the variables to use in the model was attempted by considering the landscape characteristics of the study area and the key influential factors noted in other published literature. The variables used in this analysis fit into the broad categories that are terrain-based, policyrelated, socio-economic and distance/density features. The source features for distance and density related variables were defined for specific traits of the region as place-based characteristics. For example, because of the rich oil and gas resources in the region, we included a kernel density of 
oil and gas wells within $10 \mathrm{~km}$ of each point. After geo-referencing and co-registering the vector

data, raster layers were created at a spatial resolution of $30 \mathrm{~m} \times 30 \mathrm{~m}$ cells. Table $2-1$ provides a description of all the variables we considered in this study.

Table 2-1: Variables Used in the Analysis

\begin{tabular}{|c|c|c|}
\hline ID & Data Layers & Description \\
\hline$\overline{1}$ & Distance to crop lands & Distance of each cell from crop lands \\
\hline 2 & Distance to streams & Distance of each cell from stream \\
\hline 3 & Distance to recreational sites & Distance of each cell from recreational sites \\
\hline 4 & Distance to developed lands & Distance of each cell from developed lands \\
\hline 5 & Distance to main road and highway & Distance of each cell from main road and highway \\
\hline 6 & Distance to pasture/hay & Distance of each cell from pasture/hay \\
\hline 7 & Distance to coal mines & Distance of each cell from mining points \\
\hline 8 & Distance to financial district of cities & Distance of each cell from point data of the important buildings \\
\hline 9 & Distance to urban areas & Distance of each cell from census urban areas \\
\hline 10 & Density of oil and gas wells & Density of gas within $10 \mathrm{Km}$ of each cell \\
\hline 11 & Density of developed lands & Density of developed lands within $10 \mathrm{Km}$ of each cell \\
\hline 12 & Density of crop land & Density of crop lands within $10 \mathrm{Km}$ of each cell \\
\hline 13 & Federal lands & Whether the cell is in a federal land or not \\
\hline 14 & Elevation & Elevation of the center of the cell \\
\hline 15 & Slope & Slope of the cell \\
\hline 16 & Population in 2000 & Population in year 2000 (closest to the base year 2001) \\
\hline 17 & Aspect & The aspect of each cell \\
\hline 18 & Majority of land cover within $100 \mathrm{~m}$ & Major class of land cover within $100 \mathrm{~m}$ of each cell \\
\hline 19 & Majority of land cover within $1000 \mathrm{~m}$ & Major class of land cover within $1000 \mathrm{~m}$ of each cell \\
\hline 20 & Have development plan or not & Does the metropolitan area have developed plan or not \\
\hline 21 & Urban Clustered & Is the cell in Urban Clusters (UCs) of at least 2,500 and less than 50,000 people (Census 2000) \\
\hline 22 & Urbanized Area & Is the cell in Urbanized Areas (UAs) of 50,000 or more people (Census 2000) or not \\
\hline
\end{tabular}

\section{Data Representation}


In the field of hyperspectral imaging and remote sensing, each image can represent different bands, each of which refers to the same feature but captured through different wavelength ranges. The different wavelength representations can be viewed as spectral cubes for each object. This general idea of using spectral cubes of images was adopted for data manipulation in this study. Different representations of a geographic region were considered as different feature classes. Stacking the variables on top of each other resembles the idea of hyperspectral images and creates a data cube of each patch of data.

A cross-section of data cubes, each with a dimension of $32 \times 32 \times 71^{1}$, were generated from the study area (see Fig. 2-2). Each data cube (representing a 3D patch) is then considered as one sample of data. The model was trained on binary data of developed versus non-developed regions using the National Land Cover Dataset of 2001 (Homer et al., 2013) and on the variables that are listed in Table 1; the test data is the National Land Cover Dataset of 2011 (Homer et al., 2015).

GIS raster data and Python scripts were used for the analysis. Arc Map10.5 is used for data manipulation and formatting, and Python 3.6 scripts were utilized to pre-process the data, develop the model and generate the map of study area from predicted patches. For data management and manipulation, we used NumPy library in Python and to build the model Keras library, which is a high-level neural networks API capable of running on top of TensorFlow is applied. The accuracy of the model performance was calculated according to the area under the curve of the Receiver Operating Characteristic (AUC-ROC). ROC measures the ability of a binary classifier system; the higher the ROC value the larger the difference between True Positive Rate (TPR) and False

\footnotetext{
${ }^{1}$ After changing the categorical variables to binary dummy variables, the dimensions will reach to 71
} 
Positive Rate (FPR). After a full demonstration of the model for 200 epochs the data points get rearranged in the larger map of the whole study area. The model was implemented on the NVIDIA Tesla K80 Graphics Processing Units (GPUs) at the Pittsburgh Supercomputing Center. These GPUs provide complementary, substantial power for the deep learning. To access the PSC we used XSEDE virtual system that facilitated interactive sharing of computer resources (Towns et al., 2014).

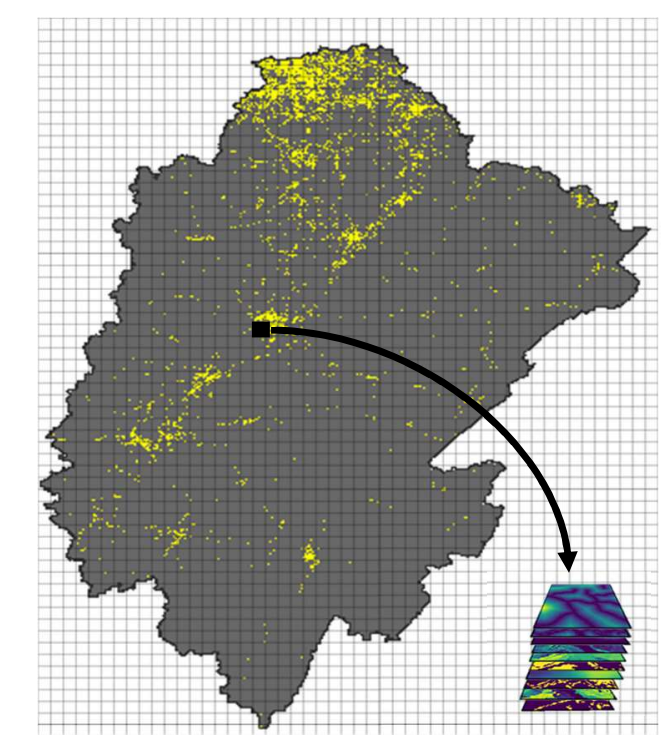

Fig.2- 2: Illustration of the multidimensional multispectral data cube.

\section{Modeling}

We introduce a new application of deep, fully convolutional neural network for predicting impervious land expansion, based on semantic pixel-wise segmentation. Essentially, we consider the problem of predicting developed land expansion as that of segmentation (pixel-wise classification) of the patches. Pixel-wise semantic segmentation is done at each patch by considering the multidimensional data cube for the patch along with the data cubes for nearby positions. 
In deepLand model, the first two convolutional layers include 64 filters of size $3 \times 3$ followed by average pooling using a $2 \times 2$ filter. The two following convolutional layers comprise 128 filters and are followed by maxpooling the following convolutional layers as illustrated in Fig. 2-3 and Fig. 2-4 which differ in the number of filters applied in convolutional layers. However, all the filters in the convolutional layers are of size $3 \times 3$ and all the poolings use $2 \times 2$ filters. Since the input spatial data (the data cubes) are highly correlated with the neighboring data cubes (Wu et al., 2009), in the first pooling this network applied an average-pooling. This also smoothens the effect of features with one in a binary feature class. This was done to prevent the sparse matrices from influencing the input of other layers. To accelerate the training and improve the model results we used dropout at the final convolutional layer of the encoder. The decoder has more convolutional layers with more upsamplings. The last convolutional network convolved the data of its prior layer to a $32 \times 32 \times 1$ image with probabilities of land transformation, which enabled the model to classify each patch cube accordingly. In all the layers except the first two layers, LeakyReLU, which is a version of rectified linear unit (ReLU) function, was used. The first two layers used ReLU as an activation function. In the last layer we applied a sigmoid function to compute the score value in range 0 and 1 for each pixel. Fig. 2-3 shows the architecture for the proposed deepLand-U model, while Fig. 2-4 shows the corresponding architecture for deepLand-S model. The same parameters (including activation functions, optimizers and loss functions) were applied in the two models. 


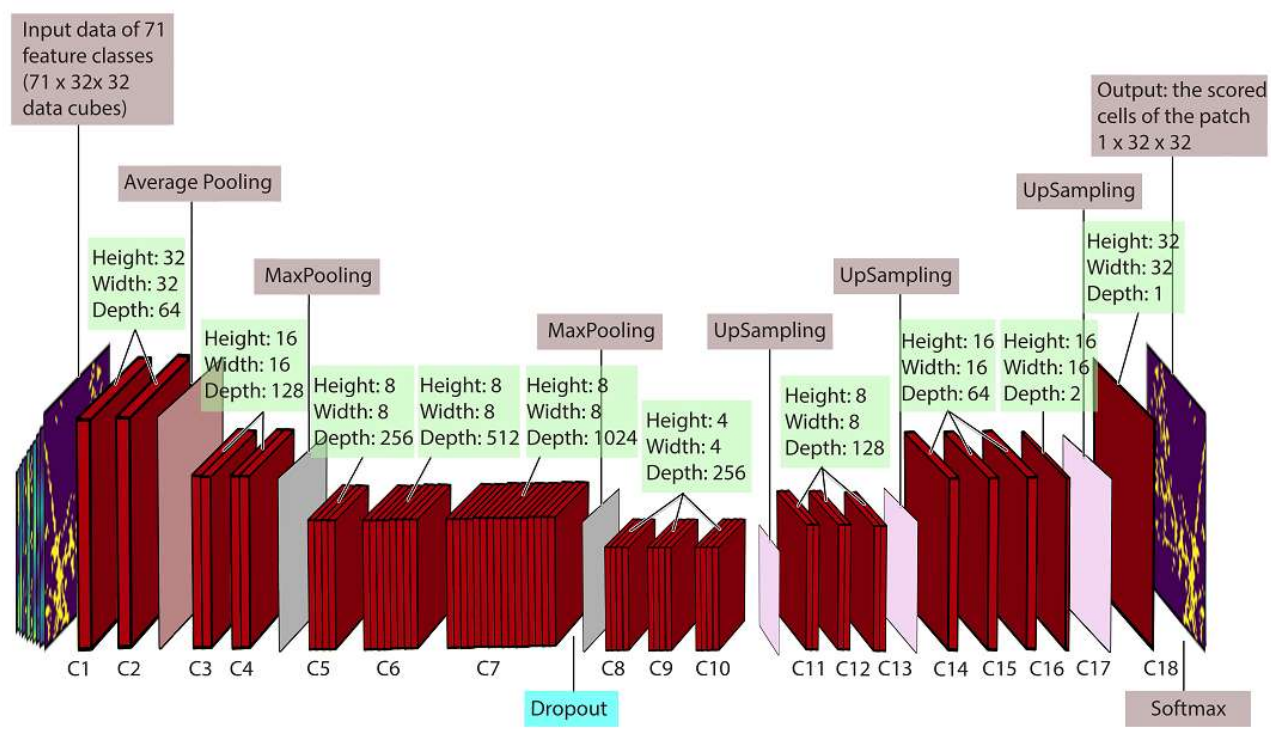

Fig. 2-3: An illustration of the deepLand-U architecture

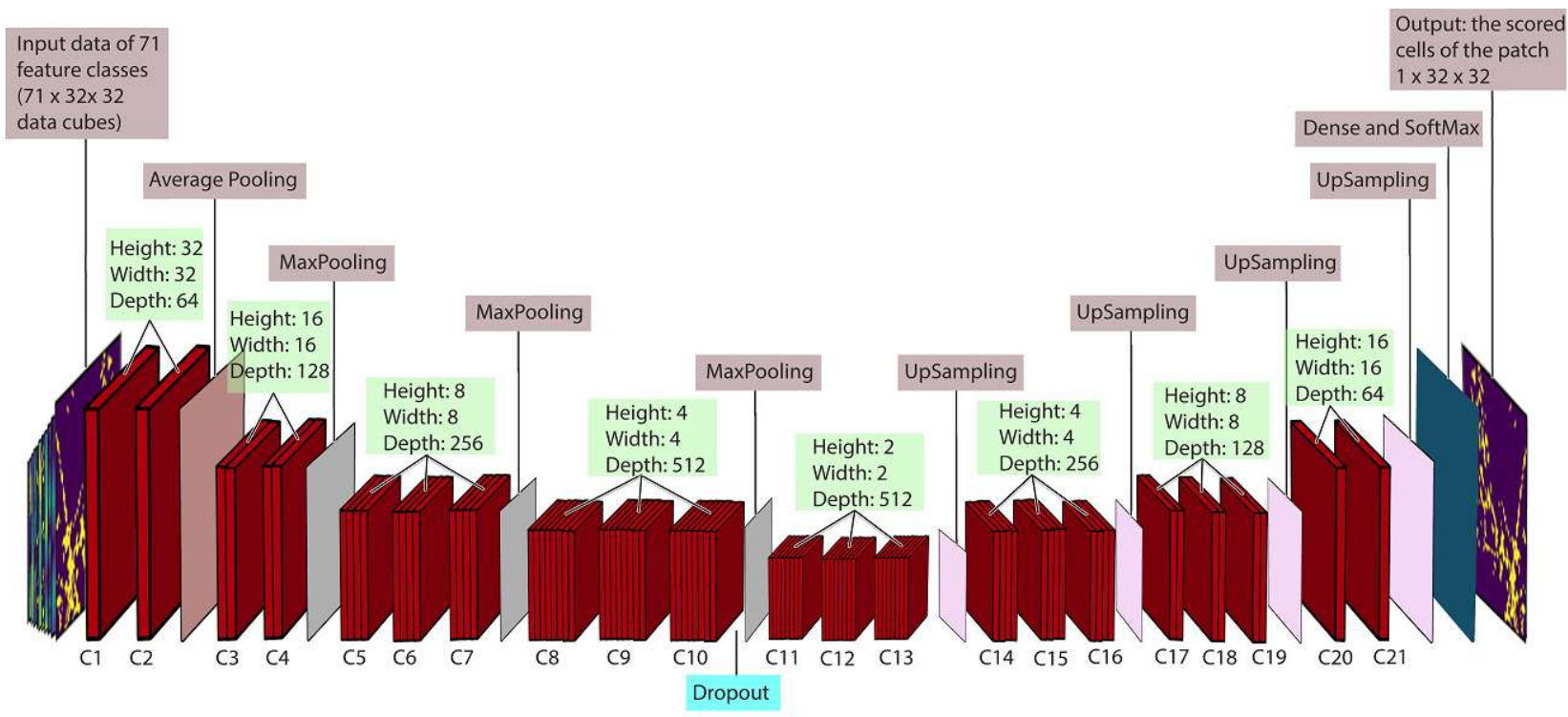

Fig. 2- 4: An illustration of the deepLand-S architecture

Activation functions: In this model we applied two different activation functions; after each convolving layer (C) an activation function was applied to the convolved data. As shown in the Fig. 2-3 and Fig. 2-4, these functions are applied after each of the convolutional layers. The activation function applied in this model was a Leaky $\operatorname{ReLU}$ function, which is like a ReLU 
function. However, this member of rectified unit family fixes the "dying ReLU" problem. Leaky ReLU computes the value of $f(x)$ according to $x$ value, minimize the effect of the class-imbalance data of the study area we applied this function:

$$
f(x)=\left\{\begin{array}{ll}
x, & \text { if } x \geq 0 \\
\alpha x, & \text { if } x<0
\end{array} \quad\right. \text { eq (2-1) }
$$

where $x$ is the value of the input for the function and $\alpha$ is a coefficient for negative values of $x$ (in our model, we used a value of 0.05 for $\alpha$ ). At the last layer, sigmoid was used as the activation function, which is a generalization of the logistic function; the output is a value which is in the range $(0,1)$.

$$
S\left(x_{i}\right)=\frac{1}{1-e^{x i}}
$$

$e q(2-2)$

where $S\left(x_{i}\right)$ is the score of the $i^{\text {th }}$ sample, $x_{i}$ is a given sample value.

Optimizer: We use the adaptive moment estimation (Adam) optimizer, which calculates the adaptive learning rates for each parameter (Ruder, 2016).

Loss function: The loss function for this model was binary cross entropy, this loss function computes the loss-value based equation (2-3).

$$
L(y-\hat{y})=-\frac{1}{N} \sum_{i=1}^{N}\left[y_{i} \log \left(\hat{y}_{i}\right)+\left(1-y_{i}\right) \log \left(1-\hat{y}_{i}\right)\right] \quad \text { eq (2-3) }
$$

where $\hat{y}_{i}$ is the estimated value per example, $y_{i}$ is the true value, and $N$ is the number of samples. 
The proposed network accepts input patches of size $32 \times 32$ with 71 channels and will output images of size $32 \times 32$. The values at cell (pixel location) in the output image denotes the score value for the impervious expansion, or development at the given cell. The scores of 0.50 or higher represent class value of 1 (developed land), and lower values denote a class value of 0 (non-developed land).

\section{Results and Discussions}

To evaluate the performance of the proposed deepLand models, we performed computational experiments on predicting developed land expansion in the identified region, using the proposed multidimensional multi-spectral data cube representation of patches within the region. For comparison, we also evaluated the performance of the two base deep learning models (segNet and U-net), and the popular neural network model in land change prediction, LTM, on the same data set. Since the data for the analysis was imbalanced, we used area under the curve (AUC) of the receiver operating characteristics (ROC) curve to measure the accuracy of the models, and to avoid the effect of class imbalance in accuracy measurement (Davis \& Goadrich, 2006).

Fig. 2-5 shows the trend of the loss function with increasing number of epochs. Specifically, the figure shows the binary cross entropy loss for deepLand-U at every iteration for both training set and validation set. We can observe that, as expected, the error falls rapidly after the first few epochs, and stabilizes after epoch 105 .

Fig. 2-6 shows the change in the Area Under Curve of ROC at each iteration for different models. The results of each iteration suggest that the AUC-ROC of the model performance increased at each iteration. Except for segNet, the accuracy seemed stabilized to after about 30 epochs. Overall best performance was produced using the proposed deepLand-U, at $98 \%$ accuracy, followed by using U-Net. We can also observe the significant improvement of the proposed deepLand-S over 
its base model of segNet. While segNet required a lot of iterations before convergence, the deepLand models converged relatively quickly, after about 120 epochs.

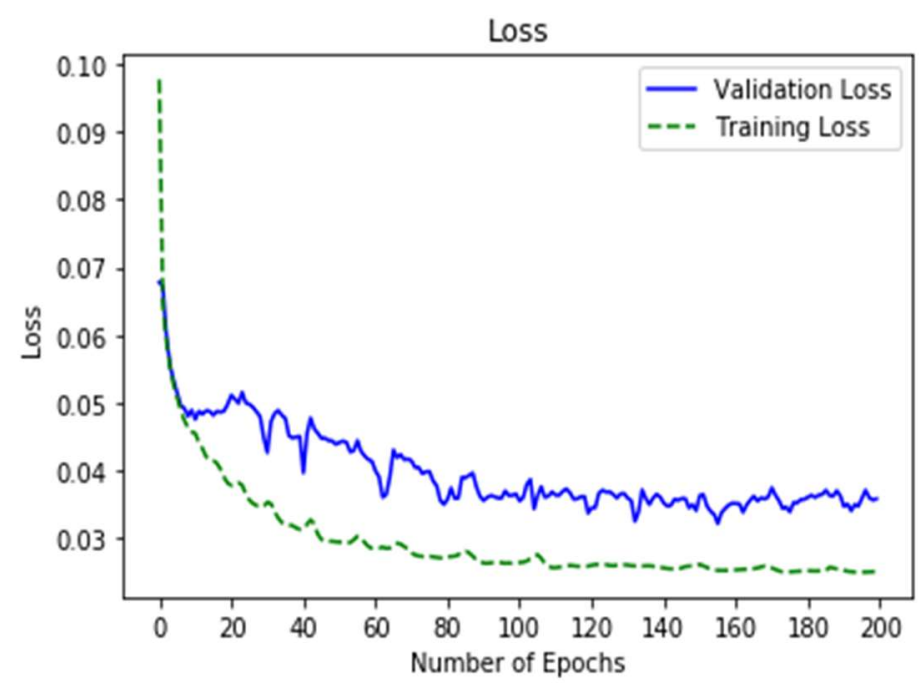

Fig. 2-5: Comparison of training loss vs. validation loss

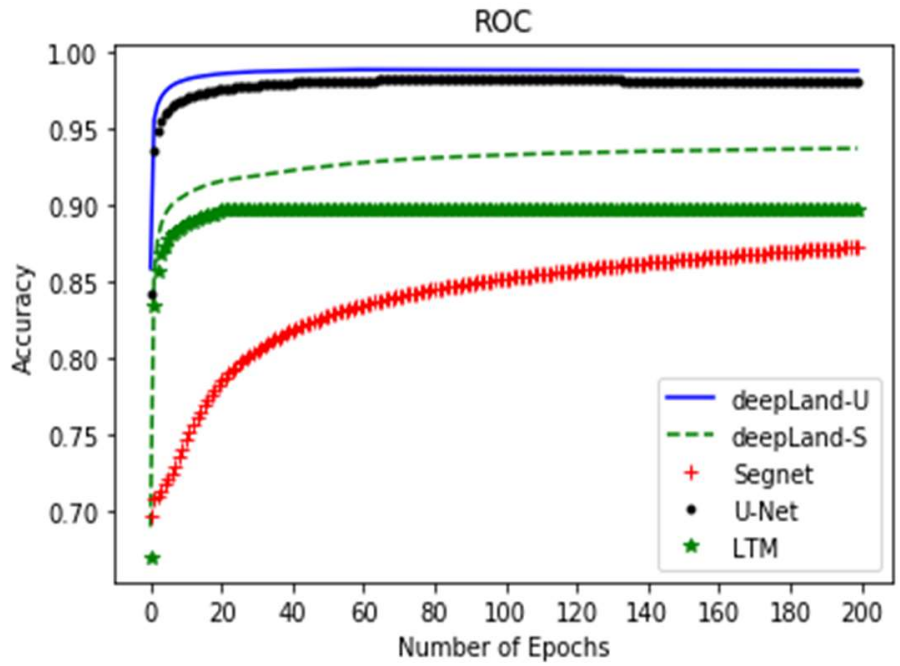

Fig. 2-6: Comparison the AUC for different models

The results also show that, model prediction on the test dataset using deepLand-U or deepLand-S resulted in an improved prediction accuracy over the popular approach using Land Transformation Model (LTM).

To further understand the working of the proposed deepLand models, Fig. 2-7 shows a visualization of the heat maps for three selected patches with different levels of impervious land 
expansion, within the region studied. In this figure left column shows the ground truth; middle column depicts the scored cells by the model and the right column represents labeled cells by deepLand-U. Top row of this figure is a patch located in rural region (with less impervious lands); Middle row shows a patch in urban region (with more impervious lands); Bottom row shows a patch in developing region (with medium level of developed lands). The model output for each pixel is a score ranging from 0 to 1 , heat maps of the selected patches in the middle row show this score. The label of each pixel is assigned according to equation (4) as it is illustrated in right column of patches in Fig 2-7.

$$
l\left(x_{i}\right)=\left\{\begin{array}{c}
1, \quad \text { if } S\left(x_{i}\right) \geq 0.5 \\
0, \quad \text { if } S\left(x_{i}\right)<0.5
\end{array}\right.
$$

where $l\left(x_{i}\right)$ is the label of the $i^{\text {th }}$ pixel in sample $x$ and $S\left(x_{i}\right)$ is the score of the $i^{t h}$ pixel in sample $x$ as shown on the heat map.

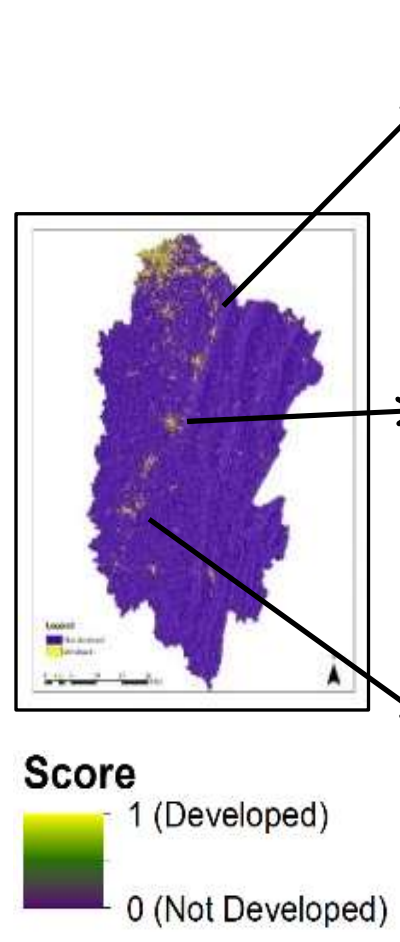

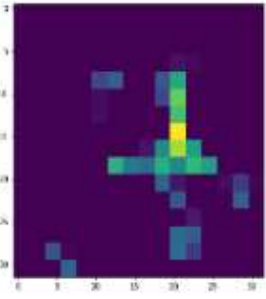
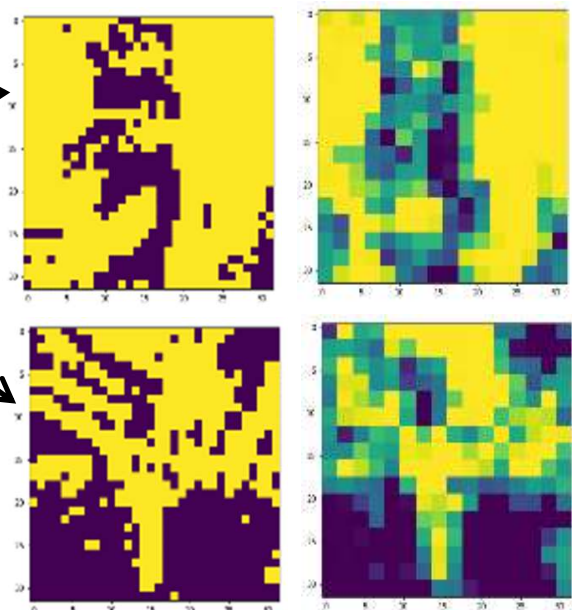
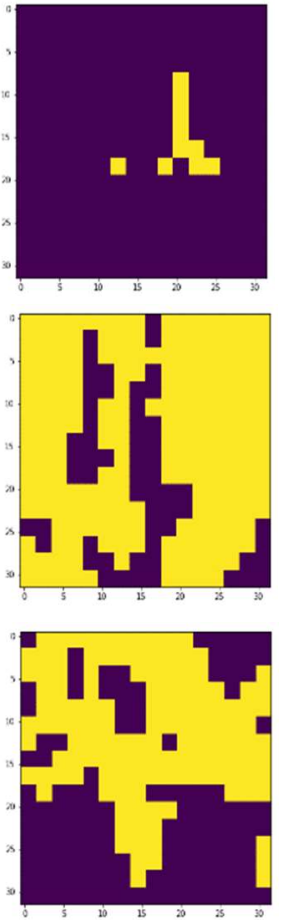

Fig. 2-7: Modeled patched 
Fig. 2-8 shows the prediction results for the entire study area using the proposed deepLand-U, along with a visual comparison with the ground truth data from NLCD 2011(Homer et al., 2015). The whole study area is a combination of rural and urban developments, Pittsburgh PA is located in the north of the study area and in the central area of the watershed metropolitan area of Morgantown, WV is located.

In Fig 2-8 this area is magnified so it is easier to visually compare the ground truth and model prediction. Given the large data sets, and the potential expanse of land that may be covered by this type analysis of developed land expansion, computational efficiency, in terms of both memory and time becomes a major consideration. To alleviate the computational requirements, we performed the experiments on high-performance computing facilities at the PSC and observed how the required computational time changes with the execution of the proposed deep convolutional neural networks.

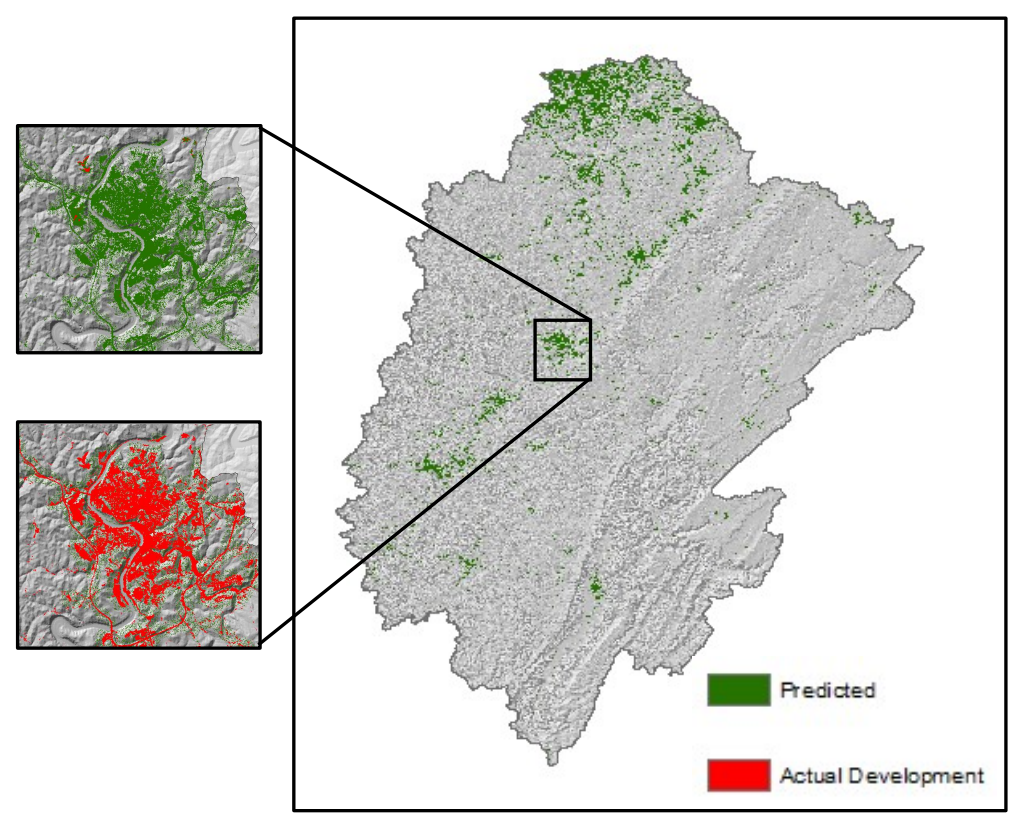

Fig. 2-8: Model prediction compared to ground truth 
We recorded the time for running each of the models on a dual processor PC with $3.47 \mathrm{GHz} \mathrm{CPUs}$ and 48GB RAM, and on the GPUs available on PSC. We used 4 NVIDIA Tesla K80 GPU nodes each of which holds two NVIDIA K80 GPU cards with 24GB of GPU memory (48GB/node). Table II shows a comparison of the time per step for each epoch, as needed for each model.

First, we can obverse the improvement in computational time using the proposed deepLand, when compared with the base models (segNet and U-Net). This is significant, especially in the light of the superior performance of deepLand models in the problem at hand-predicting impervious land expansion. Further, we can also notice how the deepLand models also performed better than the popular LTM approach - in terms of both prediction accuracy and computational time. We can observe that, segNet is generally slower that U-Net, our proposed deepLand-U was also faster that deepLand-S, whereas both deepLand-S and deepLand-U are faster than segNet and U-Net. The time difference in the model performance is a resulted from the structure of the models, the number of parameters which get fine-tuned in deepLand-U is $10,772,997$ whereas there are $17,631,969$ trainable parameters in deepLand-S. Number of trainable parameters are 30,764,805 in U-Net and $31,929,885$ in segNet. This difference in the depth of the network and number of trainable parameters essentially impact the required time for training the models.

Finally, we can observe the significant impact of using the high-performance computing resources, resulting in almost a factor of 20 speed up. We were unable to run LTM on the GPUs at PSC due to time constraints in the access to the machine. However, the substantial difference in the running times using a CPU and the PSC underlines the significance of computational resources in overcoming the huge computational resource requirements for models such as deepLand. 
Table 2-2-Comparison of the Time Required for the Model Run on CPU and GPUs

\begin{tabular}{|c|c|c|c|}
\hline & Model & Time Per Step & Time per epoch \\
\hline \multirow{5}{*}{ CPU } & deepLand_S & $127 \mathrm{~ms}$ & $1880 \mathrm{~s}$ \\
\hline & deepLand_U & $117 \mathrm{~ms}$ & $1680 \mathrm{~s}$ \\
\hline & segNet & $275 \mathrm{~ms}$ & $3940 s$ \\
\hline & U-Net & $175 \mathrm{~ms}$ & $2500 \mathrm{~s}$ \\
\hline & LTM & - & $4198 \mathrm{~s}$ \\
\hline \multirow{4}{*}{$\begin{array}{l}\text { GPUs } \\
\text { PSC }\end{array}$} & deepLand_S & $6 \mathrm{~ms}$ & $85 \mathrm{~s}$ \\
\hline & deepLand_U & $5 \mathrm{~ms}$ & $65 s$ \\
\hline & segNet & $9 \mathrm{~ms}$ & $127 \mathrm{~s}$ \\
\hline & U-Net & $7 \mathrm{~ms}$ & $105 \mathrm{~s}$ \\
\hline
\end{tabular}

\section{Conclusion}

Numerous machine learning models have been developed to predict the complex and dynamic process of land development; however highly complex processes of land development can barely be modeled to predict the future of land change. In this work, we examined the applicability of pixel-wise classification-based image segmentation models for use in studying land change. Deep deconvolutional networks for predicting impervious land expansion, namely deepLand, has been introduced in this work. These models are built up on top segNet and U-Net, two known deep learning models for semantic pixelwise segmentation. To apply these image-based models, we introduced a novel idea to represent different land characteristics in the form of a multidimensional multispectral data cube, where each spectrum (or data layer) corresponds to a different characteristic, and each cube captures data in a different patch or location within the region under study. Performance of the experiments using the proposed deepLand models, along with comparison of the prediction results against those from the base deep deconvolutional networks, and against LTM (a non-deep learning method) show that deepLand is able to learn the transition rules of the land change more accurately. Among the five compared networks of U-net, segNet, LTM, deepLand-U and deepLand-S, the suggested deepLand models (namely, deepLand-U and deepLand-S) required less parameters to be fine-tuned, and also resulted in improved prediction 
accuracy. In particular, deepLa nd-U resulted in the best overall prediction performance when compared to our implementation of LTM, segNet, U-net and deepLand-S. The differences in the architecture of the models has considerable impact on the time efficiency of models. In this research we showed the ability of the CNN based models in capturing the contextual information acquired from the state of the neighboring cells. All the applied models were able to capture the complexity of the land transformations process by fine-tuning multiple weights. All in all, the findings of this research determine how the structure of model along with application of computational facilities can lead to reduction in the temporal costs and enhancement in the accuracy of the model results. 


\section{CHAPTER III}

\section{Paper II: Integrating Multi-Source Spatial Data, Remote Sensing and Data Transformation to Analyze the Variables of Land Development in West Virginia}

\section{Introduction}

In areas with an abundance of natural resources, changes in the landscape (i.e. land cover) are followed by immense costs and irrevocable consequences (R. De Groot, 2006; J. A. Foley et al., 2005). Analysis of these changes helps policy and decision makers to plan informed decisions for future developments (Godinho et al., 2016; Hietel, Waldhardt, \& Otte, 2004). An immense spectrum of methodological approaches is available to track the land change and study the driving variables of land development(Warner, Almutairi, \& Lee, 2008). The role of different variables in land development has been studied through analysis of trends and changes in other land characteristics (Godinho et al., 2016; Lin, Huang, Chen, \& Huang, 2014; Pato, Castro, \& Tavares, 2016). Remote sensing is a critical method used for exploring the historical data of land development (Cheng \& Masser, 2003; Ou, Liu, Li, \& Chen, 2013). Historical data of land cover and land change has been widely used in analyzing the spatiotemporal patterns of urban expansion and the significance of various variables in driving this process (Maimaitijiang, Ghulama, Onésimo Sandoval, \& Maimaitiyiming, 2015; Yin et al., 2011; Zhao et al., 2015). Wei, Huang, Lam, \& Yuan (2015) used economic transition factors in the scope of decentralization, marketization and globalization to explain the urban land expansion in specific areas in the eastern and central provinces of China. They used regression analysis to explain these transitions, however, their analysis does not imply geographic information on the effect of each economic variable on land transformation (Wei et al., 2015). 
Many of the recent studies in this area broadened the scope of attention from analyzing the impact of a defined set variables on land transformation to making geographic deductions on the impact of each variable (Maimaitijiang et al., 2015; Mennis, 2006). In their study on the drivers of land use and land cover change in the St. Louis, Missouri metropolitan area, Maimaitijiang et al. (2015) utilized both Ordinary Least Squares (OLS) and Geographically Weighted Regression (GWR) to examine the impact of population change on land transformation. They used remote sensing and a Support Vector Machine (SVM) classifier to access the land cover data for the 40-year period of their study. Indeed, OLS and GWR are two broadly applied methods among environmental scientists for this purpose (Z. Huang, Wei, He, \& Li, 2015; Maimaitijiang et al., 2015). However, a major statistical critique of the OLS model that has not been addressed in this area of science is the tendency to overfitting in the presence of multicollinearity of the variables (Klenke, 2014). In a regression model with multiple explanatory variables, this major technical consideration should be addressed since it is essential to consider in a regional study of land development.

In the course of studying the driving variables of land development, a limited number of studies addressed development expansion as a process in which urban and rural land development build a system of interactions(van Leeuwen, 2015). Drawing such a big picture is advantageous in exploring the tensions and strengths of each of these types of land development in the region ( $\mathrm{Z}$. Huang, Wei, He, \& Li, 2015). We study urban and rural land development as one synthesized system in which we regard the mutual interactions of urban-rural development. Investigating this process in a larger geographic extent raises the concern of overlooking the issues such as urbanrural interactions or spatial-auto correlations. These issues are addressed by geospatial data analysis techniques. In this research we make statistical and technical inferences on the complex processes that lead to major land developments in West Virginia (WV). We explored the question 
of which factors should be speculated and how the place-based transitions impact land development in WV (Godinho et al., 2016; Eric F Lambin et al., 2001).

WV is a part of Appalachia, which is a cultural region stretching on the spine of Appalachian Mountains. This region is characterized with an abundance of natural and energy resources (Report, 2011). Landscape changes in such a region can impose a burden to the local and global communities (Foley et al., 2005). Land development, one of the dynamic forms of landscape change, demands access to a variety of services measurable in monetary and non-monetary values (Kroll, Müller, Haase, \& Fohrer, 2012; Wurster \& Artmann, 2014). It also requires policies and regulations which guarantee the ecological, economic, social and cultural well-being of individuals and communities. A balance in the services that land development demands, depends on the regulations which direct the land transformation. One of the very important pieces of knowledge that facilities regulating toward lower costs of services and higher indicators of well-being is obtained through a historical study of developed land expansion and its drivers. This accentuates the necessity of exploring the state of the land development trends and understanding its driving forces. In this research, we primarily investigated the transformations in the patterns of land development and the factors affecting those shifts. We studied the impact of socio-economic, policy-related and anthropogenic changes on the land development in WV through time. Our main objective is to provide insights upon the establishment of efficient and sustainable land development regulations. We explored multiple levels of analysis to entrench a sound geographic and context-based study. We contribute to the growing knowledge of land science and community planning by investigating the impact of various factors on the dynamic process of land development in the resource rich region of WV. To the best of our knowledge no scientific study has addressed this issue in the unique landscape of WV in a historical context. 
We conducted this study in three major steps; in the first phase we used large historical data of satellite imagery for three decades to extract the land development trends in the state of WV. The second phase included data management, formatting and co-registering of the variables. In the third step we built spatial models to analyze the driving variables of the land development. This analysis was conducted in 10 year time spans for three consecutive time steps from 1985-2015.

\section{Study Area}

WV is the only state in the United States which lies completely within the Appalachians (Fig. 31). The terrain, topography and water resources in this state along with its location provide unique context for the anthropogenic activities in WV. WV is a rich state with an abundance of natural resources, Monongahela national forest with land area of over 919,000 acres is located in the southeast part of WV; this state is also the major water source of large rivers such as Potomac and Ohio rivers. The eastern panhandle of WV is in close proximity to the Washington DC metropolitan area. The northern panhandle is also near Pittsburgh, PA, both of which areas are populated regions with considerable number of industrial and administrative sectors. Energy extraction industries play an important role in the economy of WV, such that the coal industry is one of the primary natural resources of the state. Since the early 2000 s, a considerable number of shale gas extraction sites have developed in WV (Bowen \& Christiadi, 2017). WV has a unique landscape that, benefits from rich natural and cultural resources, which led to a cycle of economic boom and bust as the value and production through these resources grow and shrink. 


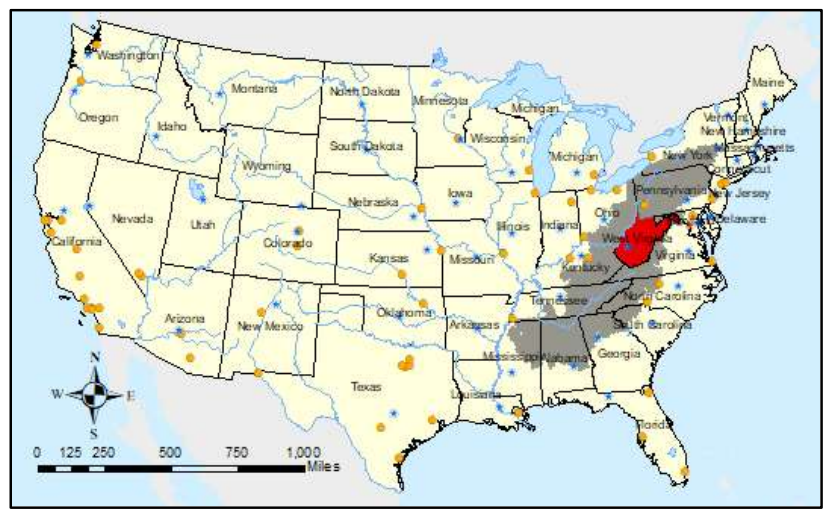

Fig. 3-1: Location of WV in the US and Appalachia

\section{Methods}

In this research, we used regression coefficient analysis methods to find the role of different variables in prompting the land development in WV. In the land change models which project the land development and urbanization, various explanatory variables and place-based information were deployed (Eric F Lambin et al., 2001; Seppelt et al., 2012); we identified these variables and explored their significance driving the land development. Essentially, to do this research we required access to compatible, consistent, reliable, transferable, and low-cost datasets. To acquire such datasets, two initial phases of data acquisition were designed.

In the first phase of data compilation and generation, the historical land development trends of WV were extracted. Following this phase, another stage of data collection was organized in which three input datasets for the model were attained. These datasets include: the variables which are identified according to the literature and the characteristics of the study area, the result of the hotspot analysis of the land development trends in each time-step and the established zones of development. Zones of development exhibit four groups of regions of development ranging between lower rural to populated/urbanized zones. In the third phase, we used the constructed database of the first two steps to explain the land development through regression coefficient analysis. One of the major methodological contributions of this research lies in the applied methods 
to analyze the coefficients of land development in the state of West Virginia. We used various tools including ArcMap 10.7, Python scripting language and R programming to undertake these steps. Fig. 3-2 provides a schematic picture of the process. The first two phases of this analysis are specified in Section IV, Section V will be focused on the third phase, where we build the models. The results of the model are described in Section VI, followed by the conclusions.

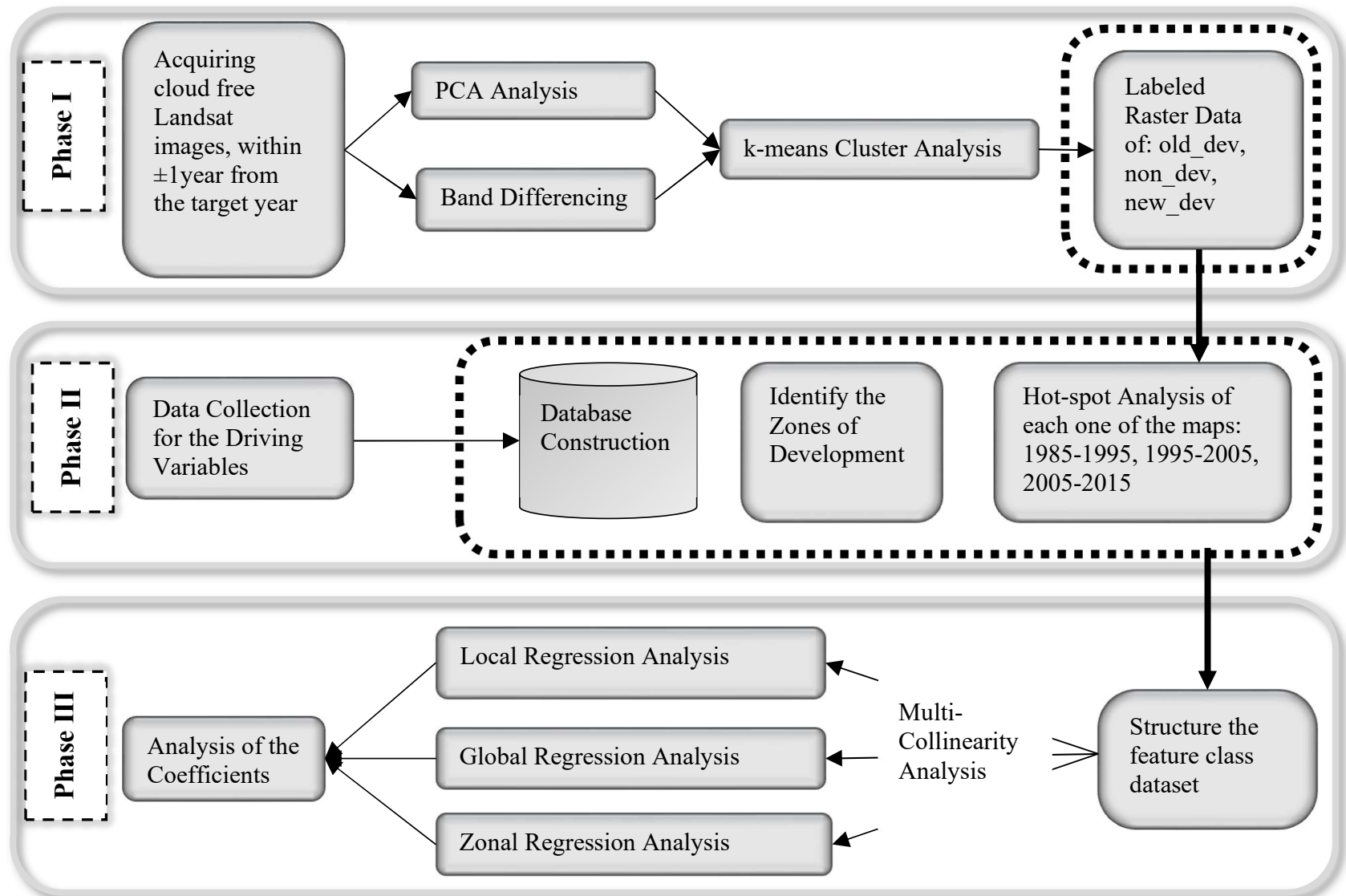

Fig. 3-2: Schematic Illustration of the Methodology

\section{Datasets and Data Preprocessing}

We based our analysis on 30-meter resolution raster datasets for the time period of 1985 to 2015. In this study, multi-source spatial data is used to extract the historical trends of land development. 
In this section, the process of land change detection is explained, then the variables of this research are elaborated.

\section{Land Change Detection}

Some landscape alterations such as land cover change are traceable through deploying remote sensing methods on satellite imagery and ancillary datasets (K. C. Huang et al., 2014; Ji et al., 2001; Warner et al., 2008). Because of the consistency in their availability, some sources of data provide the opportunity to study long-run trends of land change (Sexton, Urban, Donohue, \& Song, 2013; Xu et al., 2018). A variety of methods including multi-temporal false color composite, band differencing, multi-temporal ratios, Principal Component Analysis(PCA), the Kauth-Thomas (KT) linear transformations and Change vector analysis (CVA) have been applied in tracking the land change (K. C. Huang et al., 2014; Warner et al., 2008). In addition, there are classificationbased methods such as post-classification comparison, composite analysis and multi-date spectral mixture available to track the land change (Warner et al., 2008). Deng et al. (2019) examined two different methods of unsupervised classification and post classification to track the land cover change; their study implies that PCA based unsupervised change detection demonstrated higher accuracy compared to the post classification (J. Deng et al., 2019). A major advantage of the unsupervised detection method is that there is no need for data annotation, but still there is a necessity to label the clustered data. This advantage of these methods reduces the time expenses

of change detection. To determine the land development in WV, we utilized the Landsat data and a hybrid clustering algorithm.

To track the development in the state of West Virginia, we defined the developed lands as the areas which include constructed features. We chose this definition according to the characterization of the development in National Land Cover Dataset (NLCD) 2001 categories. In this part of the 
analysis we used 30-meter resolution Landsat images. Cloud free images of each scene in the study area (10 scenes in total) were acquired. We used a hybrid algorithm for land change detection. This algorithm integrates Principal Component Analysis (PCA) and band differencing methods with an unsupervised clustering method. Each pair of images from the base and final year and per one time-step, we implemented PCA to decompose the data, then we mapped it on the new dimension space to be able to extract specific characteristics of the data. In this analysis, we analyzed the Principal Components (PCs) of each scene to find the first three most descriptive PCs highlighting the development related characteristics of the land (example of 3 first PCs of one scene in Fig. 3-3).
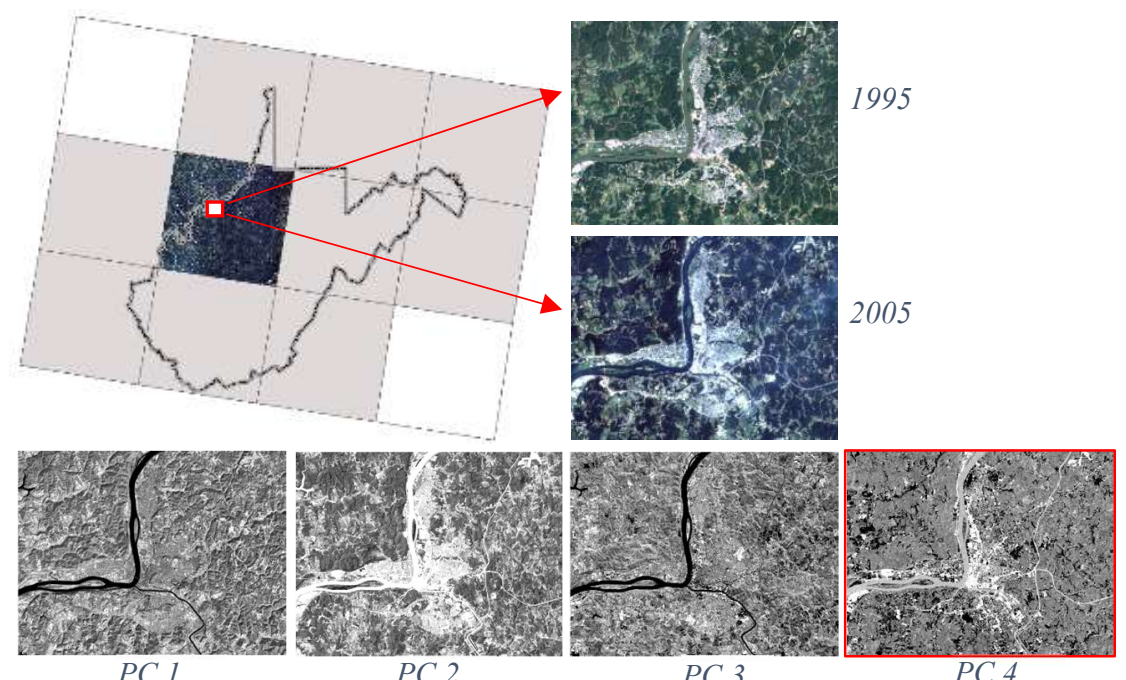

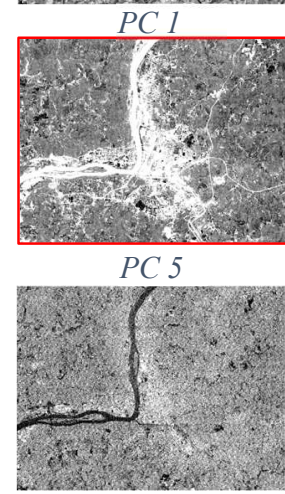

PC 9

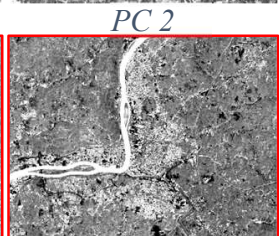

PC 6

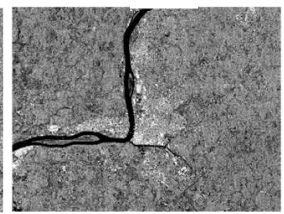

PC 10

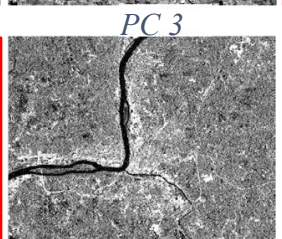

PC 7

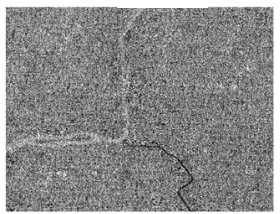

PC 11

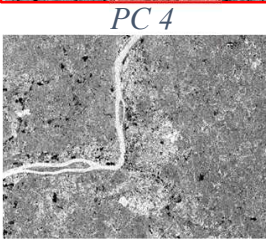

PC 8

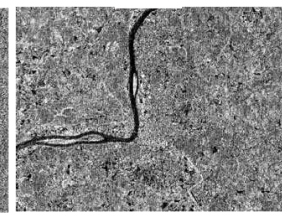

PC 12

Fig. 3- 3: PCs 
We also performed a band differencing to find the changes in the land, so a new set of features were created to be used with the three PCs. After identifying various representations of the images from PCs and the difference between the bands we implemented k-means clustering method. Through clustering, the data is sorted into 10 groups and then regrouped in three classes; this method was applied to each scene independently and the clusters were labeled by comparing the images. A user-producer accuracy measurement was done using the historical maps of Google Earth as the ground truth to validate the results of this analysis. A total of 1,000 stratified random points were checked and the overall accuracy of the change detection was estimated as $90.3 \%$.

Table 3-1: User-producer accuracy assessment of the change detection

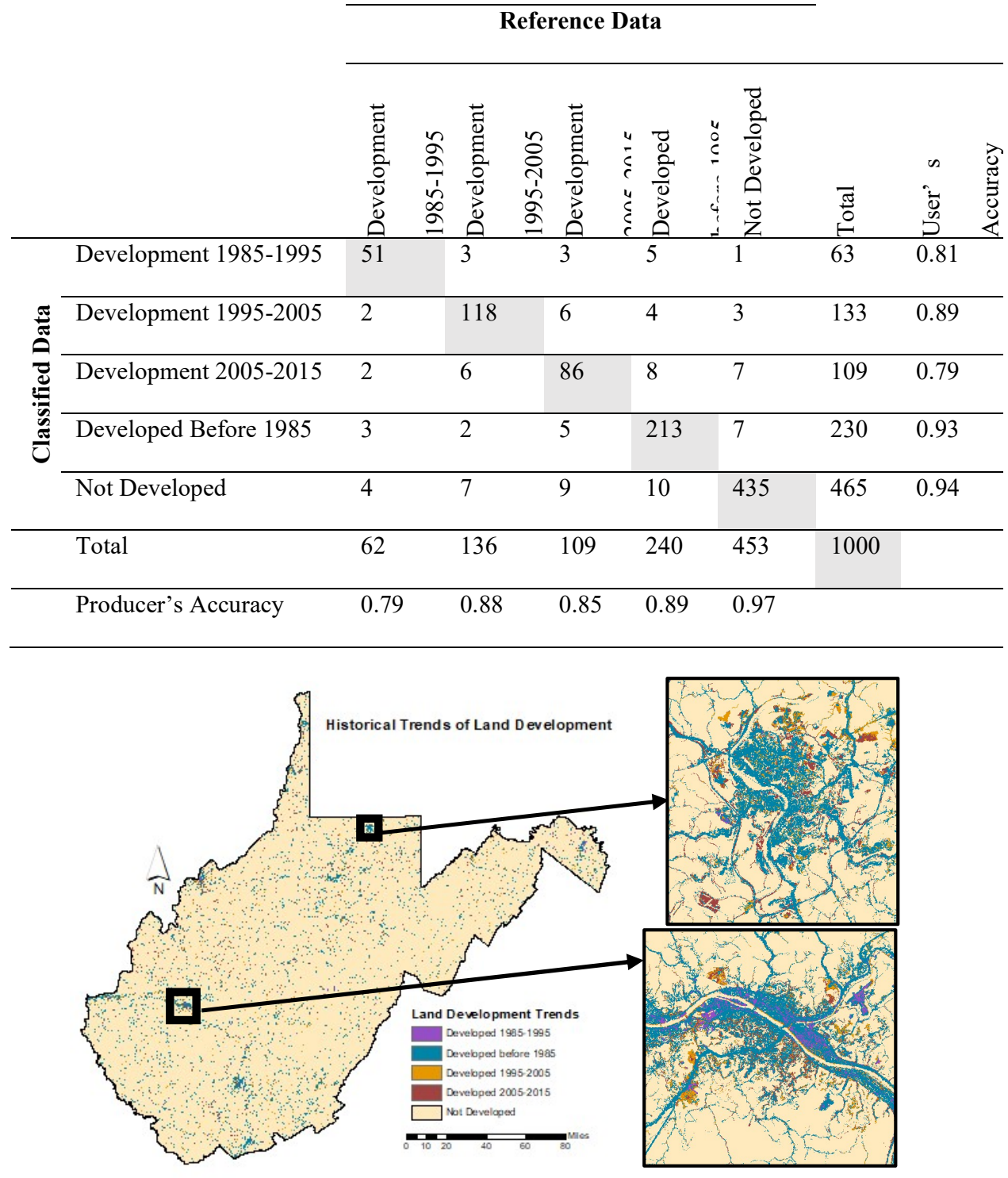

Fig. 3-4: Illustrates the land development trends in the state of WV in three decades 
An analysis of the density of land change in WV indicates that some regions have gone through major shifts in the land development over time. Fig. 3-5 depicts the visual inference on the trends of change considering the densitv of land develonment over square miles per decade.
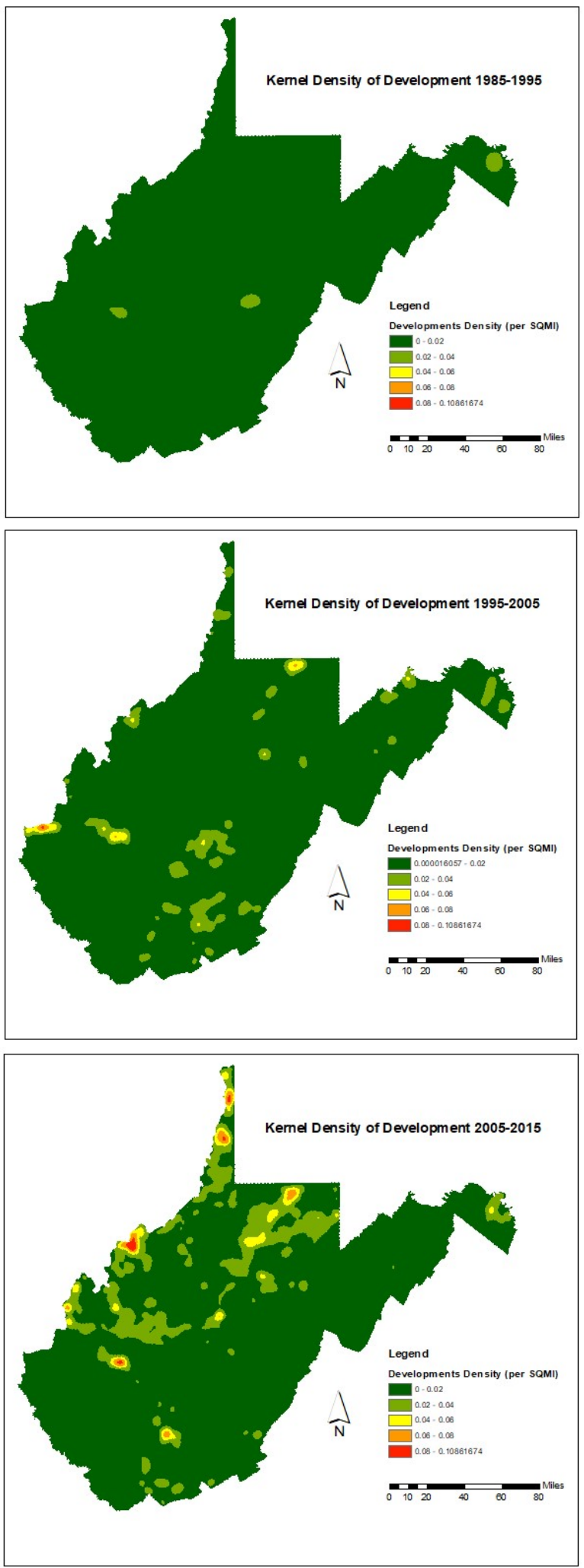

Fig. 3-5: Density of the land change per square Miles in WV 
This visualization implies that the rationale behind developed land expansion has changed its direction over the time period; accordingly, we make this assumption that the impact of driving variables has been changing the patterns of land development. The deviation in the spatial patterns of land development in WV and the impulses behind these changes makes them more interesting and debatable. Therefore, we investigated the changing spatial pattern and the variables motivating the land development in WV. The variables considered for this study are selected based on the literature and the factors that are recognized critical in the specific geography of $\mathrm{WV}$, however access to the consistent data over time is a limitation for applying these variables.

\section{Variables}

Variables of rural and urban land development can be represented as physical, socio-economic, spatial policy and neighboring cells (Pato et al., 2016; Verburg, 2006). In the historical scope of this study access to these factors, required examining the importance of the driving forces of the land development. Some of the factors, are not constant over time, these variables were required to be updated. The dynamicity of these variables contributes to the complexity of the analysis. Additionally, place-based knowledge on the study area leads to including some variables which are specific to the geography of the research. We explored the significance of contextual information on the geo-political and strategic location of the state; for example, the distance to metropolitan areas is considered as one of the factors in this study. The demographic and economic status of the study area are other major dynamic factors. We used census population data at the tract level in each decade as another variable. Also, we included the economic status of the study region by applying the County Economic Status Index. This index is extracted based on multiple economic indicators which are constructed based on the data provided through The 
U.S. Bureau of Economic Analysis and The US Bureau of Labor Statistics and US census. We used a methodology used by the Appalachian Region Commission (ARC) to assign an economic index to the counties of the Appalachian region (https://www.arc.gov), and then each land development unit included the index of the county in which it locates.

Table 3-2: Variables used in the study

\begin{tabular}{ll}
\hline & Variable Name \\
\hline Population Density (dynamic) & Inversed Distance to Oil and Gas Wells (dynamic) \\
\hline Distance to Census Urban Areas (dynamic) & Inversed Distance to Mining Permits (dynamic) \\
\hline Inversed Distance to Developed Areas (dynamic) & Economic Index (dynamic) \\
\hline
\end{tabular}

\section{Zones of Development}

Grouping the developed lands based on the zones of development requires access to different levels of rural-urban development. Land development parsing based on zones of development helps in making more specific and thorough investigations on the land development. The criteria for grouping the regions are density land development and population. The analysis of zones of development is conducted for each time step in the geography of census tracts. To identify these zones, we categorized the census tracts into four development zones including populated/urbanized, transitional area, rural and lower rural. This grouping was done based on the k-means clustering method. The urbanized/populated areas were regions with higher density of development and populated places. The areas denoted as the transition areas, were either the immediate areas surrounding the urban areas in which the population density was higher than the rural area, or some areas that are initial cores for dense population settlements in the future development. Rural areas and lower rural areas are mainly regions with scattered developed lands and dispersed population, the level of sparsity varies between these two categories. Lower rural areas are the areas with less populated places and a tendency of land development. After clustering, we applied Multivariate Analysis of Variance (MANOVA) to test the significance level 
of the difference between the groups. The homogeneity of the variables across the grouped data was then tested, the results of this test imply that all the clusters are significantly different from each other (Table 3-3).

Table 3-3: Multivariate Analysis of Variance of Zones of Development

\begin{tabular}{|c|c|c|c|c|c|c|c|}
\hline & Df & Pillai's Trace & Approx F & num Df & den Df & $\operatorname{Pr}(>\mathrm{F})$ & Residuals \\
\hline Zones of Development 1985 & 1 & 0.787 & 859.05 & 2 & 465 & $<2.2 \mathrm{e}-16 * * *$ & 466 \\
\hline Zones of Development 1995 & 1 & 0.76166 & 768.56 & 2 & 481 & $<2.2 \mathrm{e}-16 * * *$ & 482 \\
\hline Zones of Development 2005 & 1 & 0.72351 & 629.34 & 2 & 481 & $<2.2 \mathrm{e}-16 * * *$ & 482 \\
\hline
\end{tabular}

Illustration of these zones of development (Fig. 3-6) indicates that the majority of the census tracts located in the east of the state and center of WV are lower rural areas, this region is mainly covered by Monongahela National Forest. The area of urban and transitional zones in the three target time periods of the study was less than $15 \%$ of the state. Our investigations imply that the majority of detected developments occurred in rural and lower rural areas. This, highlights the importance of rural and lower rural land developments in WV.

\section{Hot Spot Analysis of the Developed Land Expansion}

Hot spot analysis of the trends of development points to the changing and dynamic the direction of land development over three time spans. Figure 3-7 illustrates the hot spot analysis based on the Gi* statistic, hot spots are identified based on $\mathrm{z}$ statistic and $\mathrm{p}$ value. 


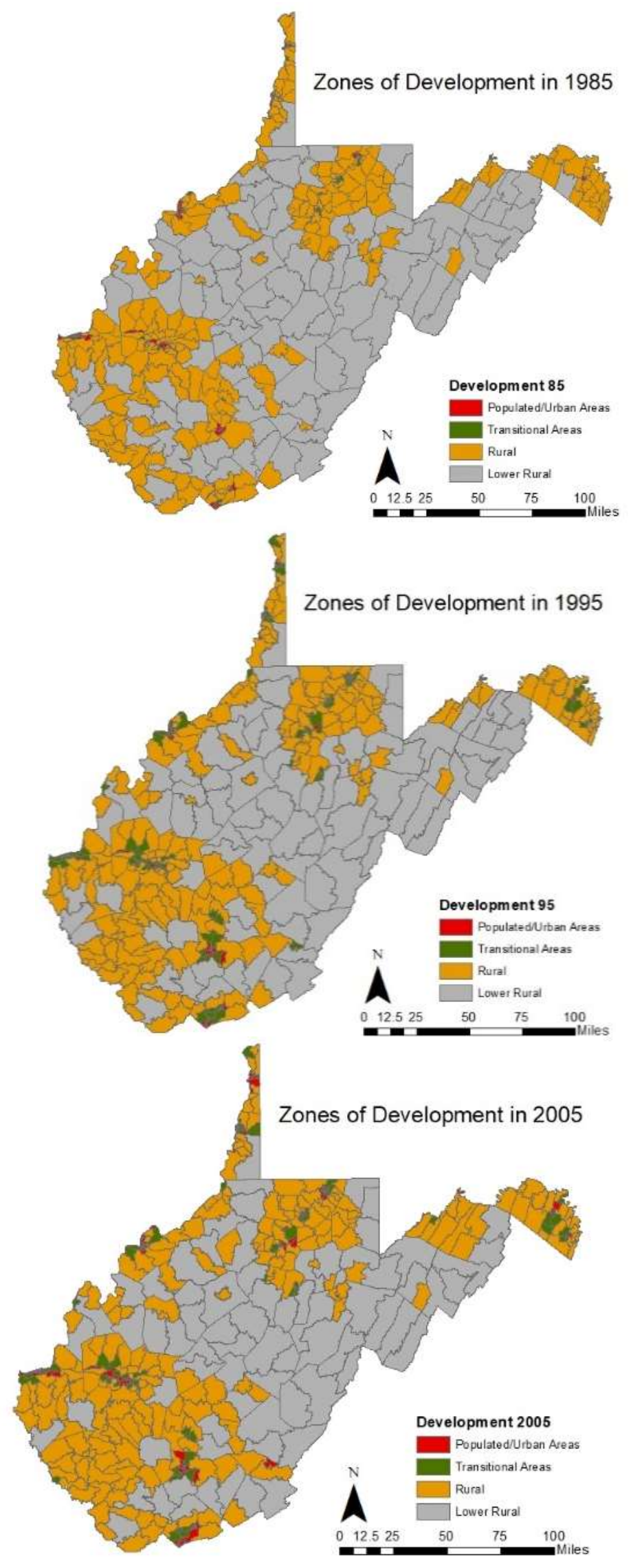

Fig.3-6: Zones of Development in WV 


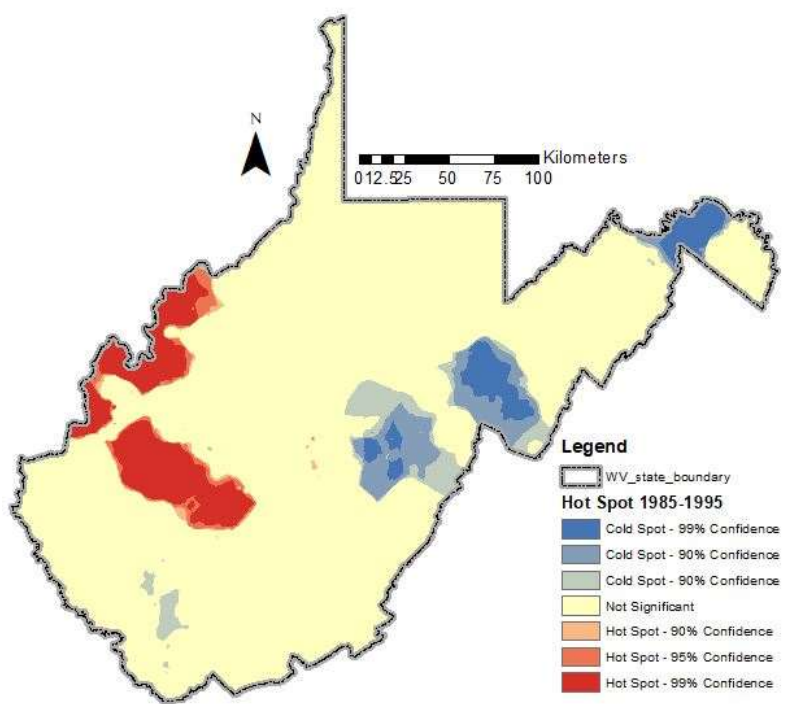

Hot Spot Analysis of Land Development in 1995-2005

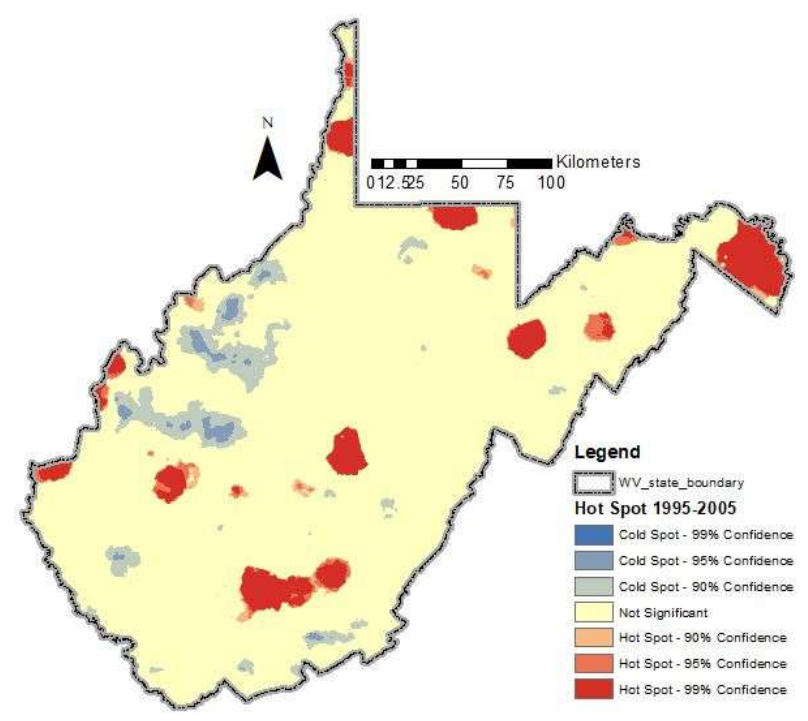

Hot Spot Analysis of Land Development in 2005-2015

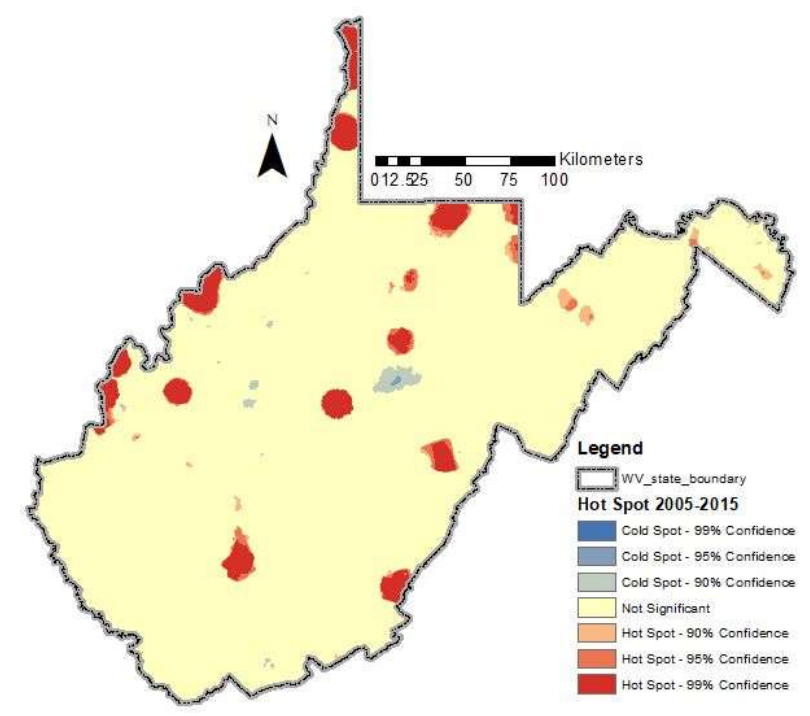

Fig. 3-7: Hot Spot Analysis of Land Development Per Decade 


\section{Modeling}

Regression coefficient analysis using standardized predictors was used to describe the importance of the variables of the land change. We utilized multiple methods for contemplating the impact of different variables from different perspectives. Pixel-wise data analysis on the fully rasterized dataset was applied to make statewide analysis. As a precondition for the regression model, we did multicollinearity diagnostics analysis of the variables. In the presence of multicollinearity, the OLS regression will be unstable (Myers \& Myers, 1990). Our investigation on the multicollinearity of variables indicates that in global scale there is a linear relationship between the variables-not necessarily between all the variables; this multicollinearity is observed in all the three time-steps of the analysis. We used Variance Decomposition Proportions (VDP) to detect the collinearity between the variables. The considered values of tolerance for condition index and VDP are10 and 0.5, respectively; figure 3-8, 3-9 and 3-10 show presence of multicollinearity in all three time steps. Indeed, the decompositions which are above the threshold and have the condition index of more than 10 represent the multicollinearity in the variables. The multicollinearity of the variables causes model overfitting, therefore, instead of OLS we utilized ridge regression to make a global regression model for the entire state of WV.

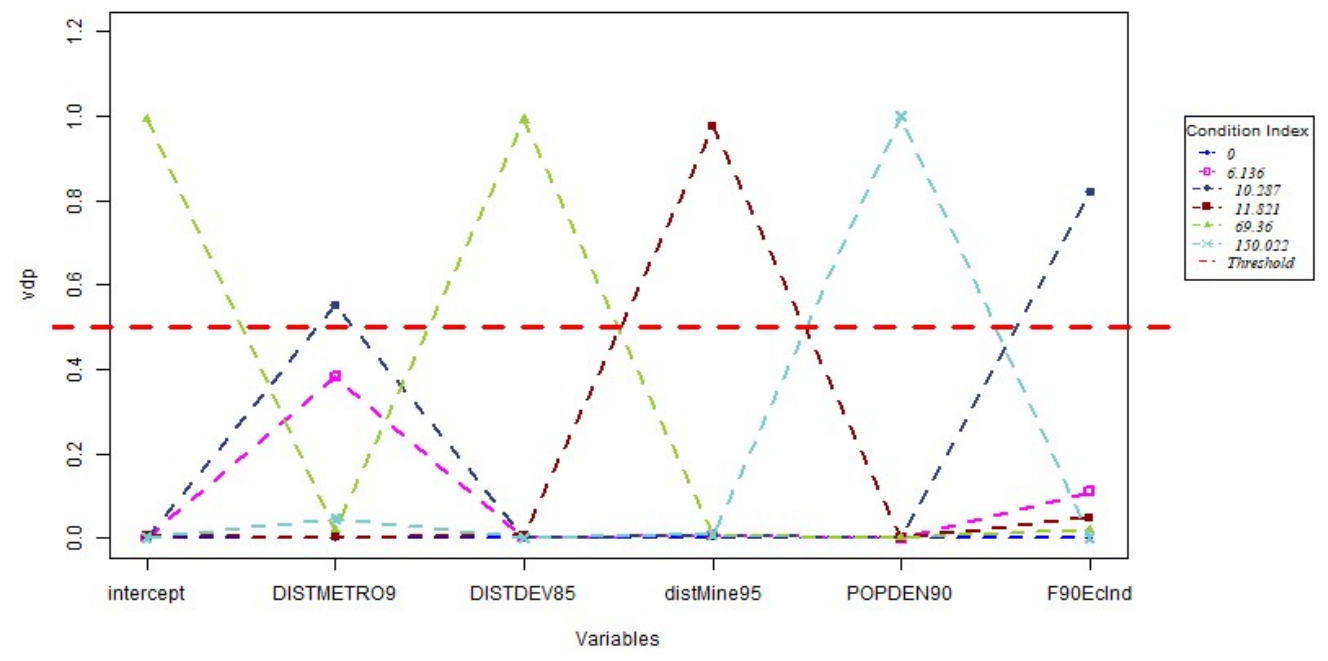

Fig.3-8: Multicollinearity Diagnostics Analysis of the Variables in Regression model of 1985-1995 


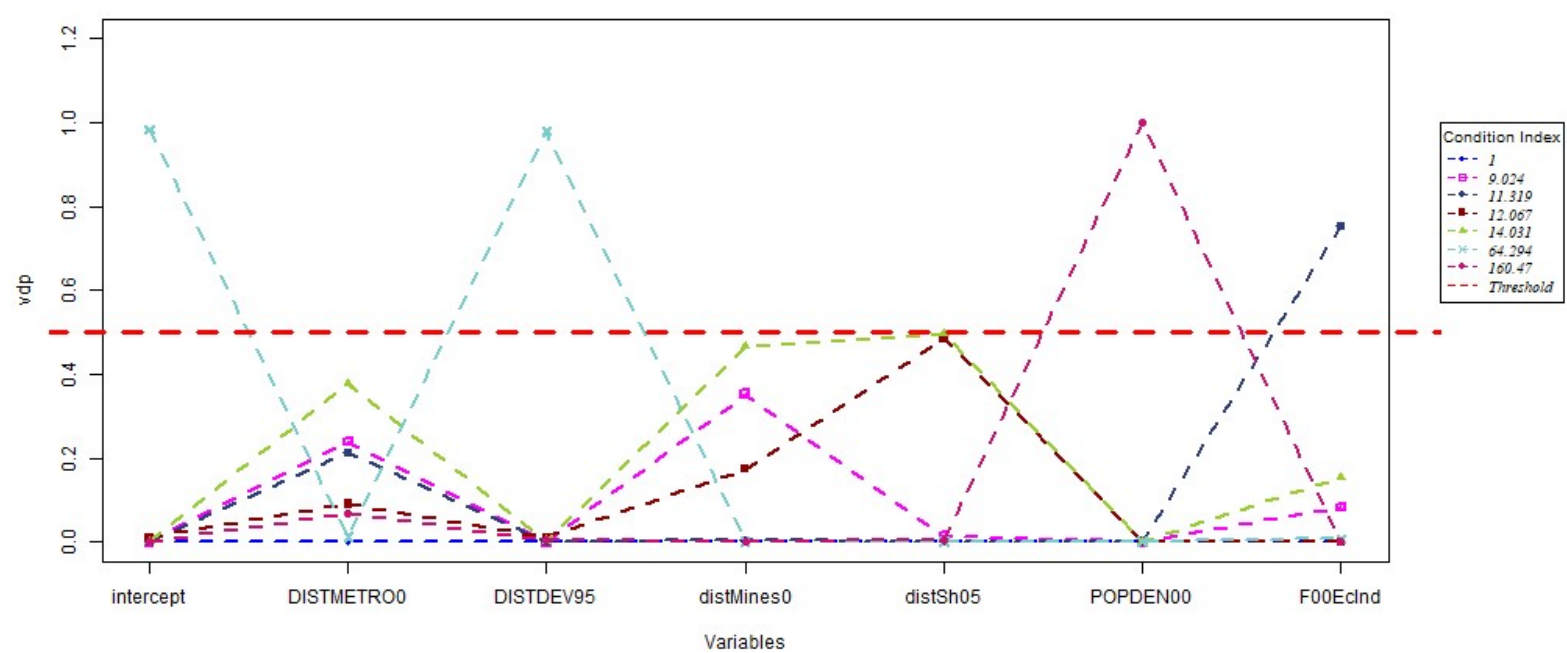

Fig. 3-9: Multicollinearity Diagnostics Analysis of the Variables in Regression model of 1995-2005

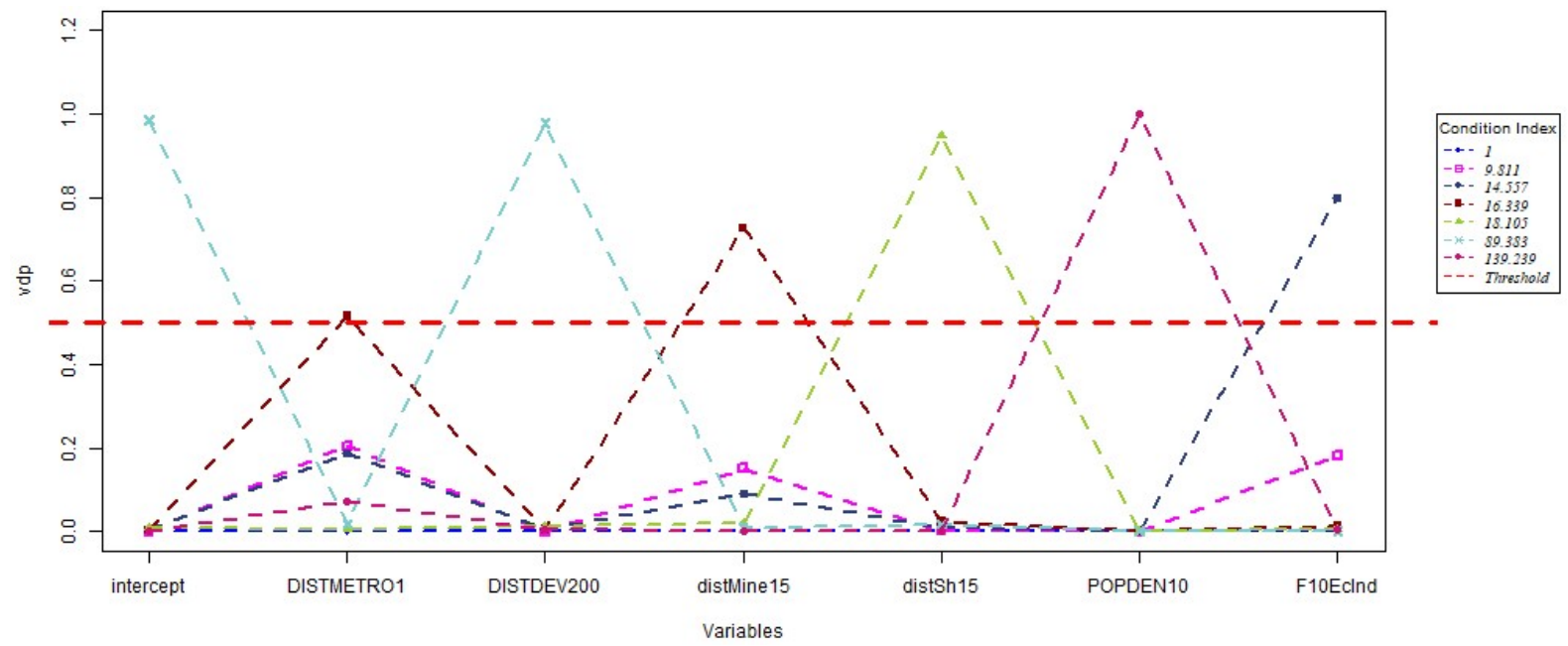

Fig.3-10: Multicollinearity Diagnostics Analysis of the Variables in Regression model of 2005-2015

Ridge regression uses regularization to avoid overfitting problem of OLS. Therefore, the large variance caused by the multicollinearity will be reduced through a slight bias in the estimates made by the model. The shrinking parameter $\lambda$ introduced in equation (3-1) solves the multicollinearity problem.

$$
\arg \min || y-X \beta\left\|_{2}^{2}+\lambda\right\| \beta \|_{2}^{2} \quad \text { eq (3-1) }
$$

where, $\beta \in \mathrm{R}^{\mathrm{p}}$ and the loss function and penalty are consecutively:

$$
\|y-X \beta\|_{2}^{2} \quad \text { eq (3-2) }
$$


and

$$
\|\beta\|_{2}^{2} \quad \text { eq (3-3) }
$$

In this study, we applied ridge regression to analyze the variables in both global scale and zones of development. OLS-based GWR models with presence multicollinearity among the variables have the same shortcoming of the OLS models ${ }^{1}$. Hence, we made an investigation into the multicollinearity of the variables in OLS-based GWR model. This analysis is done through the variance decomposition proportions test of local multicollinearity (Wheeler, 2007); GWR model for all the three time-steps multicollinearity represents multicllinearity in the majority of the regression models. With presence of multicollinearity in GWR models, we deployed Geographically Weighted Regression (GWRR) model to perform local analysis of the driving variables of land development (Wheeler, 2007).

\section{Results and Discussion}

Analysis of the variables according to the ridge regression model of land development at each time-step indicates the $\mathrm{R}^{2}$ value of $0.61,0.70$ and 0.69 for $1985-1995,1995-2005,2005-2015$ respectively. To do this analysis we computed the value of $\lambda$ using 10 -fold cross validation method. We also standardized the explanatory values before conducting this analysis so we could make a comparison between the variables and examine their importance. The model results indicate the coefficient of each variable in a regression model for the whole state of WV (see Table 3-4).

${ }^{1}$ GWR is basically built based on OLS 
1985- 1995

\begin{tabular}{|c|c|c|c|c|}
\hline & \multirow{2}{*}{\multicolumn{3}{|c|}{ Std. }} & \multirow{2}{*}{ 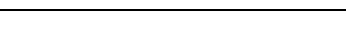 } \\
\hline & & & & \\
\hline & \multirow{2}{*}{$\begin{array}{l}\text { Scaled } \\
\text { Estimate }\end{array}$} & \multirow{2}{*}{$\begin{array}{l}\text { Error } \\
\text { (scaled) }\end{array}$} & \multirow{2}{*}{$\begin{array}{l}\mathrm{t} \text { value } \\
\text { (scaled) }\end{array}$} & \multirow[b]{2}{*}{$\operatorname{Pr}(>|t|)$} \\
\hline & & & & \\
\hline Distance to Metro & -1.3638 & 0.01706 & 79.95 & $<2 \mathrm{e}-16 * * *$ \\
\hline Inverse Distance to Development & 0.13904 & 0.0147 & 9.462 & $<2 \mathrm{e}-16 * * *$ \\
\hline Inverse Distance to Mining Sites & 0.55096 & 0.01463 & 37.647 & $<2 \mathrm{e}-16 * * *$ \\
\hline Inverse Distance to Oil and Gas Wells & - & - & - & - \\
\hline Population Density & 0.16899 & 0.01475 & 11.455 & $<2 \mathrm{e}-16 * * *$ \\
\hline \multirow[t]{3}{*}{ Economic Index } & -0.69773 & 0.01687 & 41.358 & $<2 \mathrm{e}-16 * * *$ \\
\hline & \multicolumn{4}{|c|}{ Ridge parameter: 8.69} \\
\hline & \multicolumn{4}{|c|}{ Degrees of freedom: model 4.997 , variance 4.994 , residual 5} \\
\hline
\end{tabular}

\begin{tabular}{|c|c|c|c|c|}
\hline & \multicolumn{4}{|c|}{ 1995-2005 } \\
\hline & \multicolumn{3}{|c|}{ Std. } & \multirow[b]{3}{*}{$\operatorname{Pr}(>|t|)$} \\
\hline & Scaled & Error & $\mathrm{t}$ value & \\
\hline & Estimate & (scaled) & (scaled) & \\
\hline Distance to Metro & -0.33322 & 0.008175 & 40.76 & $<2 \mathrm{e}-16 * * *$ \\
\hline Inverse Distance to Development & 0.140729 & 0.007529 & 18.69 & $<2 \mathrm{e}-16 * * *$ \\
\hline Inverse Distance to Mining Sites & 0.341333 & 0.008027 & 42.52 & $<2 \mathrm{e}-16^{* * *}$ \\
\hline Inverse Distance to Oil and Gas Wells & 0.42451 & 0.008035 & 52.83 & $<2 \mathrm{e}-16 * * *$ \\
\hline Population Density & 0.447566 & 0.00777 & 57.6 & $<2 \mathrm{e}-16^{* * *}$ \\
\hline \multirow[t]{3}{*}{ Economic Index } & -0.1587 & 0.007668 & 20.7 & $<2 \mathrm{e}-16^{* * *}$ \\
\hline & \multicolumn{4}{|c|}{ Ridge parameter: 38.5} \\
\hline & \multicolumn{4}{|c|}{ Degrees of freedom: model 5.995 , variance 5.991 , residual 6} \\
\hline
\end{tabular}

2005- 2015

Std.

Scaled Error $\mathrm{t}$ value

Estimate (scaled) (scaled) $\operatorname{Pr}(>|\mathrm{t}|)$

\begin{tabular}{lcccc}
\hline Distance to Metro & -0.4493 & 0.007628 & 58.9 & $<2 \mathrm{e}-16 * * *$ \\
\hline Inverse Distance to Development & 0.04935 & 0.006631 & 7.442 & $9.95 \mathrm{e}-14 * * *$ \\
\hline
\end{tabular}




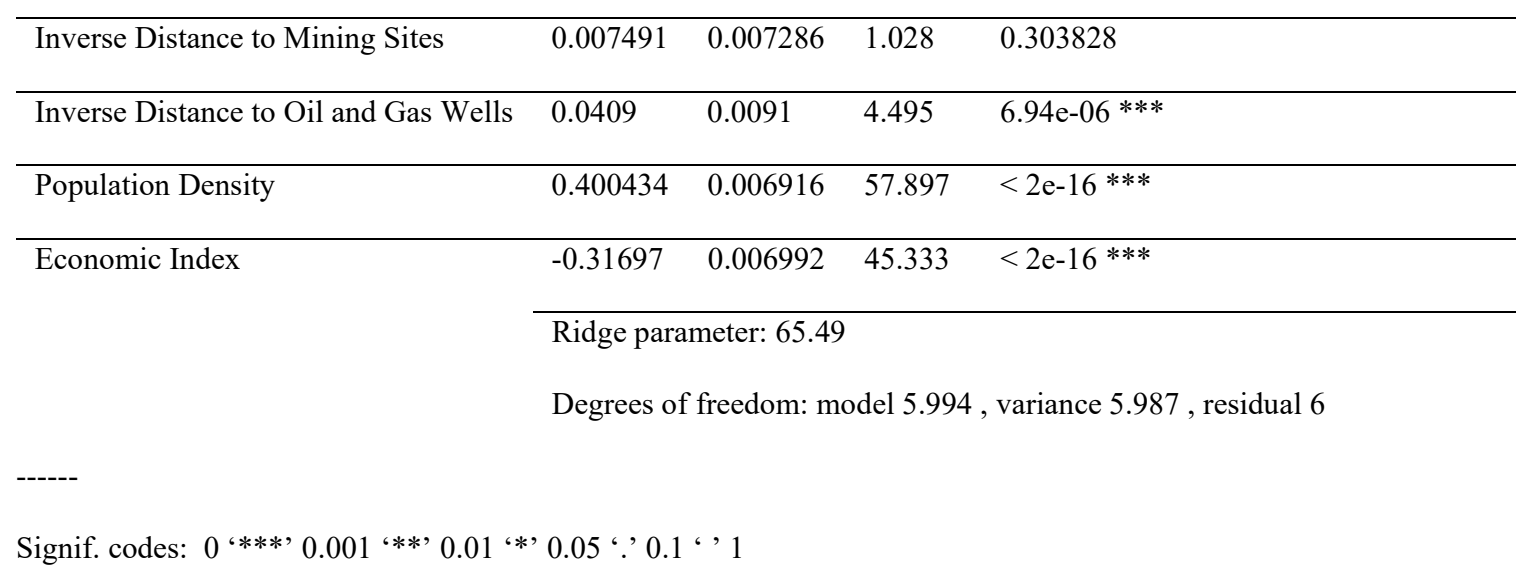

In all the time periods, all the variables significantly impact the creation of clusters of developed lands. In time period 2005-2015 distance to mines does not show a significant impact of the land development process in the state of WV. According to a study by the Bureau of Business and Economics in the state of WV, there has been a decrease in the jobs and productions in the mining sector(Bowen \& Christiadi, 2017). This also impacts the dependent industries, on the other hand the production of natural gas in WV started to increase from the early 2000. This industry acted as the substitute energy related industry in the state of WV (Bowen \& Christiadi, 2017). We believe the main reason why distance to mining sites is not a significant role in inducing the emergence of rural and urban land development is that in the past few decades this industry is not a source of economic growth in the region. Mining is fading under the shadow of relatively new energy sources of oil and gas. As table 4 implies, distance to mining sites have been a very important factor in land development in 1985-1995, this factor was an important variable in the patterns of land development in WV. It is compelling to see that only in the time period of 1995-2005, population density is the most significant variable in the land development of WV, while in 19851995 this factor is not even among the three top variables of our study. Our explanation for this result is that in this time period major land developments were in rural areas. We performed a more 
detailed analysis on these factors in different zones to examine the impact of each factor on land development.

Our analysis implies that in the time step of 1985 to 1995 land development in urban and rural areas have been greatly influenced by the distance to metropolitan areas (Figure 3-11). In 19851995 the core of some new populated areas has been formed in closer distance to the metropolitan areas located in the neighboring states on WV. Distance to Mining sites is still one of the major influencing factors in determining land development in WV.

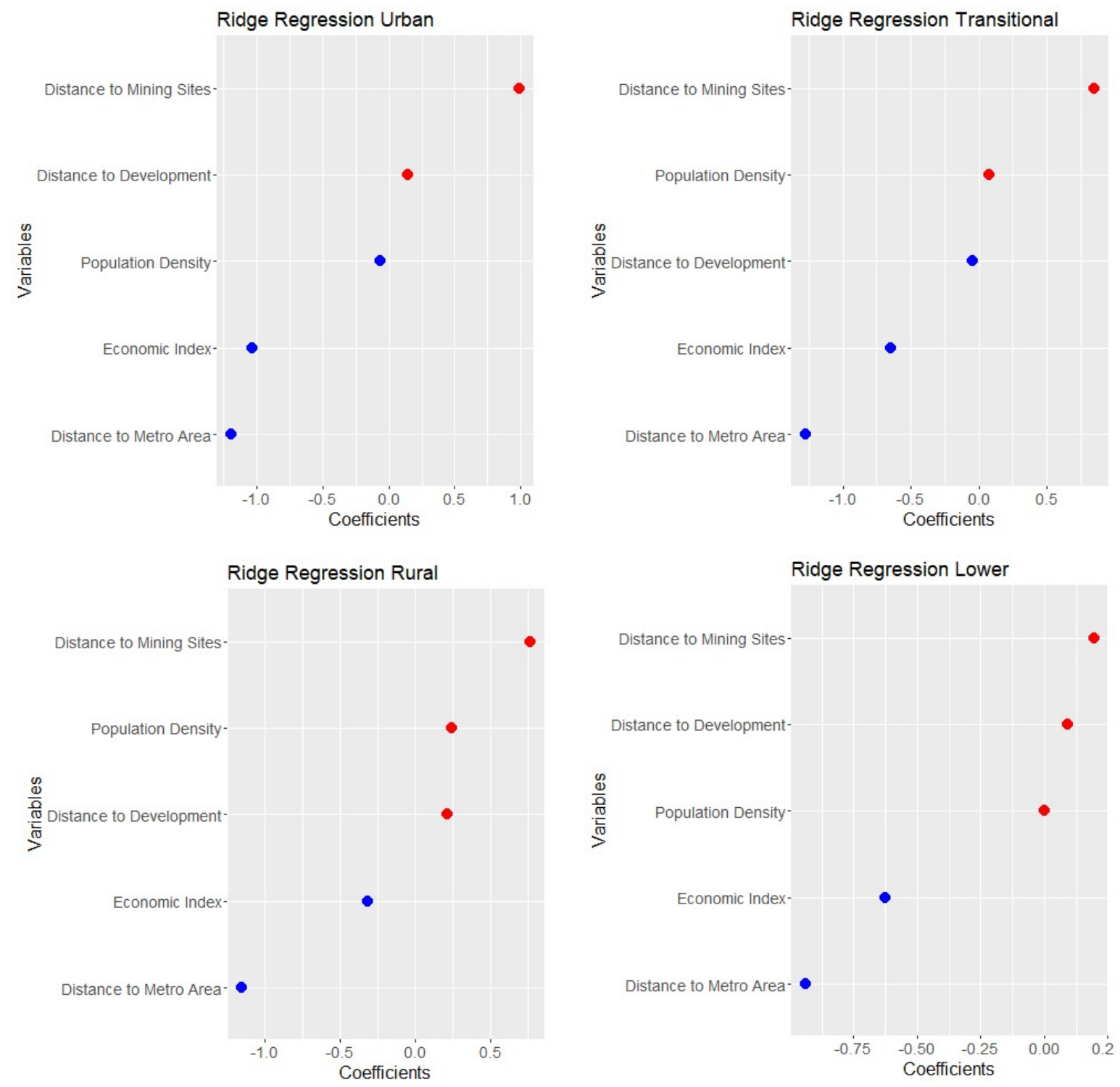

Fig.3-11: Coefficients of the Regression Analysis in Different Zones of Development (1985-1995) 
Coefficients of the variables of the land development in 1995-2005 indicate that distance to mining sites is still an important factor in land development (Figure 3-12). Land development in lower rural and urban area is affected by distance to metropolitan areas, such that there is a tendency for land development in proximity of metropolitan areas. The few oil and gas wells of WV in the time period of 1995 and 2005 are located in the north west of the state and the majority of the developments form in the northwest and southwest of WV. This helps to explain why distance to

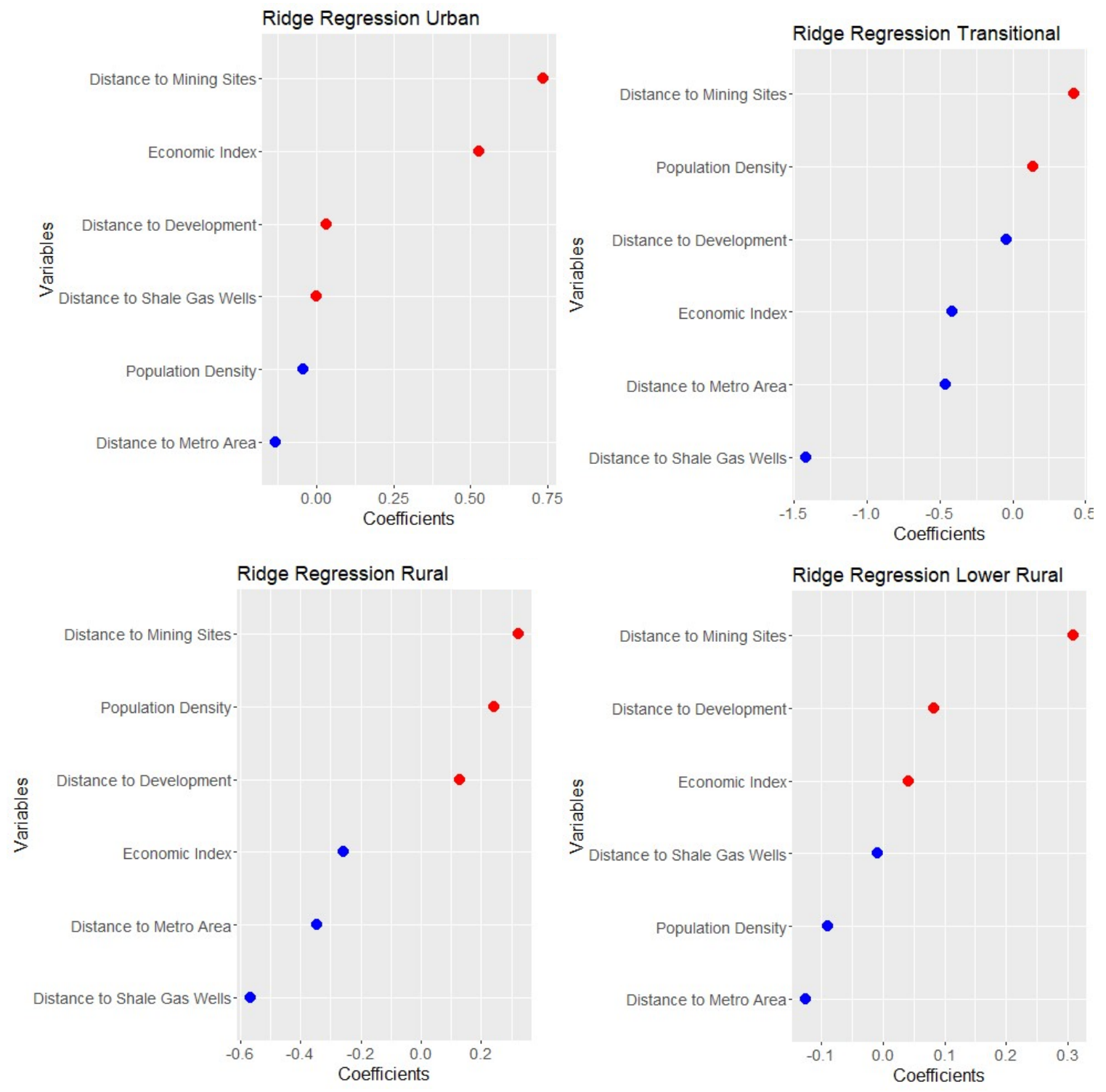

Fig. 3-12: Coefficients of the Regression Analysis in Different Zones of Development (1995-2005) 
oil and gas wells acts as a negative coefficient. Also, this variable does not have a significant impact on land development in urban and lower rural areas.

In the time period of 2005 to 2015 there is shift in the role of energy related variables in the land development transitional areas of WV (Figure 3-13); where oil and gas play a more important role in driving the land development compared to mining sites. It is compelling to see that land development in urban and transitional areas is pretty much influenced by the economic index, the lower economics index-which means lower unemployment and poverty rate and higher GDP-

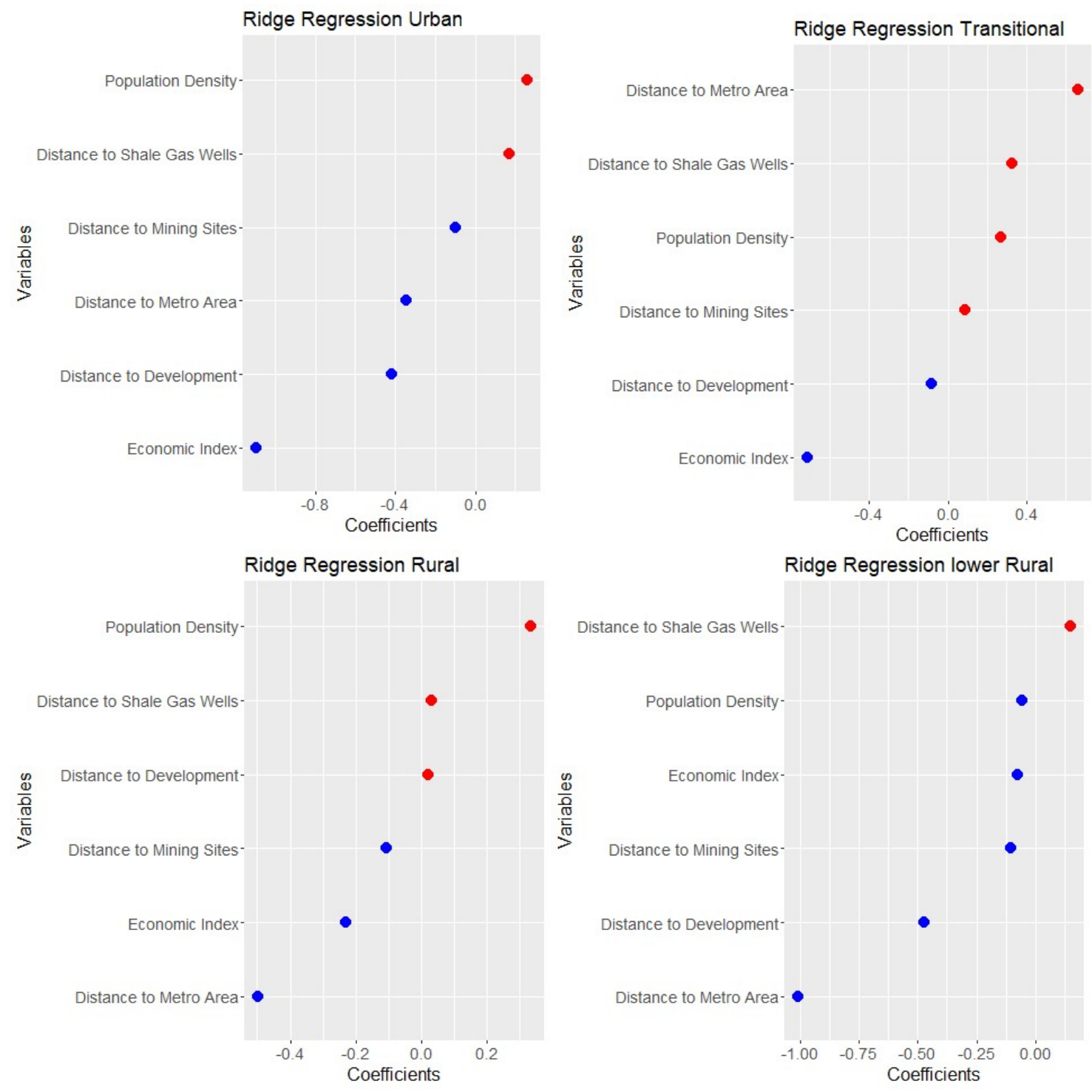

Fig.3- 13: Coefficients of the Regression Analysis in Different Zones of Development (2005-2015) 
stimulates more land development to these zones. Transitional areas, the areas that are in vicinity of urban areas, paradoxically have a tendency to grow in opposite direction from the populated areas. Where land developers prone to use the services of urban areas, still keep the distance and benefit from the landscape of rural areas.

It is conceivable that land development in various zones is stimulated by different sets of variables. In some zones, new developments are drawn by older ones, whereas in some other zones, regardless of the old pattern of land development, it is the economy of the zone that drives landscape changes. Still, we see that in the spectrum of rural and urban areas, both ends of the spectrum have this tendency to benefit from each other. It is worth to investigate where in study area any of the variables have higher impact and where some variables are not important in land development. The results of GWRR provide the ability to answer this question.

A more local analysis on the land developments variables through the GWRR method using the optimum bandwidth value. The kernel that is used for the distance is exponential and the model performance results in the following $\mathrm{R}^{2}$ values.

Table 3-5: Model Parameters and Results of GWRR

\begin{tabular}{cll}
\hline \multicolumn{1}{c}{ Model } & \multicolumn{1}{c}{ Bandwidth } & \multicolumn{1}{c}{$\mathbf{R}^{\mathbf{2}}$} \\
\hline GWRR 1985-1995 & $5801 \mathrm{~m}$ & 0.982 \\
\hline GWRR 1995-2005 & $4337 \mathrm{~m}$ & 0.956 \\
\hline GWRR 2005-1015 & $4319 \mathrm{~m}$ & 0.961 \\
\hline
\end{tabular}

The geographic coefficients of each variable of the study area in 1985- 1995 indicate that land development in the western area of WV was influenced by major factors of this study. This area is where two census metropolitan areas in 1990 were identified. It is compelling to see that changes in the distance to metropolitan area, mining sites, development and economic index in the area between these two regions and eastern areas if Charleston also induces land development. Clusters 
of development in the eastern panhandle are also influenced by distance to mining areas, developments and economic index; but distance to metropolitan areas is not as significant. Changes in the population density has almost the same impact on the clusters of development in all the regions except for the east of the state; this region is either in the vicinity of the Monongahela National Forest or a part of the state parkland. These lands are regulated with restrictions on development. It is reasonable that any change in the population of this region includes large changes in the clusters of land development (Figure 3-14). 

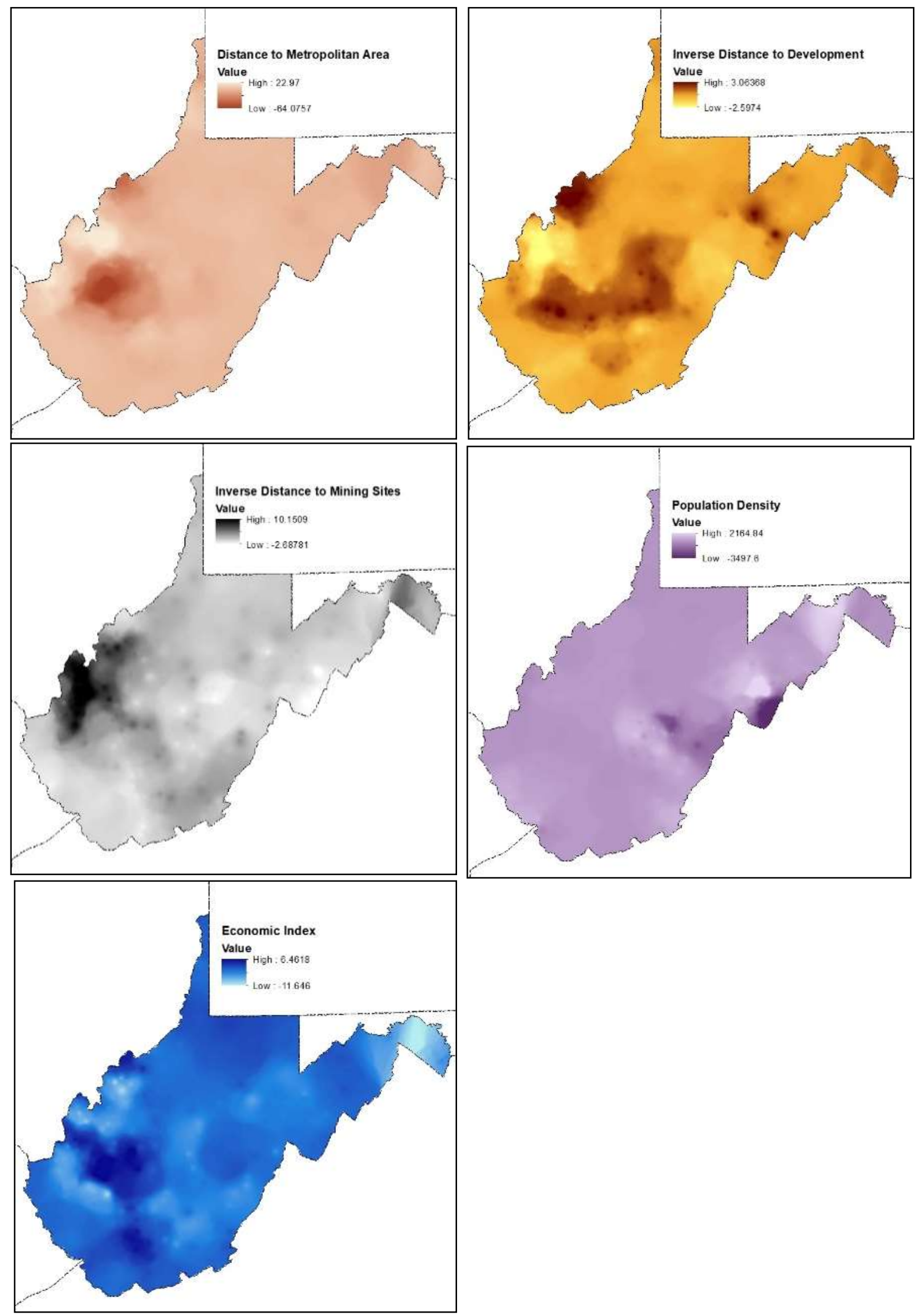

Fig. 3-14: Geographic Coefficients of 1985-1995 
In the time-step of 1995-2005 the importance of variables in both northern and eastern panhandles was considerable. Changes in the economic index and distance to mining areas exhibit notable influence on the creation of developed land clusters. Distance to both oil and gas wells and mining sites has significant impact on the land development in the eastern panhandle. The metropolitan areas of Charleston and Parkersburg do show substantial linkages to changes in distance to oil and gas wells, population change and distance to development, but the change in the distance to metropolitan areas and mining sites still appears to be influential on the clusters of land development. By making a comparison between the impact of various factors on creation of the clusters and new micro and metropolitan areas that emerged in 2000's, we can see how well these affected regions and the clusters overlap. However, oil and gas wells do not show their influence on the formation of clusters of land development in these maps and distance to mining sites' impact has spread over the state in 1995-2005 (Figure 3-15).

One of the major changes in the local coefficients in 2005-2015 is the growth of the regions where change in the distance to oil and gas wells result in creation of clusters of development. Population density has similar geographic coefficients to the previous decade, and its change in the very low populated areas has high coefficient value. Change in all the variables except the population density has considerable impact on the clusters on development in northern and eastern panhandle; however, the area of the eastern panhandle which is influenced by distance to metropolitan areas has a shift east, where there is smaller proximity to Washington DC area. 

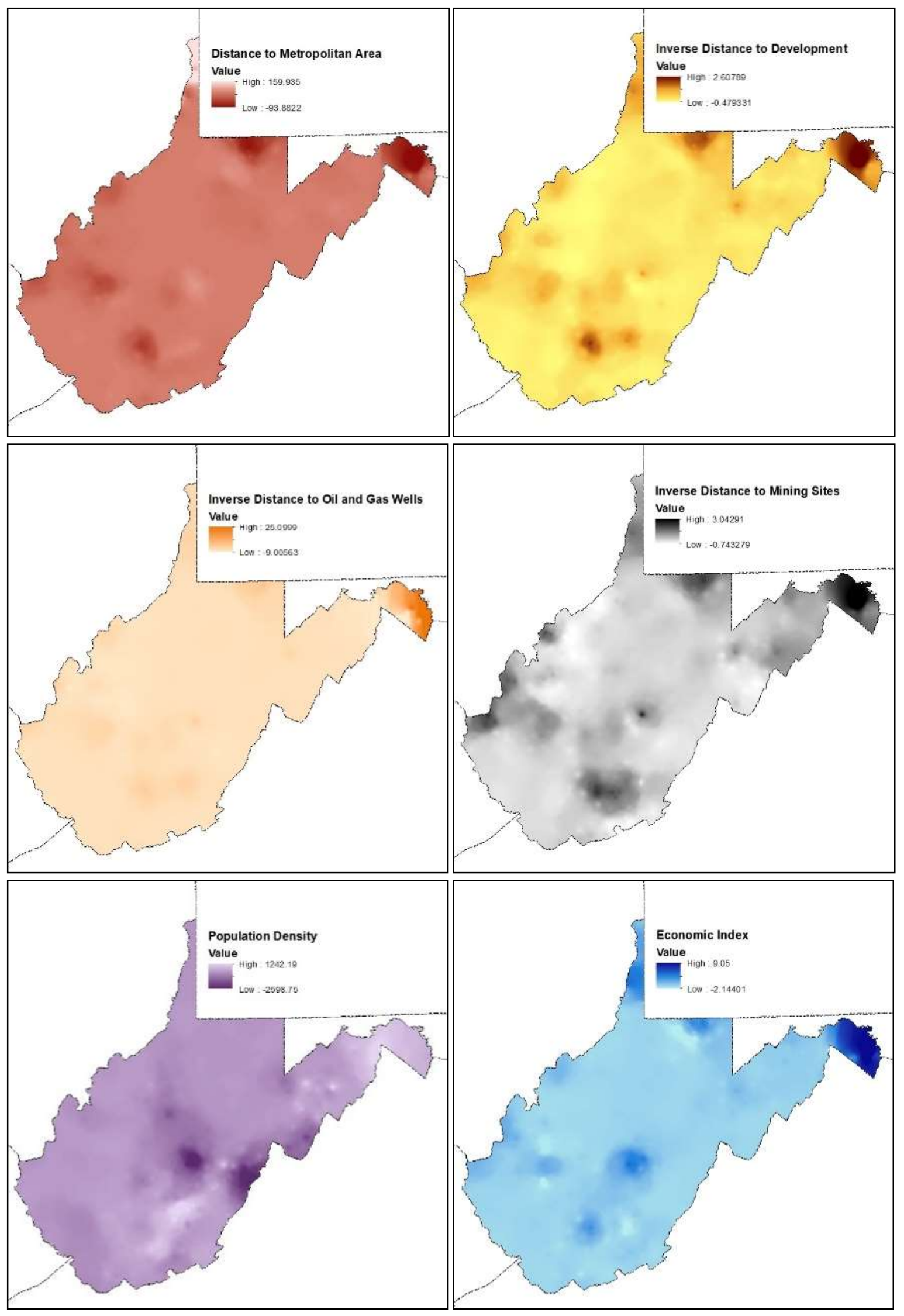

Fig.3-15: Geographic Coefficient of 1995-2005 

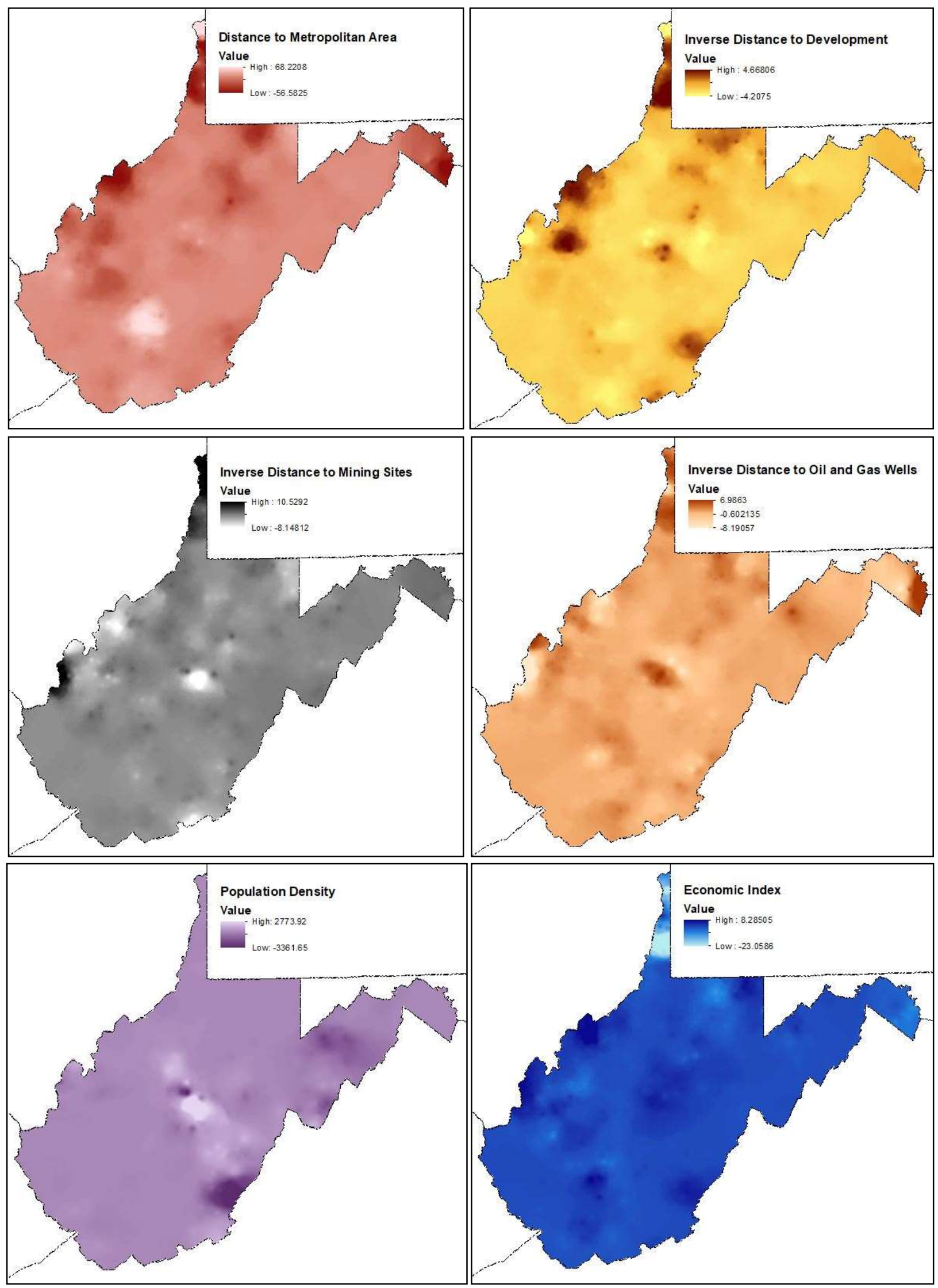

Fig.3-16: Geographic Coefficient of 2005- 2015 
Land development is a complex process, understanding the drivers can assist policy makers with the potentials. This study drew a picture of the unstable and highly dynamic trends of land development in WV. The results of this research imply that land development in the majority of regions in WV does not demonstrate a consistent pattern; in relatively small-time spans there are recognizable changes in the patterns of development expansion. Apparently, the changing patterns of land development does not support stable growth of the communities. Our results imply that the changing configurations of land development in WV root in the rapid transitions in the energy job market, attraction of external developments and population movements. According to the results of this research the role of driving variables of the land development in the state of WV has shifted over time and their significance is not consistent in various locations of the state.

Generally, in an energy rich state such as WV, land development is paired with this state's attraction for energy exploitation sectors. Whenever a new source of energy appears in the region, new energy industries find their way into this region and the region's landscape undergo considerable alterations. However, as some sources start to fail, the patterns of the land development transform consequently; in this case, the older developed areas do not provide enough incentives to keep the trends of land development and it withstand shifts. This ephemeral changing direction of land development hinders development of small communities and provokes creation of fragmented localities.

Major land transformations in WV has been observed in regions with lower population and development density. The concept of rural development in WV fundamentally differs from rural land development in European countries, developing countries or major regions of the US. Unlike the general idea of dependency of rural developments on agricultural industries, rural land development in WV does not correlate with the growth of agricultural industries. Actually, despite 
the fact that more than $80 \%$ of land development in this state occurs in rural areas, agriculture is not even among the major industries of WV (Appalachian Regional Commission, 2017). Rural land development in WV moves toward facilitating specific energy industries and their dependent services. The pattern of land development in these regions is scattered, with low and very low clusters. This form of development in a region with a majority of which is covered by forested lands (according to NLCD 2016 more than 84\% of WV is forested) is accompanied by high burdens on the ecosystem services. On the other hand, these communities require access to major health, commercial, social, educational and cultural services which either put monetary expenses on these communities or leads to low quality of life for them.

The results of this study imply that in urban and transitional areas of WV, the economic index of the region has higher impact on the land development compared to rural and lower rural regions. In rural areas staying in touch with other forms of development is a key factor in inducing land development. Energy related factors and economic status represent unstable roles in driving the land development. Local coefficient analysis of variables implies that in $\mathrm{WV}$, influential factors in land development process are not consistency over time. It also implies that the significance and the location of the spatial features- considered as driving variables- is highly dynamic. We found it a striking reason for explaining the scattered pattern of land development in WV. In West Virginia, energy, economy and access to urban areas play a crucial role in land transformation. According to the United States Department of Agriculture, WV, a rich state of streams, lakes and vegetation is a land of areas with major food deserts (https://www.nrcs.usda.gov/wps/portal/nrcs/detail/wv). The results of this research can be useful in the identification of low income, lowly populated food desserts in WV. The information acquired from each of these analyses can be utilized by local and regional planning councils and 
commissions such as Regional Planning and Development Council and Appalachian Regional Commission in prioritizing and envisioning the future development in WV. We believe this analysis opens a new perspective in making further investigation and enhancements towards the sustainability of the major trends of land development. We suggest that policy makers and local community planners consider the crucial connection of the trends of land development with the resources required for enhancing the quality of life in these communities. In addition, since land and natural resources of energy are key role players in the economy of WV, understanding how land development in WV impacts various aspects of Ecosystem Services is critical. Mapping, monitoring and publicly discussing the land transformation's impacts on regulating, provisioning, cultural and supporting ecosystem services facilitates public awareness of the environmental consequences of each act of land consumption in WV. The consequences of various scenarios of land development on the quality of services that public sector can provide to the communities is another issue that should be reviewed with the communities. Moreover, enriching and educating communities with sustainable economic development, instead of relying of transitory economic industries is another key factor which should be considered in planning the future in for WV. Community engagement steps are encouraged for the sustainability of development in this region. 


\section{CHAPTER IV}

\section{Paper III: Mapping Ecosystem Services through Land Use/Cover Change; a Non- Monetary Investigation of Landscape Change Trade-offs}

\section{Introduction}

The concept of ecosystem services (ES) has become a mainstream idea to indicate the value assigned to a variety of ecosystem functions. Ecosystem service is a term given to the products humans receive from the natural and altered ecosystems. These services are delivered to people so they can maintain personal, cultural and economic well-being. Major research on the trade-offs of supply and demand in ecosystem services argue how the status of services provided by an ecosystem builds the interconnected system of supply-demand trade-offs (Deng, Li, \& Gibson, 2016; Maes et al., 2015; Paetzold, Warren, \& Maltby, 2010). According to Burkhard et al. (2012) supply and demand in ecosystem services are defined as all the goods and services which are consumed and all the capacities offered as a bundle of goods and services by the ecosystem. The demand for ecosystem services for a particular area and over time has an abundance of impacts on different aspects of human life. These aspects are identified as demographic dynamics, the region's economy and the economy of individuals, cultural and social capitals and other well-being indicators (Day, Moerschbaecher, Pimentel, Hall, \& Yáñez-Arancibia, 2014). Measuring and representing ecosystem services is one of the major challenges in environmental science. Various monetary approaches such as cost-benefit analysis have been utilized to formulate the eco-services (Davidson, 2013); however, a shortcoming of that approach is lack of pricing methods available so the real monetary values of the services are not represented. In addition, non-monetary methods and interpretations of ecosystem services using mapping and visualization are widely used as a 
method for assessing the sustainability of human-environment interactions (Bagstad et al., 2014; Sexton et al., 2013).

Landscape changes caused by human activities are followed by changes in the ecosystem in different spatio-temporal circumstances. Land cover and land use change helps understanding and formulating the magnitude and direction of anthropogenic changes (Goldenberg et al., 2017). Linking these changes to ecosystem services through visual inferences facilitates understanding of the configuration and distribution of the complex trade-offs of ecosystem supplies and demands. Depicting these trade-offs utilizes decision makers with stronger rationales for making decisions toward a sustainable landscape with multi-functional capacities(R. S. de Groot, Alkemade, Braat, Hein, \& Willemen, 2010).

Four major types of ecosystem services include: provisioning, regulating, supporting and cultural. Burkhard et al. (2012) note that the supply of ecosystem services in a region is determined by the regional ecological integrity. They note that landscape change induced by human decisions and activities impact ecological integrity. In this research we adopt the same idea, we also investigate the changes in the landscape according to the contextual information in Monongalia County, West Virginia (WV), USA. This study is designed to bridge the changes in the ecosystem services of Monongalia County with the landscape changes in the land cover. A major contribution of this study is to investigate the anthropogenic changes of the landscape using non-monetary analysis of the services supplied by the local resources, and the benefits that the local communities draw from these services. This contribution advances the knowledge in the mapping of ecosystem services in a perfect combination of rural and urban developed land. We believe that this research is a great supplement to research done in the area of mapping and monitoring the eco-system services. It can benefit the local communities by delineating and regulating toward human well-being. In this 
context, the significant contributions of this paper are mapping and monitoring the different tradeoffs of ecosystem services with Anderson Level II classes from the National Land Cover Dataset classification. The idea of how land change and land development impacts overall ES profile of the study area is elaborated in this study.

\section{Study Area}

Monongalia County, with an area of 1470.26 sq-km is located in north central WV of the United States (Fig. 4-1). This county is part of the Appalachia region; which is a cultural region stretching on the spine of Appalachian Mountains. This region has abundant of natural, energy and cultural resources. Despite the abundance of natural resources, the economy of the majority of its 420 counties is below the national average. The state of West Virginia is rich with energy resources and is the major water source of large rivers such as Potomac and Ohio rivers. Counties of WV bear major changes in their landscape because of energy extraction.

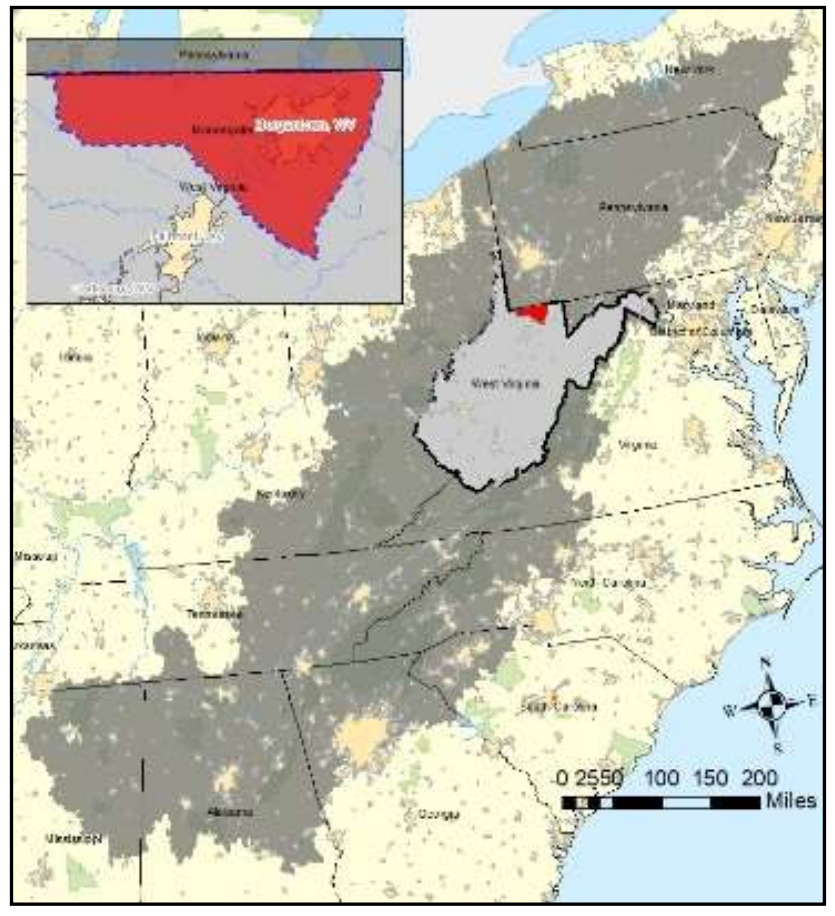

Fig.4-1: Monongalia County 
WV is the fifth state of the US in total energy production with share of $4.5 \%$ of total national energy production. Since major land changes in this state are driven by the energy industries, we examined the energy profile of WV. This state has been one of the major producers of coal, in addition, in the past decade in north central WV shale gas extraction emerged as a new type of energy source and production has increased extensively. According to the Energy Information Administration (EIA, 2016), production of natural gas increased substantially in WV since 2010, while production of coal decreased, and the state did not have significant investments in the production of renewable energy. Energy production and consumption in WV indicate that this state's energy consumption is substantially below its production. Transportation and industrial sectors are the major consumer of energy.

\section{Oil and Gas Production in WV}

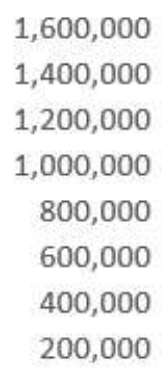

2001200220032004200520062007200820092010201120122013201420152016

Natural Gas ( Million Cubic Feet) _ Fuel Ethanol I (Thousand Barrels)

Fig. 4-2: Oil and Gas Production in WV

\section{Coal Production(Thousand Short Tons) in WV}

$$
\begin{array}{r}
180,000 \\
160,000 \\
140,000 \\
120,000 \\
100,000 \\
80,000 \\
60,000 \\
40,000 \\
20,000
\end{array}
$$

2001200220032004200520062007200820092010201120122013201420152016

Fig. 4-3: Coal Production in WV 


\section{Energy Use in WV by Sector (billion Btu)}

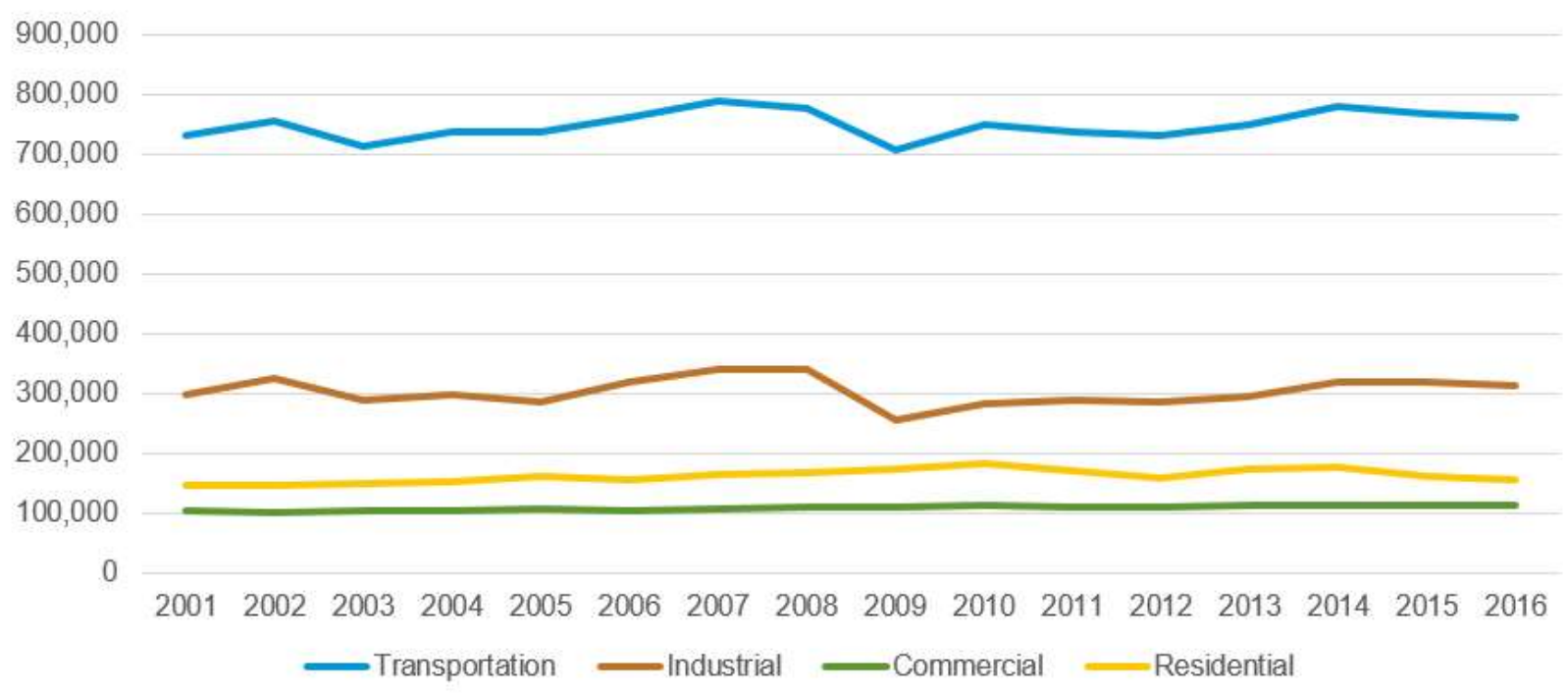

Fig. 4-4: Energy Use by Sector in WV

Majority of landscape changes followed by the shifts in energy production and consumption can be traceable through the land cover and its development patterns (i.e. fragmentation). Monongalia County is considered a growing County in WV, with both coal mining and shale gas extraction industries and resources. Morgantown is the major metropolitan area in the county. In other regions of this county land development is comprised of rural scattered lands. Fast shifts in the landscape and energy profile of the region makes this area ideal for studying the land cover change and land development of Monongalia County in the course of sustainable development and ecosystem services.

\section{Energy and Landscape Change in WV}

Coal mining and oil and gas industries are the major sources of energy in the state of WV. Mining is accompanied by principal landscape changes including mountain top removal and valley fill. In this form of coal extraction, the tops of mountains are removed by explosives and the overburden 
area fills valley shaped landscapes. This technique changes the landscape and hydrological behavior of surface water. Also, the water draining from these fields can contain pollutants which are harmful for aquatic wildlife. We included the impact of these areas in the ecosystem assessment process by making new sub-categories for barren land. These sub-classes include mining sites, valley fills, dumping sites and other barren areas. Besides mining, oil and gas extraction sites are other sources of energy which have expansive influence on the landscape and other natural resources. We particularly considered shale gas fracking sites in this study. These sites are not prolific in Monongalia County, however, serious environmental concerns are raised because of them (Zhang \& Yang, 2015). Other than land cover changes that are due to oil and gas extraction sites, extraction of shale gas can have considerable influence on the quality of water and air (Zhang \& Yang, 2015). It can cause degradation of water quality in the streams and rivers (Zhang \& Yang, 2015). Since WV is a major hydrological resource, the quality of water in the rivers and streams of this state is very crucial.

\section{Methods}

We use the non-monetary evaluation scheme proposed by Burkhard et al. (2012) as an essential approach for quantifying ecosystem services. This method is straightforward and integrates many aspects of ES. The proposed method by Burkhard et al. (2012) is applicable to land cover classes in CORINE ${ }^{1}$ classification. We adjusted this method so it can be compatible with Anderson land cover classification system (Anderson, 1976). Developed lands as a major class of land cover

\footnotetext{
${ }^{1}$ The Corine Land Cover (Coordination of Information on the Environment Land Cover, CLC) is referring to a European program establishing a computerized inventory on land cover of the $27 \mathrm{EC}$ member states and other European countries, at an original scale of 1: 100000 , using 44 classes of the 3-level Corine nomenclature (https://wiki.openstreetmap.org/wiki/Corine_Land_Cover).
} 
encompasses major sectors for eco-services. We do not consider these lands as a major class of cover in the study. However, developed lands as they are defined in Anderson classification in the study area, exhibit a combination of rural and urban development with sparse spatial pattern. Dominance of rural areas, emergence of other forms of development (i.e. energy development) besides the different demand value for ecosystem services in various land use classes urged us to create subclasses from developed land class of land cover. These sub classes include continuous developed lands, discontinuous developed lands, commercial, industrial and shale gas fracking sites.

The steps in this study involve modification of the National Land Cover Dataset 2001 and 2016 by adding sub-classes to the major classes of barren lands and developed lands, and regenerating the ecosystem services supply-demand reference tables accordingly. Thereafter, we conducted an analysis on the ecosystem well-being indicators of the local geography in Monongalia County (Fig. 4-5).

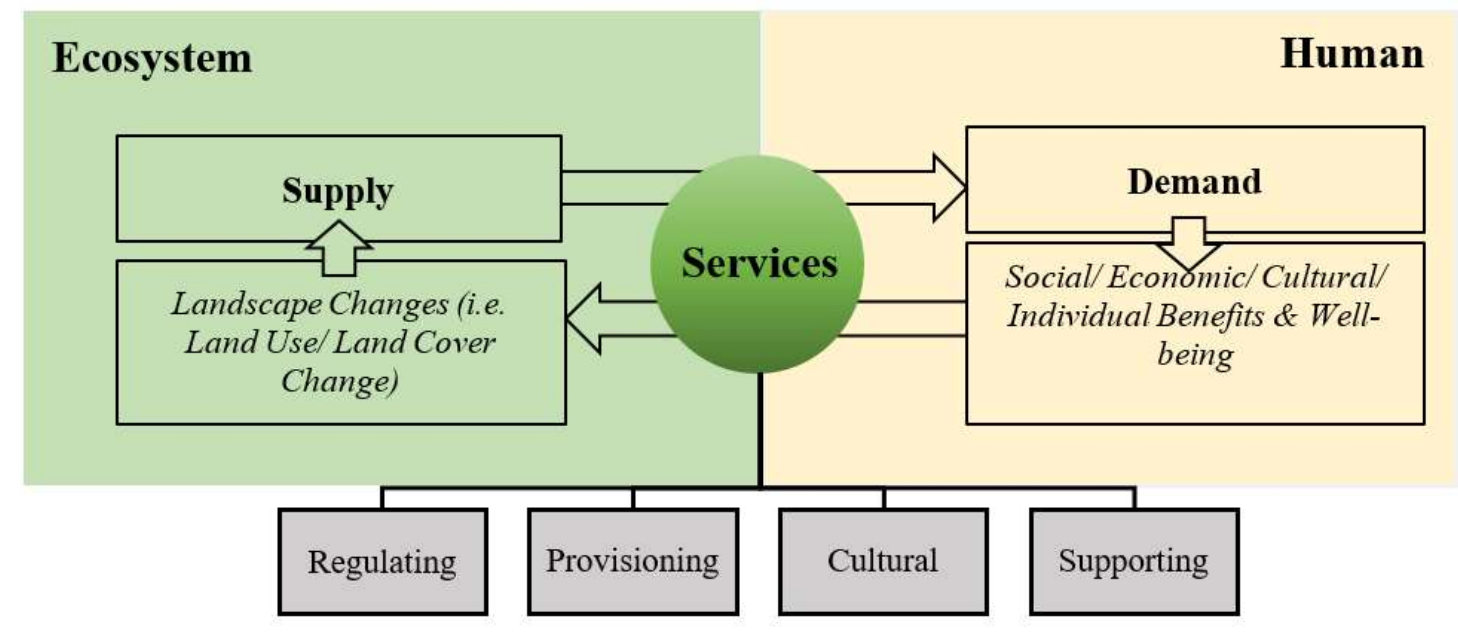

Fig. 4-5: Illustration of ecosystem services trade-offs 
The two land cover maps which are used in this analysis are acquired from post-classification analysis of the NLCD 2001 and 2016. These maps are of higher resolution of 10 meters. To conduct this analysis, we applied extraction techniques from multiple sources of data including: The National Agriculture Imagery Program (NAIP) imagery, assessor's parcel level data, Natural Resource Analysis Center classification of Land Cover (2016), digitized map of permit boundaries by West Virginia Department of Environmental Protection's (WVDEP) Division of Mining and Reclamation (DMR), and oil and gas wells information by WV Department of Environmental Protection's Office of Oil and Gas and WV Geological and Economic Survey. We conducted an incremental process of adding information to the base map of NLCD 2001 and NLCD 2016. At each iteration of this process specific layers of information have been added to the maps. Priority of the information to be added is decided based on expert knowledge. We utilized Anderson classification as the basis for classes of land cover, however, barren land and developed land are expanded according to the context information of the study area (Figure 4-6 and 4-7).

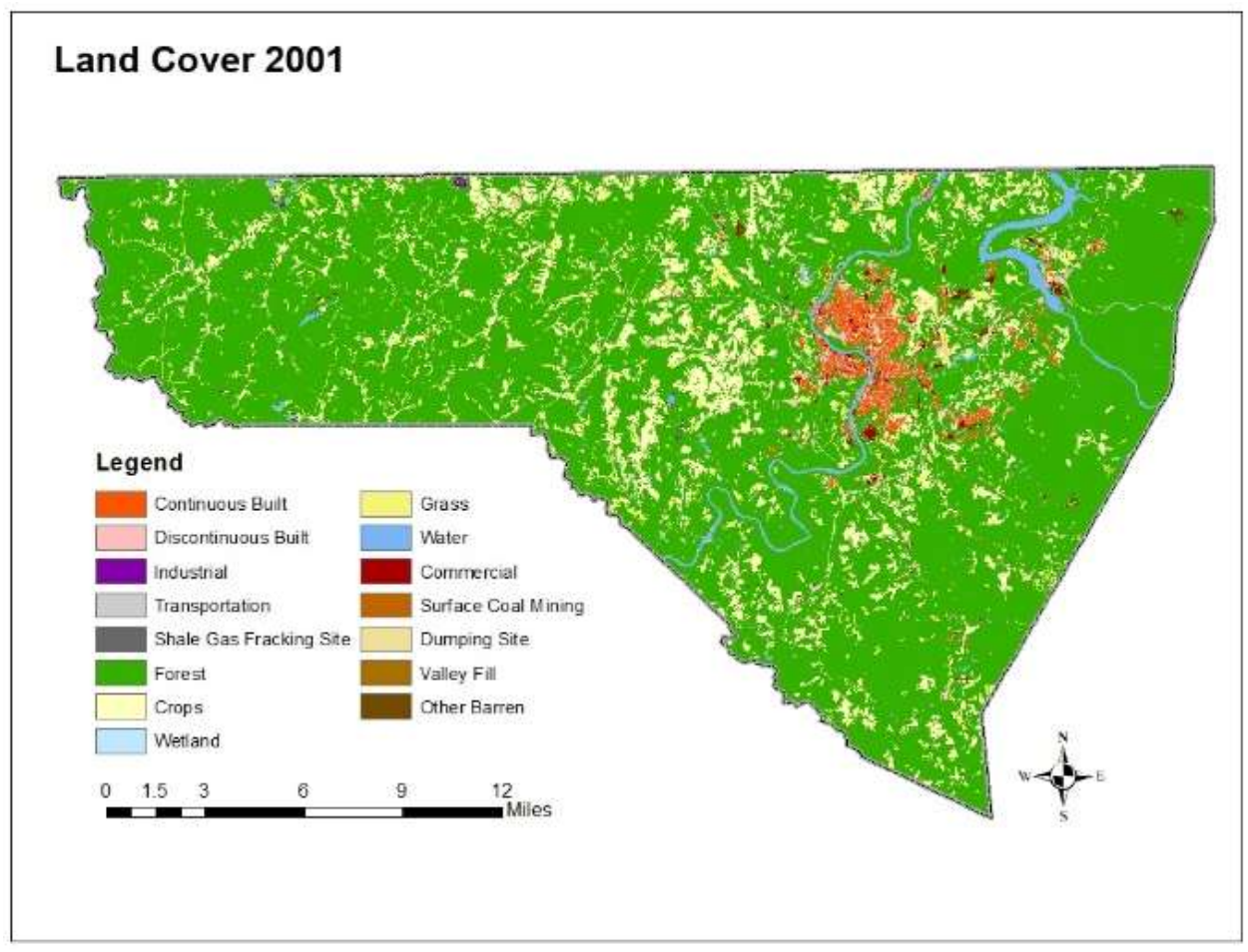

Fig. 4-6: Land Cover of Monongalia County in 2001 


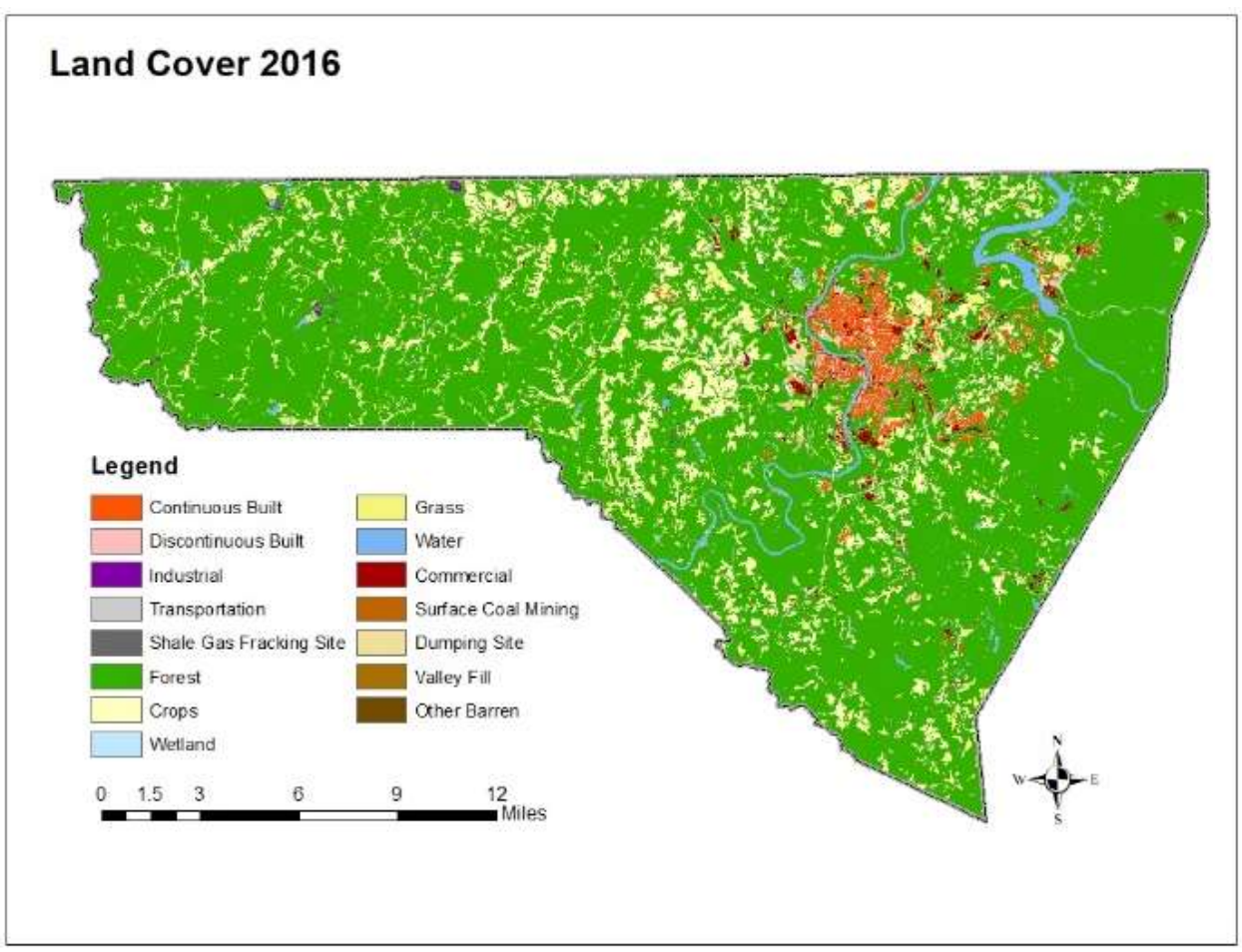

Fig. 4-7: Land Cover of Monongalia County in 2016

Fig. 4-8 shows the ratio of land conversion in each class of land cover in 2016 compared to 2001, in this figure we can see the portion of each class of land cover in 2011. According to this figure, majority of the land cover classes did not have considerable changes over the time period of 15 years. Drastic changes in the classes of land cover occur in shale gas fracking sites. Based on the data that we used in this research, in 2001 there were no shale gas wells in the study area. The majority of the regions covered by shale gas fracking sites in 2016 were converted from forested lands. Valley fills and dumping sites are two other energy extraction related classes of land cover. These classes of land cover are mainly formed in former open water and crop lands. In the majority of cross class land transformations; forests are transformed to create other classes of land (mainly developed lands). 


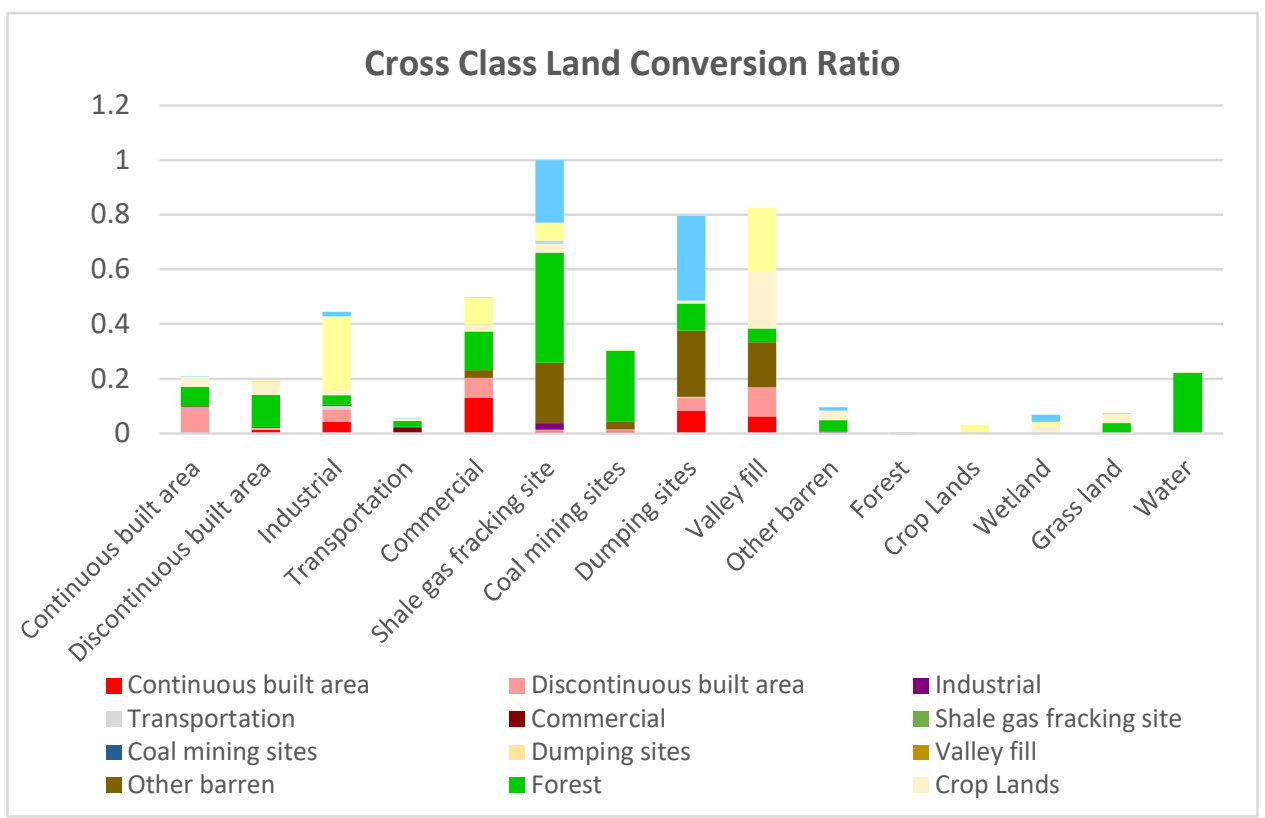

Fig. 4-8: Cross Class Land Conversion in Monongalia County, 2001-2016

In the analysis done by Burkhard et al. ( 2012), a supply-demand budget matrix is established to indicate the ES value of each CORINE land class. We used this matrix as a reference to regenerate a supply-demand matrix indicating the non-monetary value of Anderson based land, Tables 4-1, 4-2 and 4-3 show these values.

The data provided in tables above imply that in general the impact of creation and expansion of the classes of land cover which are stimulated by human built structures is negative (Figure 4-9). Anthropogenic changes in the landscape place some loads on the ecosystem, still, these changes are parts of a larger system which supplements social, economic, cultural and individual benefits. In the study area of this research, changes in the land is accompanied by changes in the energy profile of the region and the economic and social changes in the region. 
Table 4-1: The Capacity of Different Land Cover Classes- $0=$ no relevant capacity; $1=1$ low relevant capacity; $2=$ relevant capacity; 3 = medium relevant capacity; $4=$ high relevant capacity; and $5=$ very high relevant capacity (Burkhard et al., 2012)

\begin{tabular}{|c|c|c|c|c|c|c|c|c|c|c|c|c|c|c|c|c|c|c|c|c|c|c|c|c|c|c|c|c|c|c|}
\hline \multirow[b]{2}{*}{ 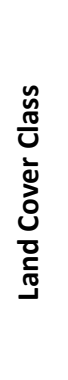 } & & \multicolumn{8}{|c|}{ Regulating Services } & \multicolumn{7}{|c|}{ Provisioning } & \multicolumn{4}{|c|}{ Cultural } & \multicolumn{8}{|c|}{ Ecological integrity } & \multirow[b]{2}{*}{$\begin{array}{l}w \\
\text { w } \\
\frac{5}{5} \\
\frac{5}{5}\end{array}$} & \multirow[b]{2}{*}{$\begin{array}{l}w \\
\text { o } \\
\frac{d}{\pi} \\
\tilde{\omega}\end{array}$} \\
\hline & & 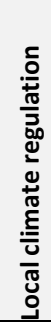 & 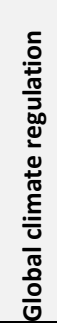 & 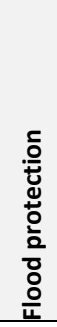 & 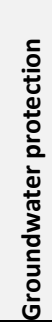 & 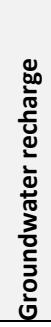 & 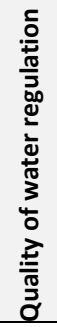 & 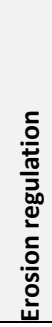 & 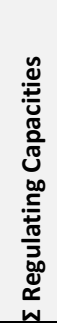 & 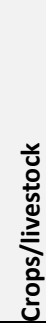 & 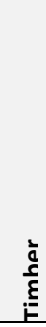 & $\begin{array}{l}\frac{y}{\frac{y}{J}} \\
\frac{\bar{v}}{\underline{4}} \\
\frac{5}{4}\end{array}$ & 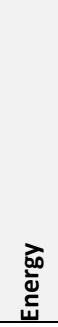 & & 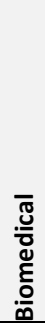 & 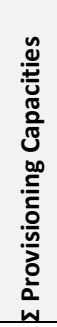 & 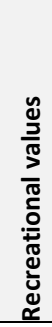 & 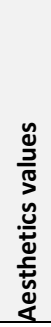 & 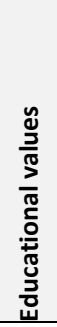 & 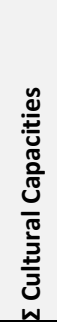 & 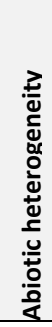 & $\begin{array}{l}\geq \\
\frac{1}{0} \\
\frac{0}{0} \\
\frac{2}{0} \\
\frac{0}{0}\end{array}$ & 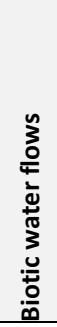 & 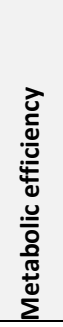 & 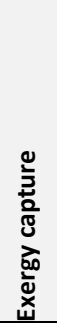 & 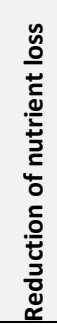 & 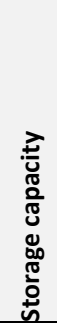 & 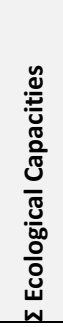 & & \\
\hline \multirow[t]{7}{*}{$\frac{n}{0}$} & CB & 0 & 0 & 0 & 0 & 0 & 0 & 0 & 0 & 0 & 0 & 0 & 1 & 0 & 0 & 1 & 0 & 0 & 0 & 0 & 0 & 0 & 0 & 0 & 0 & 0 & 0 & 0 & 1 & 0.00 \\
\hline & DB & 0 & 0 & 0 & 0 & 0 & 0 & 0 & 0 & 1 & 0 & 0 & 1 & 0 & 0 & 2 & 0 & 0 & 0 & 0 & 1 & 1 & 1 & 1 & 1 & 1 & 1 & 7 & 10 & 0.18 \\
\hline & 1 & 0 & 0 & 0 & 0 & 0 & 0 & 0 & 0 & 0 & 0 & 0 & 1 & 0 & 0 & 1 & 0 & 0 & 0 & 0 & 1 & 1 & 0 & 0 & 0 & 0 & 0 & 2 & 3 & 0.04 \\
\hline & C & 0 & 0 & 0 & 0 & 0 & 0 & 0 & 0 & 1 & 0 & 0 & 1 & 0 & 0 & 2 & 0 & 0 & 0 & 0 & 1 & 1 & 0 & 0 & 0 & 0 & 0 & 2 & 5 & 0.08 \\
\hline & $\mathbf{T}$ & 0 & 0 & 0 & 0 & 0 & 0 & 0 & 0 & 0 & 0 & 0 & 0 & 0 & 1 & 1 & 0 & 0 & 0 & 0 & 1 & 1 & 1 & 1 & 1 & 1 & 0 & 6 & 7 & 0.12 \\
\hline & SG & 0 & 0 & 0 & 0 & 0 & 0 & 0 & 0 & 0 & 0 & 0 & 5 & 0 & 0 & 5 & 0 & 0 & 0 & 0 & 1 & 1 & 0 & 0 & 0 & 0 & 0 & 2 & 7 & 0.12 \\
\hline & CM & 0 & 0 & 0 & 0 & 0 & 0 & 0 & 0 & 0 & 0 & 0 & 5 & 0 & 0 & 5 & 0 & 0 & 0 & 0 & 1 & 1 & 0 & 0 & 0 & 0 & 0 & 2 & 7 & 0.12 \\
\hline & DS & 0 & 0 & 0 & 0 & 0 & 0 & 0 & 0 & 0 & 0 & 0 & 0 & 0 & 0 & 0 & 0 & 0 & 0 & 0 & 1 & 0 & 0 & 0 & 0 & 0 & 0 & 1 & 1 & 0.00 \\
\hline & VF & 0 & 0 & 0 & 0 & 0 & 0 & 0 & 0 & 0 & 0 & 0 & 0 & 0 & 0 & 0 & 0 & 0 & 0 & 0 & 2 & 1 & 0 & 0 & 0 & 0 & 0 & 3 & 3 & 0.04 \\
\hline & OB & 1 & 0 & 1 & 1 & 0 & 1 & 4 & 4 & 4 & 0 & 0 & 0 & 0 & 0 & 0 & 0 & 0 & 0 & 0 & 3 & 3 & 0 & 0 & 0 & 0 & 0 & 6 & 6 & 0.10 \\
\hline & & 2 & 1 & 0 & 2 & 2 & 1 & 3 & 11 & 2 & 0 & 0 & 1 & 1 & 1 & 5 & 2 & 1 & 0 & 3 & 1 & 2 & 2 & 2 & 3 & 2 & 1 & 13 & 23 & 0.43 \\
\hline & & 1 & 1 & 1 & 1 & 1 & 1 & 1 & 7 & 7 & 7 & 0 & 0 & 1 & 2 & 7 & 3 & 3 & 0 & 6 & 2 & 2 & 4 & 5 & 5 & 2 & 4 & 24 & 41 & 0.78 \\
\hline & & 1 & 0 & 2 & 3 & 5 & 0 & 0 & 11 & 0 & 0 & 5 & 3 & 5 & 1 & 14 & 4 & 3 & 1 & 8 & 4 & 4 & 0 & 4 & 4 & 3 & 4 & 23 & 45 & 0.86 \\
\hline & & 5 & 4 & 3 & 2 & 5 & 5 & 5 & 29 & 0 & 5 & 0 & 2 & 0 & 1 & 8 & 5 & 5 & 4 & 14 & 3 & 4 & 4 & 4 & 5 & 5 & 5 & 30 & 52 & 1.00 \\
\hline & & 2 & 2 & 3 & 3 & 3 & 0 & 4 & 17 & 0 & 0 & 3 & 0 & 5 & 3 & 11 & 3 & 3 & 1 & 7 & 3 & 3 & 0 & 5 & 5 & 3 & 2 & 21 & 39 & 0.75 \\
\hline
\end{tabular}

Table 4-2: The Demand for $E S$ within different Land Cover Classes- $0=$ no relevant demand; $1=$ low relevant demand; $2=$ relevant demand; $3=$ medium relevant demand; $4=$ high relevant demand; and $5=$ very high relevant demand (Burkhard et al., 2012)

\begin{tabular}{|c|c|c|c|c|c|c|c|c|c|c|c|c|c|c|c|c|c|c|c|c|c|c|}
\hline \multirow[b]{2}{*}{ 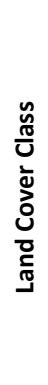 } & & \multicolumn{8}{|c|}{ Regulating Services } & \multicolumn{7}{|c|}{ Provisioning } & \multicolumn{4}{|c|}{ Cultural } & \multirow[b]{2}{*}{$\begin{array}{l}\text { W } \\
\text { ర } \\
\frac{1}{0} \\
\text { ப் }\end{array}$} & \multirow[b]{2}{*}{$\begin{array}{l}\text { W } \\
\text { D্d } \\
\text { J }\end{array}$} \\
\hline & & 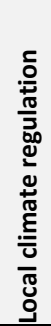 & 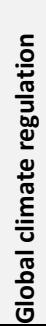 & 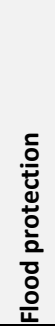 & 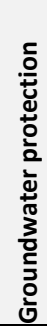 & 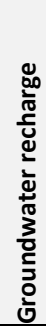 & 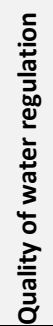 & 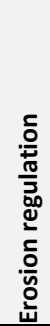 & 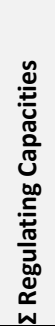 & 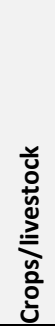 & हે & 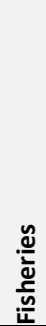 & పัँ & 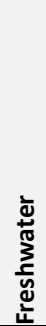 & 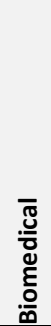 & 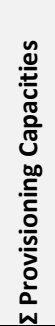 & 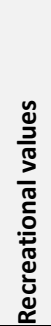 & 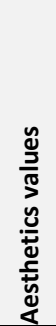 & 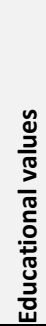 & 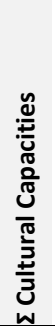 & & \\
\hline \multirow{6}{*}{ 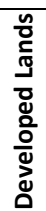 } & CB & -5 & -3 & -4 & -5 & -1 & -1 & -5 & -24 & -5 & -5 & -5 & -5 & -5 & -4 & -29 & -4 & -2 & 0 & -6 & -65 & -1.00 \\
\hline & DB & -5 & -3 & -5 & -5 & -1 & -1 & -4 & -24 & -4 & -4 & -4 & -4 & -4 & -4 & -24 & -4 & -3 & 0 & -7 & -62 & -0.95 \\
\hline & I & -1 & -5 & -5 & -5 & -3 & -3 & -5 & -27 & -5 & -5 & -4 & -4 & -4 & -1 & -23 & -1 & -1 & 0 & -2 & -54 & -0.83 \\
\hline & C & -1 & -4 & -5 & -5 & -2 & -1 & -4 & -22 & -5 & -5 & -5 & -5 & -5 & -2 & -27 & -2 & -2 & 0 & -4 & -57 & -0.88 \\
\hline & $\mathbf{T}$ & -2 & -4 & -4 & -1 & 0 & 0 & -1 & -12 & 0 & 0 & 0 & 0 & 0 & -2 & -2 & -2 & 0 & 0 & -2 & -18 & -0.28 \\
\hline & SG & -2 & -3 & -2 & -5 & -2 & 0 & -1 & -15 & -2 & 0 & -3 & -5 & -1 & 0 & -11 & 0 & 0 & 0 & 0 & -26 & -0.40 \\
\hline \multirow{4}{*}{ 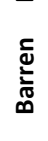 } & $\mathrm{CM}$ & -1 & -3 & -3 & -3 & 0 & 0 & -1 & -11 & 0 & 0 & -3 & -2 & 0 & 0 & -5 & 0 & 0 & 0 & 0 & -16 & -0.25 \\
\hline & DS & -2 & -2 & -1 & -2 & -1 & 0 & 0 & -8 & 0 & 0 & -1 & -2 & 0 & 0 & -3 & 0 & 0 & 0 & 0 & -11 & -0.17 \\
\hline & VF & -1 & -1 & -4 & 0 & 0 & 0 & 0 & -6 & 0 & 0 & 0 & -1 & 0 & 0 & -1 & 0 & 0 & 0 & 0 & -7 & -0.11 \\
\hline & OB & 0 & 0 & 0 & 0 & 0 & 0 & 0 & 0 & 0 & 0 & 0 & 0 & 0 & 0 & 0 & 0 & 0 & 0 & 0 & 0 & 0.00 \\
\hline \multicolumn{2}{|c|}{ GL } & 2 & 0 & 0 & -3 & -3 & -1 & -1 & -1 & -9 & 0 & 0 & 0 & -1 & -3 & 0 & -4 & 0 & 0 & 0 & 0 & -13 \\
\hline \multicolumn{2}{|c|}{$\mathrm{CL}$} & 1 & -1 & -2 & -1 & 0 & -2 & 0 & -1 & -7 & 0 & 0 & 0 & 0 & 0 & 0 & 0 & 0 & 0 & 0 & 0 & -7 \\
\hline \multicolumn{2}{|c|}{$\mathbf{w}$} & 1 & 0 & 0 & 0 & 0 & 0 & 0 & 0 & 0 & 0 & -1 & 0 & 0 & 0 & 0 & -1 & 0 & 0 & 0 & 0 & -1 \\
\hline \multicolumn{2}{|c|}{$\mathbf{F}$} & 5 & 0 & 0 & 0 & 0 & 0 & 0 & 0 & 0 & -1 & 0 & 0 & 0 & 0 & 0 & -1 & 0 & 0 & 0 & 0 & -1 \\
\hline \multicolumn{2}{|c|}{ WL } & 2 & 0 & 0 & 0 & 0 & 0 & 0 & 0 & 0 & 0 & -1 & 0 & 0 & 0 & 0 & -1 & 0 & 0 & 0 & 0 & -1 \\
\hline
\end{tabular}


Table 4-3: Budgets of ES's Supply Demand within different classes of land cover: -5 = Very High Demand; to $5=$ Very High Supply

\begin{tabular}{|c|c|c|c|c|c|c|c|c|c|c|c|c|c|c|c|c|c|c|c|c|c|c|c|c|c|c|c|c|c|c|}
\hline \multirow[b]{2}{*}{ 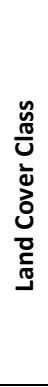 } & & \multicolumn{8}{|c|}{ Regulating Services } & \multicolumn{8}{|c|}{ Provisioning } & \multicolumn{3}{|c|}{ Cultural } & \multicolumn{8}{|c|}{ Ecological integrity } & & \multirow[b]{2}{*}{$\begin{array}{l}w \\
\text { d } \\
\text { d } \\
\text { ֶू }\end{array}$} \\
\hline & & 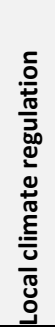 & 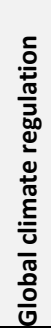 & 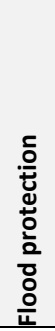 & 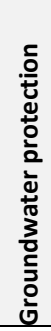 & 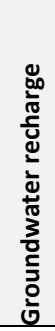 & 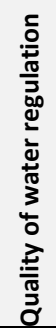 & 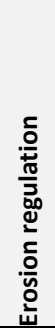 & 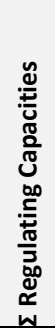 & 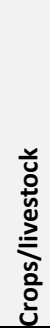 & 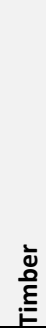 & 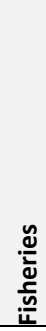 & హై & 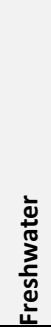 & 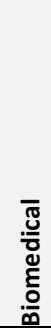 & 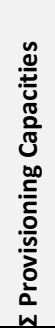 & 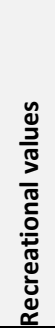 & 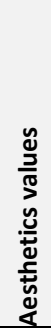 & 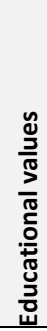 & 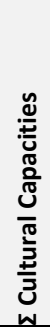 & 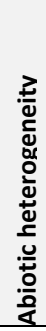 & $\frac{\geq}{\frac{2}{5}}$ & 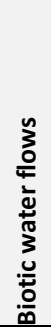 & 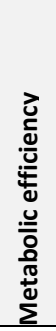 & 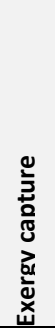 & 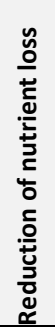 & 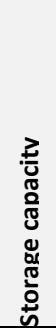 & 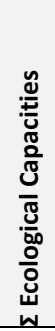 & 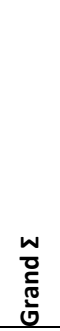 & \\
\hline \multirow{5}{*}{ 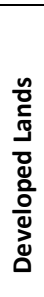 } & CB & -5 & -3 & -4 & -5 & -1 & -1 & -5 & -24 & -5 & -5 & -5 & -4 & -5 & -4 & $\begin{array}{l}- \\
28\end{array}$ & -4 & -2 & 0 & -6 & 0 & 0 & 0 & 0 & 0 & 0 & 0 & 0 & -58 & 0.00 \\
\hline & DB & -5 & -3 & -5 & -5 & -1 & -1 & -4 & -24 & -3 & -4 & -4 & -3 & -4 & -4 & $\begin{array}{l}- \\
22\end{array}$ & -4 & -3 & 0 & -7 & 1 & 1 & 1 & 1 & 1 & 1 & 1 & 6 & -47 & 0.08 \\
\hline & 1 & -1 & -5 & -5 & -5 & -3 & -3 & -5 & -27 & -5 & -5 & -4 & -3 & -4 & -1 & $\begin{array}{l}- \\
22\end{array}$ & -1 & -1 & 0 & -2 & 1 & 1 & 0 & 0 & 0 & 0 & 0 & 1 & -50 & 0.06 \\
\hline & C & -1 & -4 & -5 & -5 & -2 & -1 & -4 & -22 & -4 & -5 & -5 & -4 & -5 & -2 & $\begin{array}{l}- \\
25\end{array}$ & -2 & -2 & 0 & -4 & 1 & 1 & 0 & 0 & 0 & 0 & 0 & 1 & -50 & 0.06 \\
\hline & $\mathbf{T}$ & -2 & -4 & -4 & -1 & 0 & 0 & -1 & -12 & 0 & 0 & 0 & 0 & 0 & -1 & -1 & -2 & 0 & 0 & -2 & 1 & 1 & 1 & 1 & 1 & 1 & 0 & 5 & -10 & 0.36 \\
\hline \multirow{5}{*}{ 完 } & SG & -2 & -3 & -2 & -5 & -2 & 0 & -1 & -15 & -2 & 0 & -3 & 0 & -1 & 0 & -6 & 0 & 0 & 0 & 0 & 1 & 1 & 0 & 0 & 0 & 0 & 0 & 1 & -20 & 0.28 \\
\hline & $\mathrm{CM}$ & -1 & -3 & -3 & -3 & 0 & 0 & -1 & -11 & 0 & 0 & -3 & 3 & 0 & 0 & 0 & 0 & 0 & 0 & 0 & 1 & 1 & 0 & 0 & 0 & 0 & 0 & 1 & -10 & 0.36 \\
\hline & DS & -2 & -2 & -1 & -2 & -1 & 0 & 0 & -8 & 0 & 0 & -1 & -2 & 0 & 0 & -3 & 0 & 0 & 0 & 0 & 1 & 0 & 0 & 0 & 0 & 0 & 0 & 0 & -11 & 0.35 \\
\hline & VF & -1 & -1 & -4 & 0 & 0 & 0 & 0 & -6 & 0 & 0 & 0 & -1 & 0 & 0 & -1 & 0 & 0 & 0 & 0 & 2 & 1 & 0 & 0 & 0 & 0 & 0 & 1 & -6 & 0.39 \\
\hline & OB & 1 & 0 & 1 & 1 & 0 & 1 & 0 & 4 & 0 & 0 & 0 & 0 & 0 & 0 & 0 & 0 & 0 & 0 & 0 & 3 & 3 & 0 & 0 & 0 & 0 & 0 & 3 & 7 & 0.48 \\
\hline \multicolumn{2}{|c|}{ GL } & 2 & 1 & -3 & -1 & 1 & 0 & 2 & 2 & 2 & 0 & 0 & 0 & -2 & 1 & 1 & 2 & 1 & 0 & 3 & 1 & 2 & 2 & 2 & 3 & 2 & 1 & 12 & 18 & 0.56 \\
\hline \multicolumn{2}{|c|}{$\mathrm{CL}$} & 0 & -1 & 0 & 1 & -1 & 1 & 0 & 0 & 4 & 0 & 0 & 0 & 1 & 2 & 7 & 3 & 3 & 0 & 6 & 2 & 2 & 4 & 5 & 5 & 2 & 4 & 22 & 35 & 0.69 \\
\hline \multicolumn{2}{|c|}{$\mathbf{w}$} & 1 & 0 & 2 & 3 & 5 & 0 & 0 & 11 & 0 & -1 & 5 & 3 & 5 & 1 & 13 & 4 & 3 & 1 & 8 & 4 & 4 & 0 & 4 & 4 & 3 & 4 & 19 & 51 & 0.81 \\
\hline \multicolumn{2}{|c|}{$\mathbf{F}$} & 5 & 4 & 3 & 2 & 5 & 5 & 5 & 29 & -1 & 5 & 0 & 2 & 0 & 1 & 7 & 5 & 5 & 4 & 14 & 3 & 4 & 4 & 4 & 5 & 5 & 5 & 27 & 77 & 1.00 \\
\hline \multicolumn{2}{|c|}{ WL } & 2 & 2 & 3 & 3 & 3 & 0 & 4 & 17 & 0 & -1 & 3 & 0 & 5 & 3 & 10 & 3 & 3 & 1 & 7 & 3 & 3 & 0 & 5 & 5 & 3 & 2 & 18 & 52 & 0.81 \\
\hline
\end{tabular}

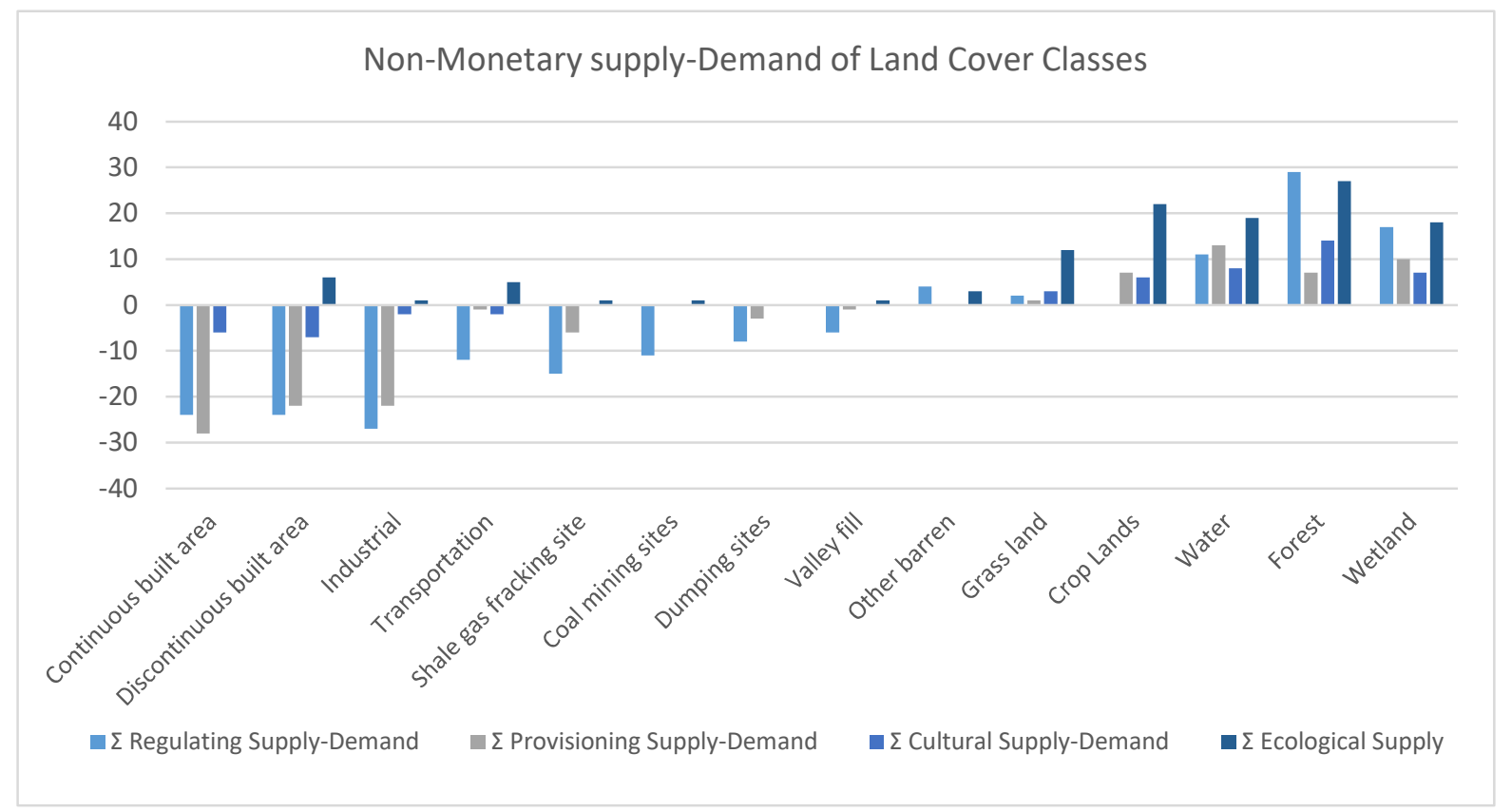

Fig. 4-9: Budget summary of land cover classes 


\section{Results and Discussions}

The essence of changes in the ecosystem services is delineated through assigning the weights of ecosystem services to each type of land cover in Monongalia County (Fig. 4-10). By measuring the difference between the values assigned to each class in 2001 and 2016 we were able to compute the ES balance changes from 2001 to 2016 .

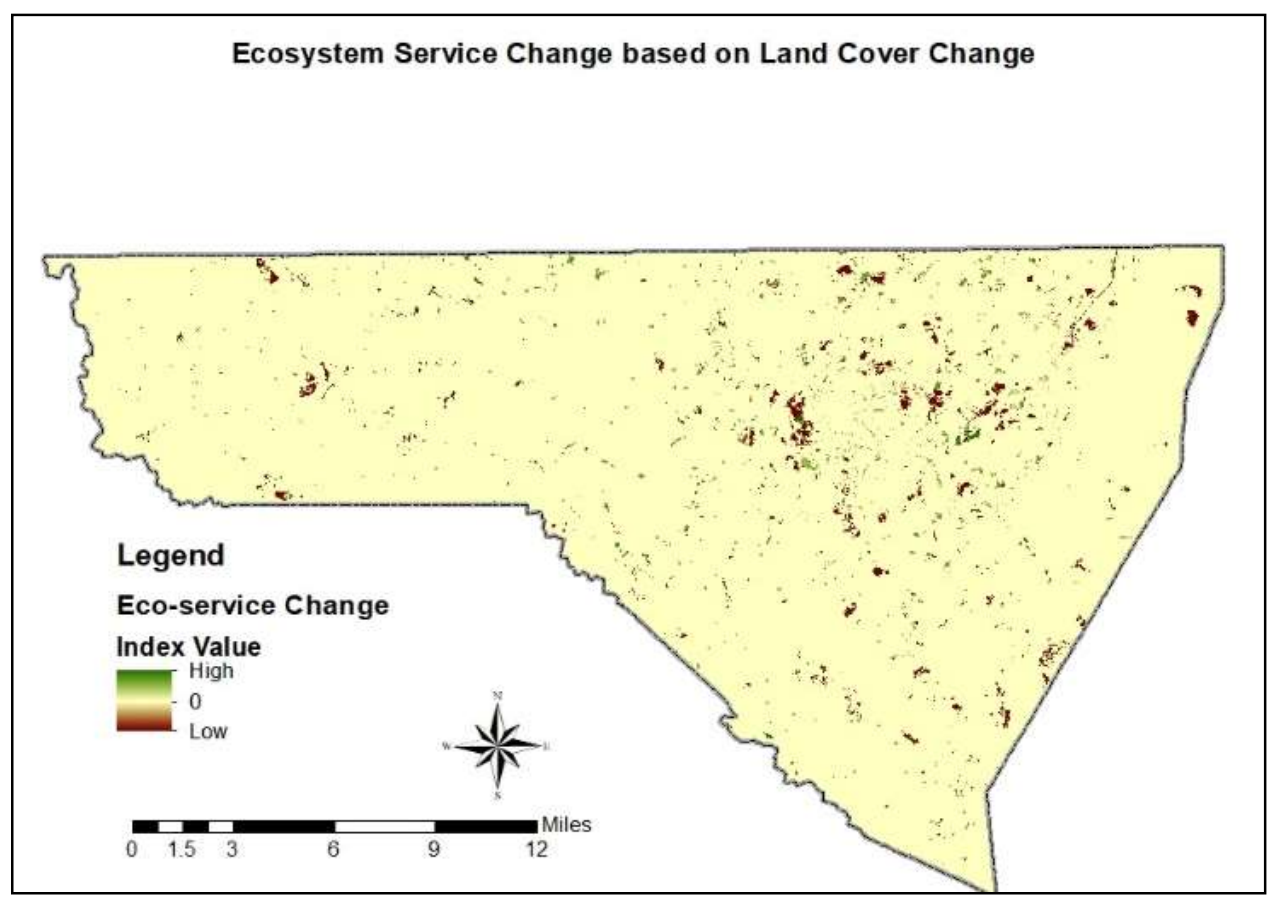

Fig. 4-10: Changes in the ES

The mapping of changes in the ecosystem services pinpoints the configuration and quality of the changes, patches of the ES change show a randomness in the distribution of these changing elements of ecosystem services. We are interested in analyzing this pattern in this study region. Also, the cross -tabulation analysis of area and ES index versus land cover classes in 2001 and 2016 indicates that the major declines in the ES budgets are in fact a result of conversion of land into any form of developed land. Converting forested land to developed classes is of high environmental cost. Monongalia County with its rich resources of forested lands and ecological 
integrity shows that the cost of using these forested lands will be higher in terms of ecosystem services.

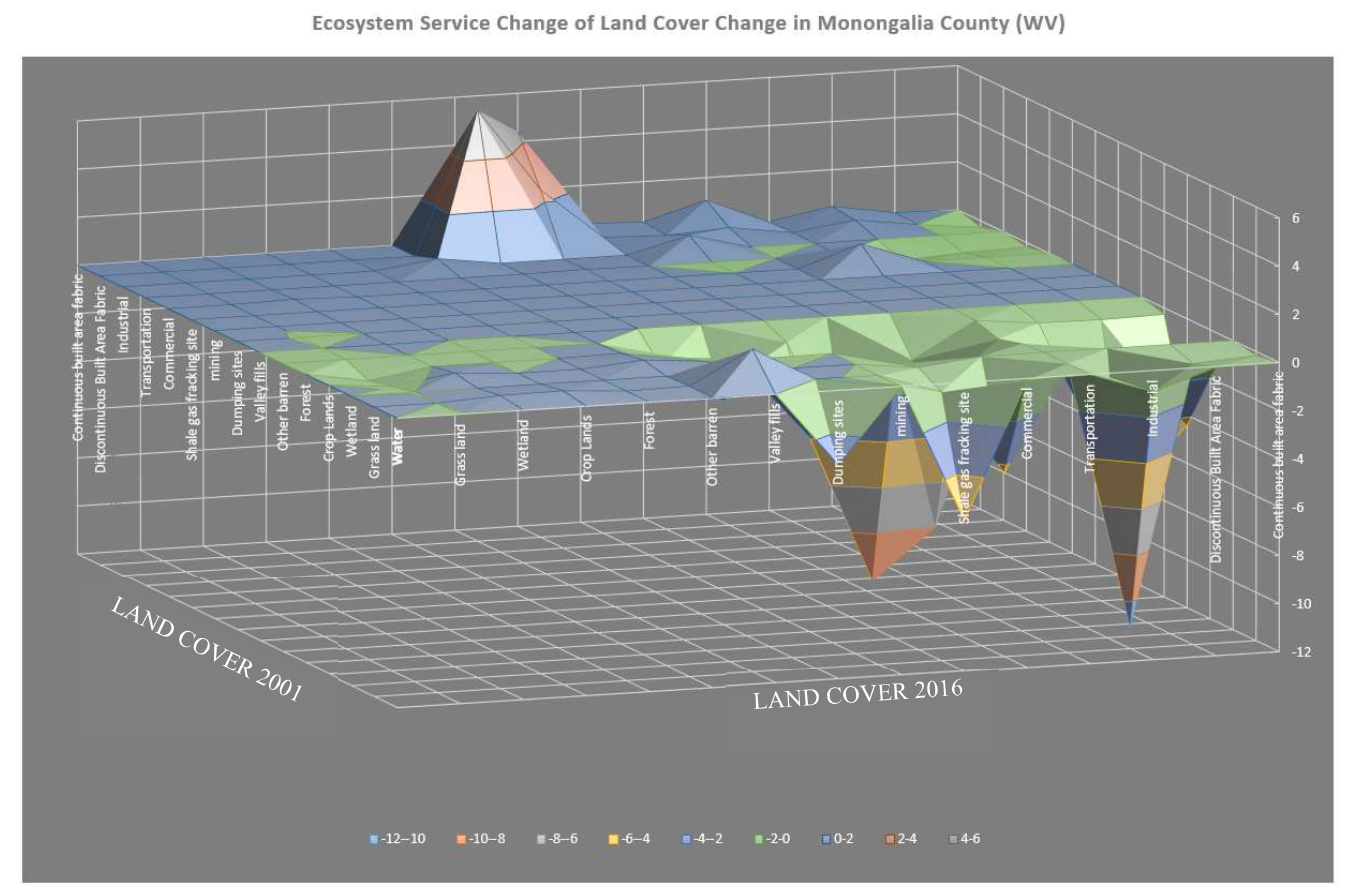

Fig. 4-11: ES Change per Land Cover Class in Monongalia County

By incorporating multiple layers of information in this analysis we can acquire deeper understanding of ES changes in Monongalia County. As demonstrated in our previous analysis, in the context of this study, major stimulators of negative changes in ecosystem services are developed lands and energy extraction land conversions. Figure 4-12 illustrates the hotspot analysis of the regions with negative change in ES. The drivers of these negative changes in ES are due to the presence of populated places, energy lands and census metropolitan area.

This result indicates that in the study area there are two primary motives for declining ES. They are the value of land cover in rural development areas and in- development in built-up regions of Morgantown, these areas are mainly located inside the Metroplan Statistical Area(MSA) of 
Morgantown. The sparse developments located in low clusters outside Morgantown are also principle stimulators for reducing the ES indices in Monongalia county.

These changes in the ecosystem services of land cover will cause a reciprocal change in the services that environmental scientists and regional planners will observe in their studies of the same area. This cycle of change is controllable through regulations and decisions made by policy makers, such that in the future land developments can be less of an environmental expense or either there are compensations for the costs that landscape change has imposed to the environment.

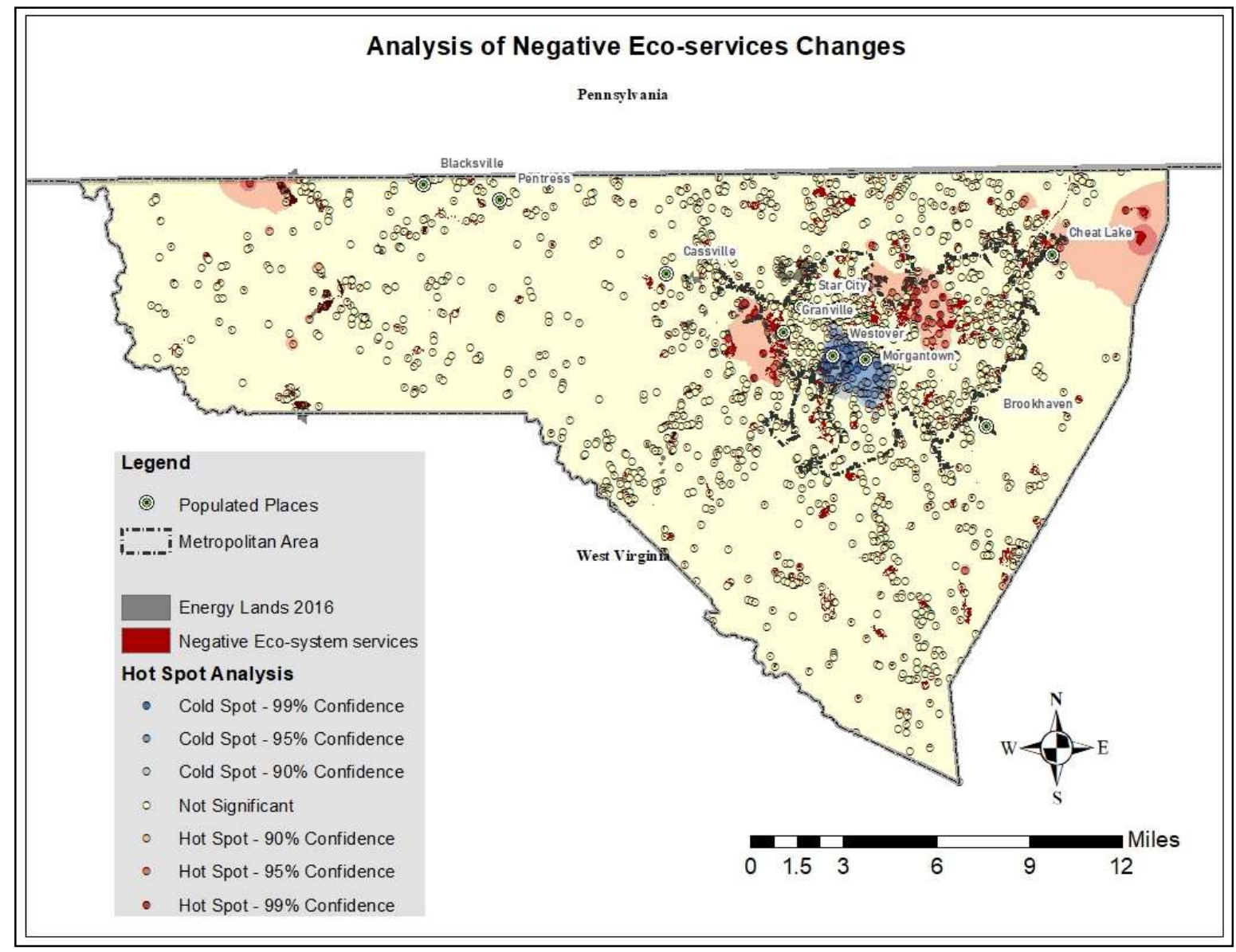

Fig. 4-12: Hotspot analysis of major ES declines and land development spatial representations 


\section{Conclusion}

Throughout this study, we addressed areas in which large context of the work fits under a larger umbrella of sustainability. The results of this study indicate that because of the rich ecosystem and resources of the Appalachia region, each piece of land in this area is of high ecological value. Such that conversion of any small patch of woodlands into any other land cover carries expenses, not only for the local community but also for national and global communities. Changes in smaller patches of land are not only at the expense of ecosystem demands; but, along with these changes there are demands for several complementary and invisible services (i.e. infrastructure) each of which has economic and ecological expenses. This exists not only for the developer but also for the local and the global communities. It is very crucial for the developers to find their way through the guidelines that are drawn by the policy makers. The results of this study show that redesign of green spaces in barren lands in the surrounding regions in Morgantown metropolitan area benefit the region with more environment-friendly land cover. Also, this study implies that different forms of land development and growth of energy industries are major reasons for the reduction of land cover and budget of the region. Environmental, economic and subjective well-being of the communities living in this region require regulations on various subjects to support the equitable and economic development.

Although the value of eco-services has been estimated through various resources, access and preferences of eco-services across stakeholders is not yet well defined. In addition, there is not enough information and knowledge on how to measure the impact of changes in eco-services on human well-being. Indeed, changes in the ecosystem services are dominated by land development and growth of energy industries, however, these types of land development are not necessarily indicating elements for the socio-economic well-being of communities. According to a report by 
the sustainable and healthy communities research program of Environmental Protection Agency of the US (https://www.epa.gov/aboutepa/about-sustainable-and-healthy-communities-researchprogram), the well-being indicators of communities are influenced by various components besides ecosystem services which is a sub-category of the environmental policy related decisions.

Various aspects of policymaking need to work together to present high standards of well-being to the communities of Monongalia county. These pieces of policy include environmental, social, political and economic policies. Issues such as how and when an existing local government's structure prevents or enhances sustainable, efficient and equitable benefits from the resources. And how the regulations provide the best for the community and the ecosystem, and how we transform out of intensely rooted systems of non-sustainable growth of sparse landscape changes to fundamentally new systems of governance and management. This issue remains inadequately addressed. These gaps in our knowledge constrain the capacity of sustainability research and using ES to inform policy management. Our study is a small part of the larger perspective of managing the utilizing non-monetary capitals in Appalachia. 


\section{CHAPTER V}

\section{Conclusions}

The results of each section of this dissertation address an aspect of land development. These sections are interconnected and contribute to the science of land transformation and landscape change in Appalachia. Our results indicate that land developments in the study areas are highly instable in regard to trends. This adds to the complexity of this process and brings in more uncertainty in predicting the land transformation. Our methodological approach in predicting the land development implies that prediction of such landscape change can be possible through the application of high-level computational methods and powerful computational infrastructure. Investigation of the past trends of land development facilitates information on predicting its future. Access to land development predictions facilitates planners with more insights on future trends. In addition, predictive models of the land transformation are helpful in including predictive environmental models such as climate change and hydrology models. Models that were developed and described in CHAPTER II demonstrated high accuracy in implementing the classification of land cover and are capable of being applied in a broader range of issues. We believe that deepLand models provide powerful and advantageous methodological approaches in other pixel wise semantic segmentation problems of land characteristics including predicting and classifying land cover and finding the location and configuration of specific landscape changes in Appalachia. Moreover, the original method of data manipulation technique in CHAPTER II suggests incorporating multiple characteristics of land, so the complex interactions of land transformation

are integrated in the models. Our analysis in CHAPTER III confirms high instability and complexity of land development in WV. 
Dependency of Appalachia on unsustainable sources of economic development adds to the level of landscape dynamicity in this region. Through this study, the patterns of land development and the transformation processes are used to investigate the sustainability of the region. Our research on the past trends of land development also support this suggestion. According the third chapter of this study, in WV density of new land developments is increasing over time, we extracted the patterns of land development. These patterns do not imply consistency in the regions of development and the coefficient analysis of these changing variables show that the motivating factors of land development are highly dynamic in WV. We suggest that the information of CHAPTER III is useful for planners and environmental scientist to gain a better understanding of the trends of land development in WV. In CHAPTER III a multi-level analysis of the variables of land development in WV imply the significance of the factors over time. Changing patterns of energy extraction in this state highly influence the patterns of land development. Because of the shifts in the energy extraction, major communities of WV miss the opportunity for growing and flourishing. The growth of these communities is mainly in small and fragmented groups. This is a phenomenon that not only impacts the patterns of land resource consumption but also influences the cultural values and sense of community and participation. Essentially, this fragmentation will suppress the power of communities in building other forms of capital and will cause a waste in the physical and natural capital. In this context the results of CHAPTER IV provide a better indicator on the ecosystem services assessment of the land transformation.

Map of the ES of Monongalia county, WV showed a sparse pattern of its decline. In fact, this map makes two major points, first, there is a substantial drop in the ES supply demand budget because of the patterns of anthropogenic changes in the land; second, the patterns of patches that are created in the forests and ES change is scattered in western regions of the county. The latter shows the 
impact of rural development and random energy extraction sites. By bridging the results of inconsistent patterns of land development from CHAPTER III to the information gained from ES budget, we can deduce that through longer time spans the dynamic patterns of landscape change will have considerable impacts on the ES budget of this region. It is crucial for the communities of the region to comprehend the effect of their decisions in land consumption on the assets that the region owns and the benefits that these communities can gain from them. We strongly recommend bringing the results of this research to the local level so planners and decision makers can make each decision in allocating land development projects regarding the environmental and social consequences of their decisions. 


\section{REFERENCES}

Appalachian Regional Commission. (2017). Appalachian Regional Commission POWER Award Summaries by State, (February). Retrieved from https://www.arc.gov/images/grantsandfunding/POWER2017/ARCPOWERAwardSummarie sbyState1-25-2017.pdf

Badrinarayanan, V., Kendall, A., \& Cipolla, R. (2017). SegNet: A Deep Convolutional EncoderDecoder Architecture for Image Segmentation. IEEE Transactions on Pattern Analysis and Machine Intelligence, 39(12), 2481-2495. https://doi.org/10.1109/TPAMI.2016.2644615

Bagstad, K. J., Villa, F., Batker, D., Harrison-Cox, J., Voigt, B., \& Johnson, G. W. (2014). From theoretical to actual ecosystem services: Mapping beneficiaries and spatial flows in ecosystem service assessments. Ecology and Society, 19(2). https://doi.org/10.5751/ES06523-190264

Bovini, M. G., \& Giordano, L. C. da S. (2005). Loasaceae Lindl. no Estado do Rio de Janeiro, Brasil. Acta Botanica Brasilica, 19(2), 265-271. https://doi.org/10.1590/S010233062005000200008

Bowen, E., \& Christiadi. (2017). Fossil Fuel Opportunities for West Virginia : 2017 Update.

Burkhard, B., Kroll, F., Nedkov, S., \& Müller, F. (2012). Mapping ecosystem service supply, demand and budgets. Ecological Indicators, 21, 17-29. https://doi.org/10.1016/j.ecolind.2011.06.019

Castelluccio, M., Poggi, G., Sansone, C., \& Verdoliva, L. (2015). Land Use Classification in Remote Sensing Images by Convolutional Neural Networks, 1-11. Retrieved from http://arxiv.org/abs/1508.00092

Cheng, J., \& Masser, I. (2003). Urban growth pattern modelling : a case study of Wuhan city, PR 
China Urban growth pattern modeling : a case study of Wuhan city, PR China. Landscape and Urban Planning, 62(August), 199-217. https://doi.org/10.1016/S0169-2046(02)00150-0

Davidson, M. D. (2013). On the relation between ecosystem services, intrinsic value, existence value and economic valuation Marc. Ecological Economics, 95, 171-177.

Davis, J., \& Goadrich, M. (2006). The relationship between Precision-Recall and ROC curves. Proceedings of the 23rd International Conference on Machine Learning - ICML '06, 233240. https://doi.org/10.1145/1143844.1143874

Day, J. W., Moerschbaecher, M., Pimentel, D., Hall, C., \& Yáñez-Arancibia, A. (2014). Sustainability and place: How emerging mega-trends of the 21 st century will affect humans and nature at the landscape level. Ecological Engineering, 65, 33-48. https://doi.org/10.1016/j.ecoleng.2013.08.003

De Groot, R. (2006). Function-analysis and valuation as a tool to assess land use conflicts in planning for sustainable, multi-functional landscapes. Landscape and Urban Planning, 75(34), 175-186. https://doi.org/10.1016/j.landurbplan.2005.02.016

de Groot, R. S., Alkemade, R., Braat, L., Hein, L., \& Willemen, L. (2010). Challenges in integrating the concept of ecosystem services and values in landscape planning, management and decision making. Ecological Complexity, 7(3), 260-272. https://doi.org/10.1016/j.ecocom.2009.10.006

Deng, J., Huang, Y., Chen, B., Tong, C., Liu, P., Wang, H., \& Hong, Y. (2019). A methodology to monitor urban expansion and green space change using a time series of multi-sensor SPOT and Sentinel-2A images. Remote Sensing, 11(10). https://doi.org/10.3390/rs11101230

Deng, X., Li, Z., \& Gibson, J. (2016). A review on trade-off analysis of ecosystem services for sustainable land-use management. Journal of Geographical Sciences, 26(7), 953-968. 
https://doi.org/10.1007/s11442-016-1309-9

Foley, A. (1999). Estimating historical changes in global land cover: Croplands historical have converted areas, 13(4), 997-1027.

Foley, J. A., DeFries, R., Asner, G. P., Barford, C., Bonan, G., Carpenter, S. R., ... Snyder, P. K. (2005). Global consequences of land use. Science, 309(5734), 570-574. https://doi.org/10.1126/science.1111772

Godinho, S., Guiomar, N., Machado, R., Santos, P., Sá-Sousa, P., Fernandes, J. P., ... PintoCorreia, T. (2016). Assessment of environment, land management, and spatial variables on recent changes in montado land cover in southern Portugal. Agroforestry Systems, 90(1), 177192. https://doi.org/10.1007/s10457-014-9757-7

Goldenberg, R., Kalantari, Z., Cvetkovic, V., Mörtberg, U., Deal, B., \& Destouni, G. (2017). Distinction, quantification and mapping of potential and realized supply-demand of flowdependent ecosystem services. Science of the Total Environment, 593-594, 599-609. https://doi.org/10.1016/j.scitotenv.2017.03.130

Hietel, E., Waldhardt, R., \& Otte, A. (2004). Analysing land-cover changes in relation to environmental variables in Hesse, Germany. Landscape Ecology, 19(5), 473-489. https://doi.org/10.1023/B:LAND.0000036138.82213.80

Homer, C., Dewitz, J., Yang, L., Jin, S., Danielson, P., Coulston, J., ... Megown, K. (2015). Completion of the 2011 National Land Cover Database for the Conterminous United States - Representing a Decade of Land Cover Change Information. Programmetic Engineering \& Remote Sensing, 345-354.

Homer, C., Huang, C., Yang, L., Wylie, B., \& Coan, M. (2013). Development of a 2001 National Land-Cover Database for the United States. Photogrammetric Engineering \& Remote 
Sensing, 70(7), 829-840. https://doi.org/10.14358/pers.70.7.829

Hu, W., Huang, Y., Wei, L., Zhang, F., \& Li, H. (2015). Deep convolutional neural networks for hyperspectral image classification. Journal of Sensors, 2015. https://doi.org/10.1155/2015/258619

Huang, K. C., Chan, S. L., Li, Y., Liu, G., Bovini, M. G., Giordano, L. C. da S., ... Lambin, E. F. (2014). Monitoring land-cover changes: A comparison of change detection techniques. International Journal of Remote Sensing, 19(4), 139-152. https://doi.org/10.1080/014311699213659

Huang, Z., Wei, Y. D., He, C., \& Li, H. (2015). Urban land expansion under economic transition in China: A multi-level modeling analysis. Habitat International, 47, 69-82. https://doi.org/10.1016/j.habitatint.2015.01.007

Ji, C. Y., Liu, Q., Sun, D., Wang, S., Lin, P., \& Li, X. (2001). Monitoring urban expansion with remote sensing in China. International Journal of Remote Sensing, 22(8), 1441-1455. https://doi.org/10.1080/01431160117207

Kampffmeyer, M., Salberg, A.-B., \& Jenssen, R. (2016). Semantic Segmentation of Small Objects and Modeling of Uncertainty in Urban Remote Sensing Images Using Deep Convolutional Neural Networks. Proceedings of the IEEE Conference on Computer Vision and Pattern Recognition Workshops, 1-9. https://doi.org/10.1109/CVPRW.2016.90

Kamusoko, C., \& Gamba, J. (2015). Simulating Urban Growth Using a Random Forest-Cellular Automata (RF-CA) Model. ISPRS International Journal of Geo-Information, 4(2), 447-470. https://doi.org/10.3390/ijgi4020447

Klenke, A. (2014). Probability Theory. Springer-Verlag London. https://doi.org/10.1007/978-14471-5361-0 
Kroll, F., Müller, F., Haase, D., \& Fohrer, N. (2012). Rural-urban gradient analysis of ecosystem services supply and demand dynamics. Land Use Policy, 29(3), 521-535. https://doi.org/10.1016/j.landusepol.2011.07.008

Lambin, E. .., Rounsevell, M. D. A., \& Geist, H. J. (2000). "Are agricultural land-use Models able to predict changes in land use intensity?". Agriculture, Ecosystems and Environment, 82, 321- 331 .

Lambin, E. F., Turner, B. L., Geist, H. J., Agbola, S. B., Angelsen, A., Folke, C., ... Veldkamp, T. A. (2001). The causes of land-use and land-cover change : moving beyond the myths, 11, 261-269. https://doi.org/10.1016/S0959-3780(01)00007-3

Lin, J., Huang, B., Chen, M., \& Huang, Z. (2014). Modeling urban vertical growth using cellular automata-Guangzhou as a case study. Applied Geography, 53, 172-186. https://doi.org/10.1016/j.apgeog.2014.06.007

Maes, J., Barbosa, A., Baranzelli, C., Zulian, G., Batista e Silva, F., Vandecasteele, I., ... Lavalle, C. (2015). More green infrastructure is required to maintain ecosystem services under current trends in land-use change in Europe. Landscape Ecology, 30(3), 517-534. https://doi.org/10.1007/s10980-014-0083-2

Maimaitijiang, M., Ghulama, A., Onésimo Sandoval, J. S., \& Maimaitiyiming, M. (2015). Drivers of land cover and land use changes in St. Louis metropolitanarea over the past 40 years characterized by remote sensing andcensus population data. International Journal of Applied Earth Observation and Geoinformation, 35(PB), 161-174. https://doi.org/10.1016/j.jag.2014.08.020

Mennis, J. (2006). Mapping the Results of Geographically Weighted Regression. The Cartographic Journal, 43(2), 171-179. https://doi.org/10.1179/000870406x114658 
Myers, R. H. ., \& Myers, R. H. (1990). Classical and modern regression with applications (Vol. 2). Belmont, CA: Duxbury press.

Ou, J., Liu, X., Li, X., \& Chen, Y. (2013). Quantifying the relationship between urban forms and carbon emissions using panel data analysis. Landscape Ecology, 28(10), 1889-1907. https://doi.org/10.1007/s10980-013-9943-4

Paetzold, A., Warren, P. H., \& Maltby, L. L. (2010). A framework for assessing ecological quality based on ecosystem services. Ecological Complexity, 7(3), 273-281. https://doi.org/10.1016/j.ecocom.2009.11.003

Pato, R. L., Castro, P., \& Tavares, A. O. (2016). The relevance of physical forces on land-use change and planning process. Journal of Environmental Planning and Management, 59(4), 607-627. https://doi.org/10.1080/09640568.2015.1035773

Pijanowski, B. C., Brown, D. G., Shellito, B. A., \& Manik, G. A. (2002). Using neural networks and GIS to forecast land use changes : a Land Transformation Model, 26, 553-575.

Pijanowski, B. C., Hyndman, D., \& Shellito, B. A. (2001). The application of the land transformation, groundwater flow and solute transport models for michigan's grand traverse bay watershed. National American Planning Association Meeting, 1-12.

Pijanowski, B. C., Tayyebi, A., Delavar, M. R., \& Yazdanpanah, M. J. (2009). Urban Expansion Simulation Using Geospatial Information System and Artificial Neural Networks. Int. J. Environ. $\quad$ Res, $3(4), \quad$ 493-502. $\quad$ Retrieved from https://ijer.ut.ac.ir/article_64_80eb548a103046e304fa36957aaf42e3.pdf

Pijanowski, B. C., Tayyebi, A., Doucette, J., Pekin, B. K., Braun, D., \& Plourde, J. (2014). A big data urban growth simulation at a national scale: Configuring the GIS and neural network based Land Transformation Model to run in a High Performance Computing (HPC) 
environment. Environmental Modelling and Software, 51, 250-268. https://doi.org/10.1016/j.envsoft.2013.09.015

Pijanowski B.C., Brown D.G., Shellito B.A.A., M. G. (2002). "Using Neural Networks and GIS to Forecast Land Use Changes: A Land Transformation Model,." Computers, Environment and Urban Systems, 26, 553-575. https://doi.org/10.1016/S0198-9715(01)00015-1

Report, F. (2011). Economic Impact of Energy and Environmental Policy in Appalachia Final Report.

Ronneberger, O., Fischer, P., \& Brox, T. (2015). U-net: Convolutional networks for biomedical image segmentation. Lecture Notes in Computer Science (Including Subseries Lecture Notes in Artificial Intelligence and Lecture Notes in Bioinformatics), 9351, 234-241. https://doi.org/10.1007/978-3-319-24574-4_28

Ruder, S. (2016). An overview of gradient descent optimization, 1-14.

Seppelt, R., Fath, B., Burkhard, B., Fisher, J. L., Grêt-Regamey, A., Lautenbach, S., ... Van Oudenhoven, A. P. E. (2012). Form follows function? Proposing a blueprint for ecosystem service assessments based on reviews and case studies. Ecological Indicators, 21, 145-154. https://doi.org/10.1016/j.ecolind.2011.09.003

Sexton, J. O., Urban, D. L., Donohue, M. J., \& Song, C. (2013). Long-term land cover dynamics by multi-temporal classification across the Landsat-5 record. Remote Sensing of Environment, 128, 246-258. https://doi.org/10.1016/j.rse.2012.10.010

Shafizadeh-Moghadam, H., \& Helbicha, M. (2015). Spatiotemporal variability of urban growth factors: A globaland local perspective on the megacity of Mumbai. International Journal of Applied Earth Observation and Geoinformation, 35(PB), 187-198. https://doi.org/10.1016/j.jag.2014.08.013 
Sherrah, J. (2016). Fully Convolutional Networks for Dense Semantic Labelling of HighResolution Aerial Imagery, 1-22. Retrieved from http://arxiv.org/abs/1606.02585

Tayyebi, A., \& Pijanowski, B. C. (2014). Modeling multiple land use changes using ANN, CART and MARS: Comparing tradeoffs in goodness of fit and explanatory power of data mining tools. International Journal of Applied Earth Observation and Geoinformation, 28(1), 102116. https://doi.org/10.1016/j.jag.2013.11.008

Towns, J., Cockerill, T., Dahan, M., Foster, I., Gaither, K., Grimshaw, A., ... Wilkins-Diehr, N. (2014). Accelerating Scientific Discovery. Computing in Science and Engineering, 16(October), 62-74. https://doi.org/10.1109/MCSE.2014.80

van Leeuwen, E. (2015). Urban-Rural Synergies: An Explorative Study at the NUTS3 Level. Applied Spatial Analysis and Policy, 8(3), 273-289. https://doi.org/10.1007/s12061-0159167-x

Verburg, P. H. (2006). Simulating feedbacks in land use and land cover change models. Landscape Ecology, 21(8), 1171-1183. https://doi.org/10.1007/s10980-006-0029-4

Warner, T. A., Almutairi, A., \& Lee, J. Y. (2008). Remote Sensing of Land Cover Change. The SAGE Handbook of Remote Sensing, 459-474. https://doi.org/10.4135/9780857021052.n33

Wei, Y., Huang, C., Lam, P. T. I., \& Yuan, Z. (2015). Sustainable urban development: A review on urban carrying capacity assessment. Habitat International, 46, 64-71. https://doi.org/10.1016/j.habitatint.2014.10.015

Wheeler, D. C. (2007). Diagnostic tools and a remedial method for collinearity in geographically weighted regression. Environment and Planning A, 39(10), 2464-2481. https://doi.org/10.1068/a38325

Wu, D., Liu, J., Zhang, G., Ding, W., Wang, W., \& Wang, R. (2009). Incorporating spatial 
autocorrelation into cellular automata model: An application to the dynamics of Chinese tamarisk (Tamarix chinensis Lour.). Ecological Modelling, 220(24), 3490-3498. https://doi.org/10.1016/j.ecolmodel.2009.03.008

Wurster, D., \& Artmann, M. (2014). Development of a concept for non-monetary assessment of urban ecosystem services at the site level. Ambio, 43(4), 454-465. https://doi.org/10.1007/s13280-014-0502-2

Xu, Y., Yu, L., Zhao, F. R., Cai, X., Zhao, J., Lu, H., \& Gong, P. (2018). Tracking annual cropland changes from 1984 to 2016 using time-series Landsat images with a change-detection and post-classification approach: Experiments from three sites in Africa. Remote Sensing of Environment, 218(August), 13-31. https://doi.org/10.1016/j.rse.2018.09.008

Yin, J., Yin, Z., Zhong, H., Xu, S., Hu, X., Wang, J., \& Wu, J. (2011). Monitoring urban expansion and land use/land cover changes of Shanghai metropolitan area during the transitional economy (1979-2009) in China. Environmental Monitoring and Assessment, 177(1-4), 609621. https://doi.org/10.1007/s10661-010-1660-8

Zhang, D., \& Yang, T. (2015). Environmental impacts of hydraulic fracturing in shale gas development in the United States. Shiyou Kantan Yu Kaifa/Petroleum Exploration and Development, 42(6), 801-807. https://doi.org/10.11698/PED.2015.06.14

Zhao, S., Zhou, D., Zhu, C., Qu, W., Zhao, J., Sun, Y., ... Liu, S. (2015). Rates and patterns of urban expansion in China's 32 major cities over the past three decades. Landscape Ecology, 30(8), 1541-1559. https://doi.org/10.1007/s10980-015-0211-7 